Prepared in cooperation with the Missouri Department of Natural Resources

\title{
Occurrence and Origin of Escherichia coli in Water and Sediments at Two Public Swimming Beaches at Lake of the Ozarks State Park, Camden County, Missouri, 2011-13
}

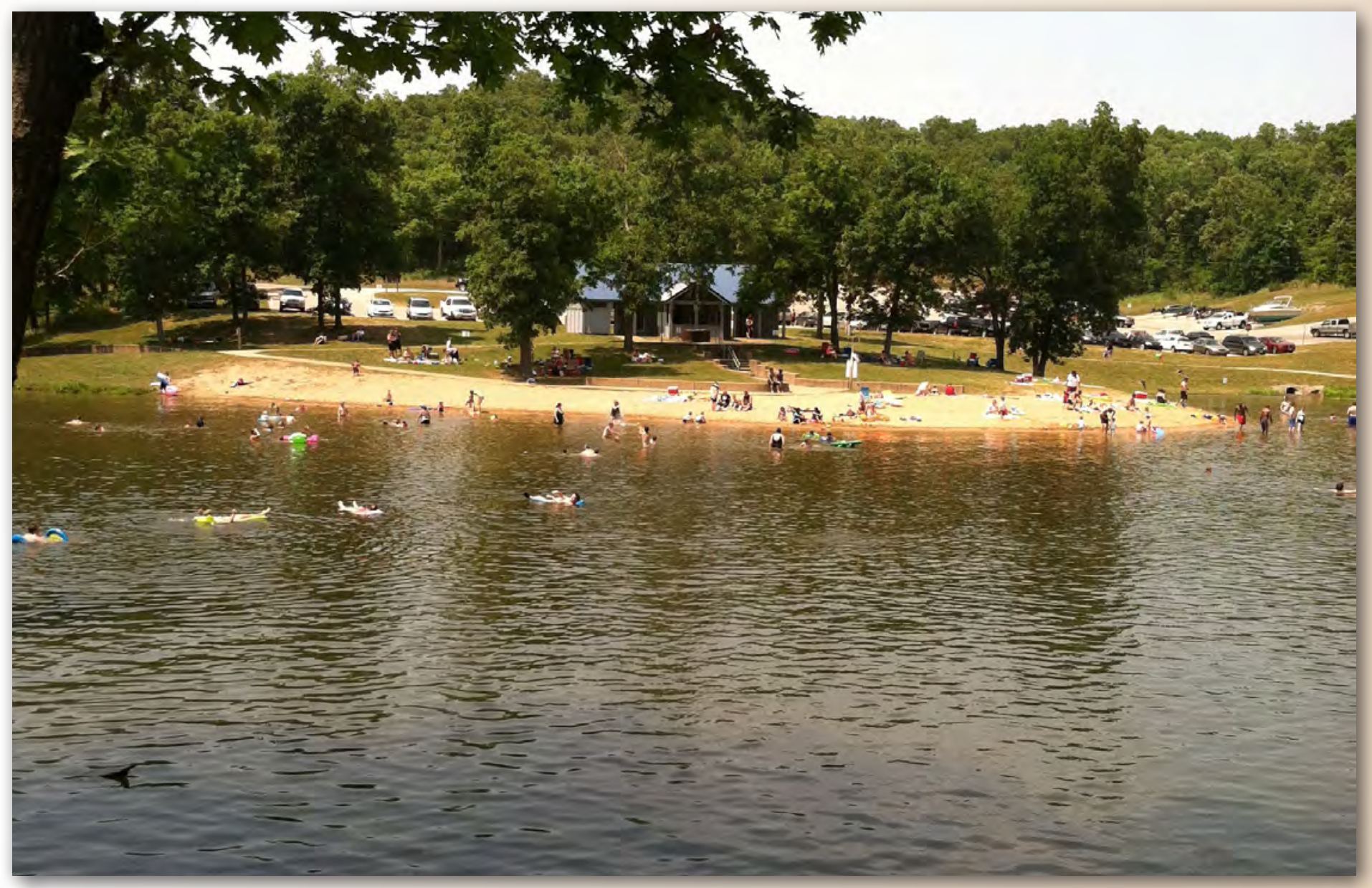

Scientific Investigations Report 2014-5005 
Cover. Photograph showing Grand Glaize Beach in Lake of the Ozarks State Park; Saturday of Memorial Day weekend, May 26, 2012. 


\section{Occurrence and Origin of Escherichia coli in Water and Sediments at Two Public Swimming Beaches at Lake of the Ozarks State Park, Camden County, Missouri, 2011-13}

By Jordan L. Wilson, John G. Schumacher, and Joel G. Burken

Prepared in cooperation with the Missouri Department of Natural Resources

Scientific Investigations Report 2014-5005 


\title{
U.S. Department of the Interior SALLY JEWELL, Secretary
}

\section{U.S. Geological Survey \\ Suzette M. Kimball, Acting Director}

\author{
U.S. Geological Survey, Reston, Virginia: 2014
}

For more information on the USGS - the Federal source for science about the Earth, its natural and living resources, natural hazards, and the environment, visit http://www.usgs.gov or call 1-888-ASK-USGS.

For an overview of USGS information products, including maps, imagery, and publications, visit http://www.usgs.gov/pubprod

To order this and other USGS information products, visit http://store.usgs.gov

Any use of trade, firm, or product names is for descriptive purposes only and does not imply endorsement by the U.S. Government.

Although this information product, for the most part, is in the public domain, it also may contain copyrighted materials as noted in the text. Permission to reproduce copyrighted items must be secured from the copyright owner.

Suggested citation:

Wilson, J.L., Schumacher, J.G., and Burken, J.G., 2014, Occurrence and origin of Escherichia coli in water and sediment at two public swimming beaches at Lake of the Ozarks State Park, Camden County, Missouri, 2011-13: U.S. Geological Survey Scientific Investigations Report 2014-5005, 59 p., http://dx.doi.org/10.3133/sir20145005. 


\section{Acknowledgments}

The authors would like to thank Bill Arnold and staff at the Missouri Department of Natural Resources at Lake of the Ozarks State Park as well as the marina operators at Grand Glaize Beach and Public Beach 1 for giving access to facilities and assisting with logistics for the project. The authors also thank Larry Pierce with the Missouri Department of Natural Resources Geological Survey Program for his expertise in water tracing conducted during the study. Special thanks to Jim Divincen, and members of the Four County Wastewater Task Force and the Lake of the Ozarks Watershed Alliance for their logistical support in access to remote sampling sites. 


\section{Contents}

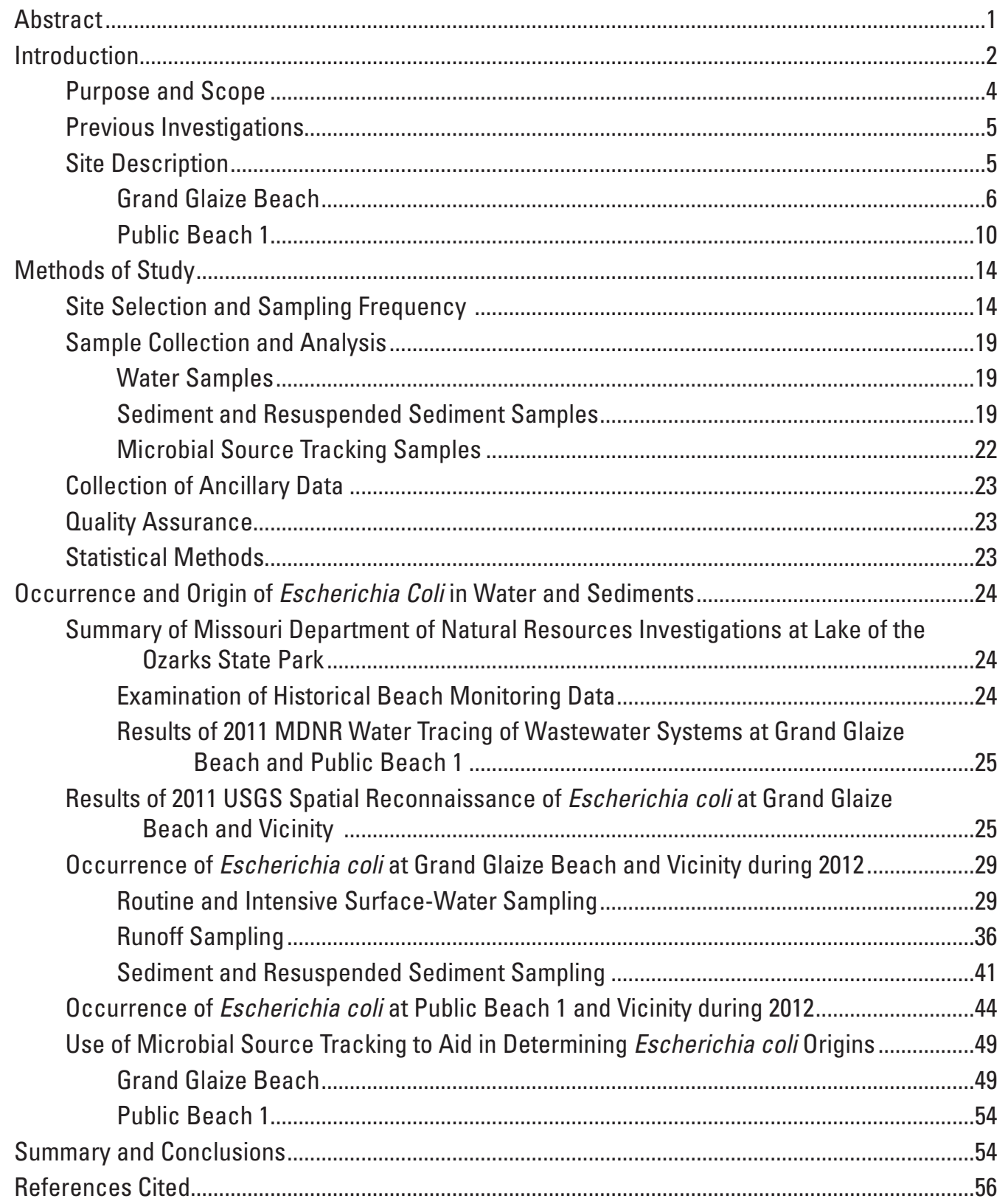




\section{Figures}

1. Map showing Grand Glaize arm of the Lake of the Ozarks and location of public swimming beaches at Lake of the Ozarks State Park near Osage Beach, Missouri........3

2. Graph showing number of beach closures at Grand Glaize Beach and Public Beach 1, Lake of the Ozarks State Park, 2009-11...

3. Map showing known wastewater systems in the vicinity of Grand Glaize Beach and watershed areas of tributaries to GGB cove, Lake of the Ozarks State Park, Missouri

4. Map showing major features and Missouri Department of Natural Resources beach monitoring locations in the vicinity of Grand Glaize Beach, Lake of the Ozarks State Park, Missouri

5. Photographs of Grand Glaize Beach and Public Beach 1 during selected holidays at Lake of the Ozarks State Park, Missouri, 2011-12 ....................................................

6. Photographs of geese activity at Grand Glaize Beach, May 2012 ...................................11

7. Graph showing curves for high and low lake level limits, target lake level, and actual lake levels, Lake of the Ozarks, Missouri, 2011-12

8. Map showing major features, Missouri Department of Natural Resources beach monitoring locations, and 2012 U.S. Geological Survey sampling locations in the vicinity of Public Beach 1, Lake of the Ozarks State Park, Missouri..

9. Map showing average Escherichia coli concentrations in samples from 2011 sites from Grand Glaize Beach cove, cove A, and cove B, Lake of the Ozarks State Park, Missouri.

10. Map showing location and average Escherichia coliconcentration in water samples collected during 2012 from Grand Glaize Beach cove, tributaries, and cove A, Lake of the Ozarks State Park, Missouri.

11. Map showing locations of sediment and resuspended sediment samples collected at Grand Glaize Beach and adjacent swimming area, 2012-13.

12. Photographs showing resuspended sediment sample and foreshore and ankledeep nearshore sediment sample collection, 2012-13

13. Graph showing weekly maximum Escherichia coli concentrations at Grand Glaize Beach during the 2011 recreational season reported by the Missouri Department of Natural Resources, daily mean discharge of the Niangua River at Tunnel Dam near Macks Creek, Missouri, and daily precipitation recorded at a National Oceanic and Atmospheric Association station at Lee C. Fine Memorial Airport in Kaiser, Mo., 2011

14. Graph showing weekly maximum Escherichia coli concentrations at Public Beach 1 during the 2010 recreational season reported by the Missouri Department of Natural Resources, daily mean discharge of the Niangua River at Tunnel Dam near Macks Creek, Missouri, and daily precipitation recorded at a National Oceanic and Atmospheric Association station at Lee C. Fine Memorial Airport in Kaiser, Mo., 2010

15. Boxplots showing concentrations of Escherichia coli in water samples collected during the 2011 reconnaissance from Grand Glaize Beach cove, cove A, and cove B, Lake of the Ozarks State Park, Missouri

16. Boxplots showing concentrations of Escherichia coli and values of specific conductance and water temperature in water samples collected from Grand Glaize Beach cove, 2011 
17. Boxplots showing concentrations of Escherichia coli in water samples collected during 2012 from Grand Glaize Beach cove and cove A, Lake of the Ozarks State

Park, Missouri

18. Graph showing temporal variation of the daily average of the maximum Escherichia coli concentrations at GB-L and GB-R and the daily maximum total number of bathers at the beach at Grand Glaize Beach, 2012.

19. Contingency table and calender displaying the number of days sampled during the 2012 recreational season by the U.S. Geological Survey with or without an exceedance of the single sample value standard and the beach status of Grand Glaize Beach on those days based on weekly Missouri Department of Natural Resources routine testing, 2012

20. Graphs showing continuous specific conductance and turbidity at sites GI-R and GB-R during Hurricane Isaac showing potential recirculation of tributary runoff back toward Grand Glaize Beach, 2012

21. Photographs showing turbidity plume from Hurricane Isaac runoff from the west tributary into Grand Glaize Beach cove, August 31 and September 2, 2012.

22. Graph showing discharge at GI-T in the west tributary, rainfall intensities, and Escherichia coli concentrations measured at GI-T during the Hurricane Isaac runoff event, 2012.

23. Graph showing Escherichia coli concentrations in sediment samples collected at Grand Glaize Beach between May 31, 2012, and February 5, 2013.

24. Graph showing Escherichia coli concentrations in resuspended sediment samples at Grand Glaize Beach between June 8, 2012, and February 5, 2013.

25. Boxplot showing concentrations of Escherichia coli in water samples collected during 2012 from Public Beach 1 and vicinity, Lake of the Ozarks State Park, Missouri......

26. Pie charts showing total number of microbial source tracking markers detected in routine water, sediment, resuspended sediment, and west tributary runoff samples at Grand Glaize Beach and GGB cove, 2012 


\section{Tables}

1. Surface-water and groundwater sampling sites at Lake of the Ozarks State Park, 2011-12

2. Summary of Escherichia coli concentrations in colony-forming units per 100 milliliters in routine water samples at all sites, 2011-12

3. Grain-size distribution of sediment samples collected at Grand Glaize Beach and GGB cove on October 3, 2012 .

4. Escherichia coli concentrations in sediment samples collected at Grand Glaize Beach and GGB cove, 2012-13..

5. Escherichia coli concentrations in resuspended sediment samples collected at Grand Glaize Beach and GGB cove, 2012-13.

6. Concentrations of Escherichia coli and genetic markers and relative percent difference between concentrations of $E$. coli in U.S. Geological Survey Missouri Water Science Center and USGS Ohio Water Microbiology Laboratory samples in water, resuspended sediment, and runoff samples collected at Public Beach 1, Grand Glaize Beach, and GGB cove, 2012.

7. Concentrations of Escherichia coli and genetic markers and relative percent difference between concentrations of E. coli in U.S. Geological Survey Missouri Water Science Center and USGS Ohio Water Microbiology Laboratory samples in sediment samples collected at Public Beach 1, Grand Glaize Beach, and GGB cove, 2012. 


\section{Conversion Factors and Abbreviations}

\begin{tabular}{|c|c|c|}
\hline Multiply & By & To obtain \\
\hline \multicolumn{3}{|c|}{ Length } \\
\hline inch (in.) & 2.54 & centimeter $(\mathrm{cm})$ \\
\hline foot (ft) & 0.3048 & $\operatorname{meter}(\mathrm{m})$ \\
\hline mile (mi) & 1.609 & kilometer (km) \\
\hline \multicolumn{3}{|c|}{ Area } \\
\hline acre & 4,047 & square meter $\left(\mathrm{m}^{2}\right)$ \\
\hline acre & 0.4047 & hectare (ha) \\
\hline square mile $\left(\mathrm{mi}^{2}\right)$ & 259.0 & hectare (ha) \\
\hline square mile $\left(\mathrm{mi}^{2}\right)$ & 2.590 & square kilometer $\left(\mathrm{km}^{2}\right)$ \\
\hline \multicolumn{3}{|c|}{ Volume } \\
\hline gallon (gal) & 3.785 & liter $(\mathrm{L})$ \\
\hline gallon (gal) & 0.003785 & cubic meter $\left(\mathrm{m}^{3}\right)$ \\
\hline cubic foot $\left(\mathrm{ft}^{3}\right)$ & 28.32 & liter $(\mathrm{L})$ \\
\hline cubic foot $\left(\mathrm{ft}^{3}\right)$ & 0.02832 & cubic meter $\left(\mathrm{m}^{3}\right)$ \\
\hline acre-foot (acre-ft) & 1,233 & cubic meter $\left(\mathrm{m}^{3}\right)$ \\
\hline \multicolumn{3}{|c|}{ Flow rate } \\
\hline cubic foot per second $\left(\mathrm{ft}^{3} / \mathrm{s}\right)$ & 0.02832 & cubic meter per second $\left(\mathrm{m}^{3} / \mathrm{s}\right)$ \\
\hline cubic foot per second $\left(\mathrm{ft}^{3} / \mathrm{s}\right)$ & 448.8 & gallon per minute (gal/min) \\
\hline \multicolumn{3}{|l|}{ SI to Inch/Pound } \\
\hline Multiply & By & To obtain \\
\hline \multicolumn{3}{|c|}{ Length } \\
\hline micrometer $(\mu \mathrm{m})$ & 0.00003937 & inch (in.) \\
\hline millimeter (mm) & 0.03937 & inch (in.) \\
\hline \multicolumn{3}{|c|}{ Volume } \\
\hline milliliter $(\mathrm{mL})$ & 0.06102 & cubic inches $\left(\mathrm{in}^{3}\right)$ \\
\hline \multicolumn{3}{|c|}{ Mass } \\
\hline $\operatorname{gram}(\mathrm{g})$ & 0.03527 & ounce, avoirdupois (oz) \\
\hline
\end{tabular}

Temperature in degrees Celsius $\left({ }^{\circ} \mathrm{C}\right)$ may be converted to degrees Fahrenheit $\left({ }^{\circ} \mathrm{F}\right)$ as follows: ${ }^{\circ} \mathrm{F}=\left(1.8 \times{ }^{\circ} \mathrm{C}\right)+32$

Horizontal coordinate information is referenced to the North American Datum of 1983 (NAD 83).

Specific conductance is given in microsiemens per centimeter at 25 degrees Celsius $(\mu \mathrm{S} / \mathrm{cm}$ at $\left.25^{\circ} \mathrm{C}\right)$.

Turbidity is reported in Nephelometric Turbidity Units (NTU).

Concentrations of chemical constituents in water are given either in milligrams per liter (mg/L) or micrograms per liter $(\mu \mathrm{g} / \mathrm{L})$.

Concentrations of bacteria in water are reported in colony-forming units per 100 milliliters (CFU/100 mL) and Most Probable Number per 100 milliliters (MPN/100 mL),

Concentrations of bacteria in sediment are reported in colony-forming units per gram dry weight $\left(\mathrm{CFU} / \mathrm{g}_{\mathrm{DW}}\right.$ ) and Most Probable Number per gram dry weight (MPN $\left./ \mathrm{g}_{\mathrm{DW}}\right)$.

Concentrations of markers in water are reported as copies per $100 \mathrm{~mL}$ (copies/100 mL).

Concentrations of markers in sediment are reported as copies per gram dry weight (copies $/ \mathrm{g}_{\mathrm{DW}}$ ). 


\section{Abbreviations and Symbols}

\begin{tabular}{|c|c|}
\hline$A D$ & ankle deep \\
\hline BDL & below detection limit \\
\hline BT & Bacteroides thetaiotaomicron \\
\hline CFU & colony-forming unit \\
\hline CFU/100 mL & colony-forming units per 100 milliliters \\
\hline $\mathrm{CFU} / \mathrm{g}_{\mathrm{DW}}$ & colony-forming units per gram of dry weight \\
\hline CWOM & continuous water-quality monitor \\
\hline DNA & deoxyribonucleic acid \\
\hline ESP & Environmental Services Program \\
\hline $\mathrm{E}$ & estimated value \\
\hline E. coli & Escherichia coli \\
\hline FS & foreshore \\
\hline GGB & Grand Glaize Beach \\
\hline GM & geometric mean \\
\hline LOSP & Lake of the Ozarks State Park \\
\hline LOWA & Lake of the Ozarks Watershed Alliance \\
\hline MST & microbial source tracking \\
\hline $\min$ & minute \\
\hline MDNR & Missouri Department of Natural Resources \\
\hline Missouri S\&T & Missouri University of Science and Technology \\
\hline MPN & most probable number \\
\hline MPN/100 mL & most probable number per 100 milliliters \\
\hline $\mathrm{MPN} / \mathrm{g}_{\mathrm{DW}}$ & most probable number per gram of dry weight \\
\hline MWSC & Missouri Water Science Center \\
\hline NOAA & National Oceanic and Atmospheric Administration \\
\hline NTU & Nephelometric Turbidity Unit \\
\hline NWIS & National Water Information System \\
\hline OWML & Ohio Water Microbiology Laboratory \\
\hline PB1 & Public Beach 1 \\
\hline $\mathrm{QA}$ & quality assurance \\
\hline $\mathrm{QC}$ & quality control \\
\hline qPCR & quantitative polymerase chain reaction \\
\hline RPD & relative percent difference \\
\hline SSV & single sample value \\
\hline USEPA & U.S. Environmental Protection Agency \\
\hline USGS & U.S. Geological Survey \\
\hline WD & waist deep \\
\hline WSC & Water Science Center \\
\hline${ }^{\circ} \mathrm{C}$ & degree Celsius \\
\hline$\mu S$ & microsiemen \\
\hline$\mu \mathrm{S} / \mathrm{cm}$ at $25^{\circ} \mathrm{C}$ & microsiemens per centimeter at $25 \mathrm{~d}$ \\
\hline
\end{tabular}




\title{
Occurrence and Origin of Escherichia coli at Two Public Swimming Beaches at Lake of the Ozarks State Park, Camden County, Missouri, 2011-13
}

\author{
By Jordan L. Wilson', John G. Schumacher', and Joel G. Burken²
}

\section{Abstract}

In the past several years, the Missouri Department of Natural Resources has closed two popular public beaches, Grand Glaize Beach (GGB) and Public Beach 1, at Lake of the Ozarks State Park in Osage Beach, Missouri when monitoring results exceeded the established Escherichia coli (E. coli) standard. As a result of the beach closures, the U.S. Geological Survey, in cooperation with the Missouri Department of Natural Resources, and in collaboration with the Missouri University of Science and Technology, led an investigation into the occurrence and origins of E. coli at GGB and Public Beach 1. The study included the collection of more than 1,300 water, sediment, and fecal source samples between August 2011 and February 2013 from the two beaches and vicinity. Spatial and temporal patterns of $E$. coli concentrations in water and sediments combined with measurements of environmental variables, beach-use patterns, and Missouri Department of Natural Resources water-tracing results were used to identify possible sources of $E$. coli contamination at the two beaches and to corroborate microbial source tracking (MST) sampling efforts.

Results from a 2011 reconnaissance sampling indicate that water samples from GGB cove contained significantly larger E. coli concentrations than adjacent coves and were largest at sites at the upper end of GGB cove, indicating a probable local source of $E$. coli contamination within the upper end of the cove. Results from an intensive sampling effort during 2012 indicated that $E$. coli concentrations in water samples at GGB cove were significantly larger in ankle-deep water than waist-deep water, trended downward during the recreational season, significantly increased with an increase in the total number of bathers at the beach, and were largest during the middle of the day. After an initial spike of 9,200 colony-forming units per 100 milliliters on the Saturday of Memorial Day weekend (May 26, 2012), the first high-use

\footnotetext{
${ }^{1}$ U.S. Geological Survey.

${ }^{2}$ Department of Civil, Architectural, and Environmental Engineering, Missouri University of Science and Technology.
}

day of the season, subsequent spikes in E. coli concentrations on high-use days decreased in amplitude throughout the 2012 recreational season although the number of bathers and turbidity remained similar. The observed trends in E. coli concentration despite steady bather activity and turbidity on high use days during the recreational season combined with a strong correlation between turbidity and total number of bathers indicates that bather activity, rather than the bathers themselves, may be an important component of the observed spikes in E. coli concentrations at GGB during the 2012 recreational season.

Concentrations of $E$. coli in nearshore sediment (sediment near the shoreline) at GGB were significantly larger in foreshore samples (samples collected above the shoreline) than in samples collected in ankle-deep water below the shoreline, significantly larger in the left and middle areas of the beach than the right area, and substantially larger than similar studies at $E$. coli-contaminated beaches on Lake Erie. Concentrations of $E$. coli in the water column also were significantly larger after resuspension of sediments.

Results of MST indicate a predominance of waterfowlassociated markers in nearshore sediments at GGB consistent with frequent observations of goose and vulture fecal matter in sediment, especially on the left and middle areas of the beach. The combination of spatial and temporal sampling and MST indicate that an important source of $E$. coli contamination at GGB during 2012 was $E$. coli released into the water column by bathers resuspending $E$. coli-contaminated sediments, especially during high-use days early in the recreational season. The predominate origin of $E$. coli in sediments seems to be from geese and vultures that frequent the beach, especially during the winter and early spring when lake water levels are low and sediments are exposed. Additional contributions of $E$. coli from other sources within the west and east tributary watersheds happen during runoff events, which cause inflow of runoff into GGB cove.

Sampling of minor rainfall events that resulted in only localized runoff in the west tributary, which enters the lake adjacent to GGB, indicated large E. coli concentrations and, on several occasions, $E$. coli concentrations indicative of 
raw sewage (as large as 2,400,000 colony-forming units per 100 milliliters), related to contamination from soils disturbed during removal of a septic tank at a nearby seasonal residence in 2012. The fact that the septic tank had not been used since 2010 indicates that $E$. coli in adjacent soil and shallow groundwater within the drain field have remained viable for nearly 2 years. Analyses of runoff from a major rainfall event associated with Hurricane Isaac on August 31, 2012, indicated that runoff can be an important source of $E$. coli contamination at GGB as approximately 20,000 cubic feet of runoff and an estimated total of $2.9 \times 10^{11}$ colonies of E. coli entered the upper end of GGB cove from the west tributary. Most of this loading during runoff was not from the seasonal residence septic tank area but from farther up in the watershed. Because the total precipitation for the 2012 recreational season was below normal (4.29 inches compared to the normal 12.22-inch total), runoff into GGB cove may be a more important source of $E$. coli contamination at GGB during a more typical year than during 2012.

Microbial source tracking confirmed human-associated contamination in all samples collected from the west tributary as they all contained the human-associated marker and at the largest concentrations of all water samples collected in this study. However, the near absence of runoff into GGB cove during 2012, an extreme drought year for the region, and the predominance of waterfowl-associated markers in nearshore sediments at GGB indicates that the west tributary probably did not contribute substantially to $E$. coli observed in nearshore sediments at GGB during 2012, but it is likely that runoff during years with more normal rainfall is an important source of E. coli at GGB.

Analysis of water samples collected at Public Beach 1 indicated that $E$. coli concentrations were significantly larger than at a background beach and were significantly smaller than at GGB as well as sites nearby Public Beach 1. Although overall $E$. coli concentrations in water samples collected from Public Beach 1 during 2012 were generally well below standards, MST data from water samples indicated only detections of the human-associated marker and suggest that a nearby wastewater treatment plant may be an important contributor to E. coli loading at Public Beach 1 during major runoff events.

\section{Introduction}

Swimming in recreational waters is a common activity with an associated risk of ingestion and contact with diseasecausing pathogens (U.S. Environmental Protection Agency, 1999). These pathogens, which typically originate from the fecal matter of warm-blooded animals, are difficult to monitor directly because of the large possible number of microorganisms that can cause illness in humans and the small, yet harmful, concentrations at which pathogens typically occur. Because the current (2013) knowledge of pathogens is incomplete and measuring each pathogen individually is time and cost prohibitive, the use of a microbiological indicator organism is the most commonly applied approach to assess this public health threat (U.S. Environmental Protection Agency, 2012). In the 1976 U.S. Environmental Protection Agency (USEPA) document "Quality Criteria for Water", the USEPA suggests that an ideal microbiological indicator organism would be applicable to all types of water, present in the same environment as that of pathogens, exhibit identical survival time, and unable to reproduce in the environment (U.S. Environmental Protection Agency, 1976). In 1986, the USEPA, to protect human health at public swimming beaches, recommended biological water-quality criteria for recreational bodies of water (U.S. Environmental Protection Agency, 1986). Based on correlations between gastroenteritis rates and bacterial concentrations from epidemiological studies, these recommendations included the use of Escherichia coli (E. coli) and enterococci as microbiological indicator organisms of the presence of pathogens at freshwater beaches.

In the early 2000s, the Missouri Department of Natural Resources (MDNR) adopted the USEPA's 1986 water-quality criteria and began monitoring public swimming beaches for E. coli. The MDNR beach monitoring program consists of weekly sampling of 20 swimming beaches across the State (Missouri Department of Natural Resources, 2011). A beach is closed if the $E$. coli concentration in a sample either exceeds a single sample value (SSV) of 235 colonies per 100 milliliters or if the geometric mean (GM) of samples collected within the past 30 days from the beach exceeds 126 colonies per 100 milliliters (Missouri Attorney General's Office, 2010). Although the beach closure criteria is in colonies per $100 \mathrm{~mL}$, the USEPA-approved method used for enumeration of $E$. coli concentrations determines the units used, which are typically in colony-forming units per 100 milliliters $(\mathrm{CFU} / 100 \mathrm{~mL})$ or most probable number per 100 milliliters (MPN/100 mL).

In the past several years, the MDNR beach monitoring program has become widely publicized due to $E$. coli concentrations exceeding standards on several occasions at Grand Glaize Beach (GGB) and Public Beach 1 (PB1) at Lake of the Ozarks State Park (LOSP). Much of the publicity has arisen because the beaches and park are located on the Lake of the Ozarks, one of the largest and most popular recreational lakes in the Midwestern United States (fig. 1). The Lake of the Ozarks attracts millions of visitors annually (Missouri Department of Natural Resources, 2012a) and generates nearly 5 billion dollars in tourism revenue annually (Missouri Attorney General's Office, 2010), roughly one-half of the total tourism revenue in the State of Missouri (Lake Area Chamber of Commerce, 2012).

During 2009, beach closures at LOSP and confusion between release of data from the routine MDNR beach-monitoring program and a separate, unrelated water-quality study of the entire Lake of the Ozarks caused considerable controversy within the media and general public resulting in the Missouri Attorney General holding a symposium in August 2010 to address perceived water-quality issues at the lake (Missouri Attorney General's Office, 2010). The controversy continued into 2011 as E. coli concentrations at GGB exceeded either 


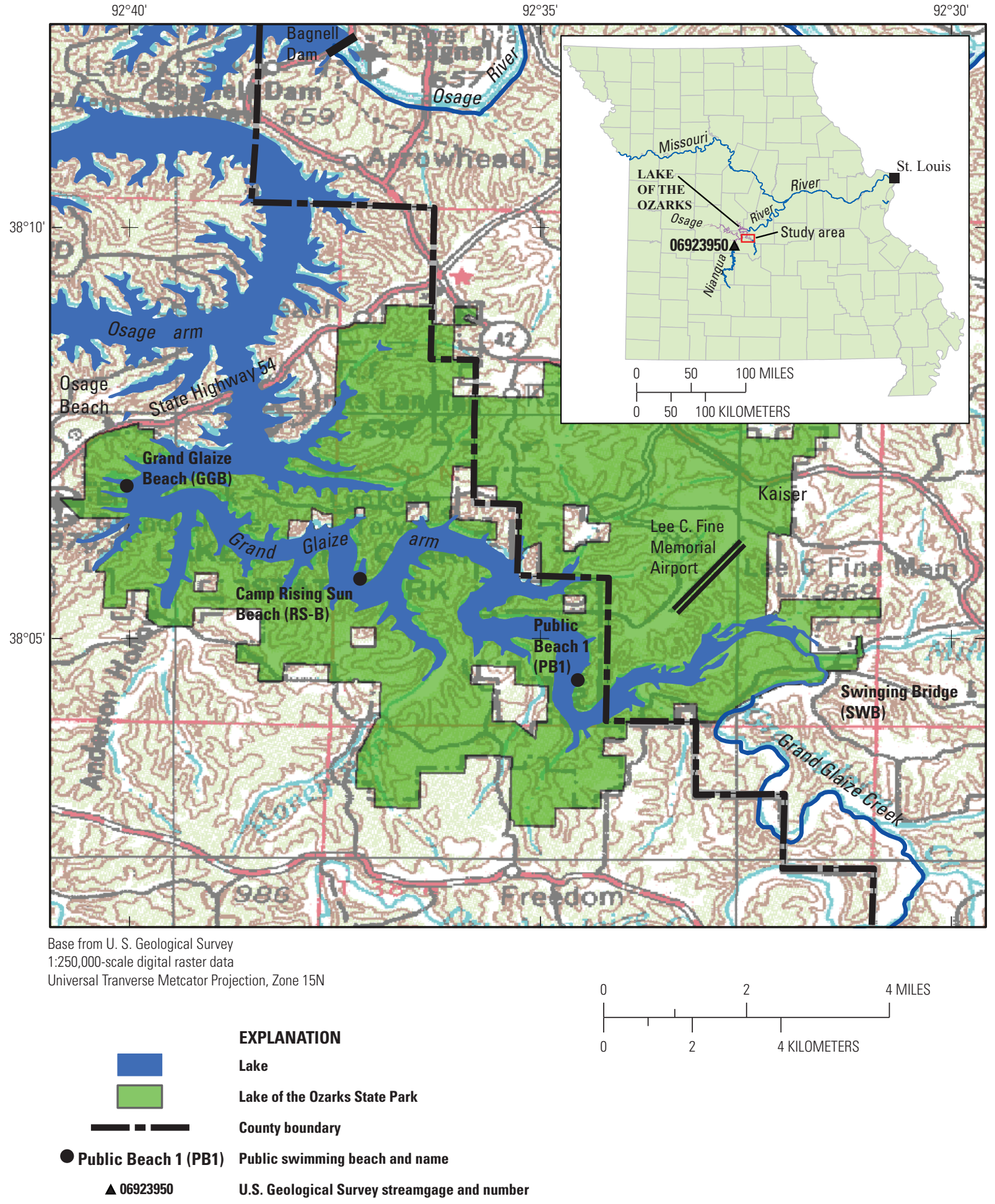

Figure 1. Grand Glaize arm of the Lake of the Ozarks and location of public swimming beaches at Lake of the Ozarks State Park near Osage Beach, Missouri. 
the SSV or the GM standard for five consecutive weeks resulting in beach closures from June through July of 2011 and more than one-third of the recreational season in total. In response to beach closures, the MDNR began testing and inspecting wastewater systems at LOSP, and in August 2011, began a cooperative investigation with the U.S. Geological Survey (USGS), and in collaboration with Missouri University of Science and Technology (Missouri S\&T), to understand possible sources or origins of $E$. coli contamination at LOSP swimming beaches.

In response to the continued controversy with beach closures at LOSP as well as new USEPA water-quality criteria (U.S. Environmental Protection Agency, 2012), bills were introduced into the Missouri Senate (SB140; Missouri State Senate, 2013;) and House of Representatives (HB 51; Missouri State Senate, 2013) and passed in July 2013, causing Missouri State Parks to change from a beach closure policy to one that directed each state park to post advisories when monitoring results exceeded the established standard for E. coli bacteria.

A potential problem with using E. coli as an indicator organism is that it is not unique to humans and is present in the intestinal tracts of all warm-blooded animals, making it difficult to determine host (s) of fecal contamination. Heavy rainfall and subsequent runoff is recognized as a substantial cause of $E$. coli contamination in bodies of water through watershed-wide transport of fecal matter from various animal and human sources into nearby waters; however, this mechanism alone does not always have the most dominant effect on E. coli concentrations in water (Natural Resources Defense Council, 1996). In a guide to water quality at public swimming beaches across the United States, the Natural Resources Defense Council stated that of the beach closures in 1995, 371 were caused by rainfall, whereas 510 were not associated with rainfall events, but were instead considered to be caused by unknown sources (1996). Other common suspected sources of fecal contamination at public swimming beaches include septic tanks, wastewater treatment effluent, combined- and sanitary-sewer overflows, boat privies, and fecal pollution from animals and bathers (Francy and others, 2006). The innate spatial and temporal variability of $E$. coli coupled with the dynamic lake environment including lake currents, weather, and other natural processes further complicate investigations, making it difficult to pinpoint and determine fecal pollution sources using only single methods. The combination of multiple lines of evidence is critical, requiring the application of intensive water sampling, microbial source tracking (MST), and sometimes the development of statistical, hydrodynamic, and transport models.

Other than the source of fecal bacteria, the survival of bacteria in water and sediments is another important factor to be considered. Solar radiation, temperature, salinity, and predation are established, influential factors in the survival of E. coli in the water column (Anderson and others, 2005; Carlucci and Pramer, 1960; Craig and others, 2004; Flint, 1987; Harwood and others, 2005; Muela and others, 2000). Studies also have been done on the survival of $E$. coli in sediments and indicate sediment and turbidity (suspended sediment in the water column) can act as reservoirs for $E$. coli because sediment provides protection from sunlight, decreased availability to predators, and a degree of thermal stability (Craig and others, 2004; Davies and others, 1995; García-Armisen and Servais, 2009; Lee and others, 2006; Pote and others, 2009). Davies and others (1995) reported that fecal coliform bacteria can survive in freshwater sediments for as much as 60 days with a half-life from 11-30 days in sediments compared to roughly 3 days in overlying waters. Because $E$. coli survives longer in sediments than in water and is the only accepted indicator of fecal contamination at Missouri swimming beaches, the enumeration of $E$. coli in sediment is an important component of any investigation of $E$. coli sources in the water column.

\section{Purpose and Scope}

This report presents results of an investigation of the occurrence and origin of E. coli at two public swimming beaches at LOSP and includes a summary of historical MDNR monitoring data from GGB and PB1 at LOSP collected from 2009 through 2011. Data are then presented and discussed from more than 1,300 water, sediment, and fecal source samples collected specifically for this study during August 2011 to February 2013 at GGB, PB1, and vicinities. Also included is a summary of water tracing of wastewater systems in the vicinity of the two beaches done by the MDNR in conjunction with this water-quality investigation.

Surface-water and sediment samples from as many as 36 sites at and in the vicinity of the two beaches were collected and analyzed for $E$. coli concentrations for a variety of environmental and hydrologic conditions. Spatial and temporal patterns of $E$. coli concentrations in water and sediments combined with measurements of environmental variables, beach-use patterns, and MDNR water-tracing results were used to identify possible sources of $E$. coli contamination at the two beaches. These spatial and temporal data were then used to corroborate MST sampling efforts.

Using routine surface-water samples, possible correlations between $E$. coli and environmental data including precipitation, water temperature, specific conductance, $\mathrm{pH}$, dissolved oxygen, turbidity, lake level, wave height, total number of bathers at the beach, wind speed, and wind direction were examined. Sediment and resuspended sediment samples were collected to determine the temporal and spatial distribution of E. coli in sediments at GGB. Escherichia coli concentrations were measured for a range of environmental conditions including before, during, and after major rainfall events; during dry and calm weather; for various wave heights; before, during, and after substantial beach use; during and after substantial geese inhabitation; and at normal and low lake stages. MST was used to provide information on the occurrence and distribution of host-associated genetic markers from the following 
potential sources: human, ruminant (for example, cattle and deer), and waterfowl (for example, ducks and geese). Ancillary data collected from a lake gage and meteorological station installed at GGB by Missouri S\&T were used in statistical analyses as well as in an E. coli flow and transport model in GGB cove in support of a Missouri S\&T master's thesis (Wilson, 2013).

\section{Previous Investigations}

Water quality at the Lake of the Ozarks has been a topic of concern since the 1980s when members of local government and private parties expressed concern of potential water-quality degradation due to shoreline development. A 1985 report by the MDNR described the geography of the area and the potential effect of shoreline development and waste disposal on water quality. The report concluded that the fast moving, shallow groundwater and steep slopes surrounding the lake presented moderate to severe limitations to local on-site waste disposal systems (Vandike and others, 1985). In 1996, local government officials commissioned a plan to assess the feasibility of establishing a lake-wide water and wastewater district. The study, published in 1999, reported 15,000 to 20,000 septic tanks around the lake and recommended the funding and construction of a lake-wide water and wastewater system to protect lake quality and public health (HNTB Corporation, 1999).

In 2007, a 5-year cooperative study between the MDNR and the Lake of the Ozarks Watershed Alliance (LOWA), referred to as the LOWA study, assessed lake-wide water quality at the Lake of the Ozarks. Between 2007 and 2011, the LOWA study assessed 118 coves through the collection of 1,619 samples from 451 sampling sites. Each year the study focused on coves in different regions of the lake by sampling 50 to 60 sites per month, 3 to 5 times during the recreational season. Using boats, LOWA volunteers collected grab samples of water from between 6 to 12 in. (inches) below the water surface at several locations per cove, and samples were transported to the MDNR laboratory and analyzed for E. coli concentrations. Results from the 5-year study indicated that the largest monthly GM of E. coli concentrations was reported in May of each year and that water quality at the Lake of the Ozarks was relatively good as only 2.6 percent of samples were greater than the SSV standard of $235 \mathrm{CFU} / 100 \mathrm{~mL}$ (Missouri Department of Natural Resources, 2012b).

During 2007-08, a graduate student from the University of Missouri studied the anthropogenic effects of humans on water quality at the Lake of the Ozarks (O'Hearn, 2009). A total of 35 coves and 3 open-water locations on the Grand Glaize and Osage arms of the lake (fig. 1) were sampled and analyzed for nutrients as well as concentrations of fecal coliform, E. coli, and Bacteroides thetaiotaomicron (BT). Water samples were collected on Mondays and Tuesdays from midMay through August of 2007, and in 2008, 13 high-use coves and 2 main channel sites were selected for additional sampling around major holidays. Of the 311 samples collected in 2007 , fecal coliform was detected in 84 percent of samples and ranged from less than 1 to $4,900 \mathrm{CFU} / 100 \mathrm{~mL}$, and E. coli was detected in 94 percent of the samples and ranged from less than 1 to $550 \mathrm{CFU} / 100 \mathrm{~mL}$. In the Osage arm, fecal coliform and $E$. coli concentrations were larger at upstream locations and decreased towards Bagnell Dam; however, in the Grand Glaize arm, no gradient was present. Concentrations of BT in coves were similar to main-arm concentrations in both arms of the lake, and no gradient was observed (O'Hearn, 2009).

Since the early 2000s, the MDNR has monitored public swimming beaches during the recreational season (April through September) for $E$. coli according to USEPA criteria (U.S. Environmental Protection Agency, 1986). Water at each beach is sampled in waist-deep water on the left and right side (orientation when standing on the beach facing the water) on Monday or Tuesday of each week by MDNR park staff and shipped chilled overnight to the MDNR Environmental Services Program (ESP) laboratory in Jefferson City, Missouri. Concentrations of $E$. coli are enumerated within 48 hours of collection using the Colilert Quanti-Tray $/ 2000^{\circledR}$ method (IDEXX Laboratories, Inc., Westbrook, Maine), a 24-hour, USEPA-approved method (U.S. Environmental Protection Agency, 2007) that reports E. coli in MPN/100 mL. Sample results are transmitted from the MDNR laboratory to the individual state park beach managers generally by Wednesday or Thursday when the results are publicly posted and beach management decisions made. Since monitoring began, the MDNR policy was to close beaches if the E. coli concentration reported by the MDNR laboratory in an individual water sample from either side of the beach was equal to or greater than the SSV standard of $235 \mathrm{MPN} / 100 \mathrm{~mL}$ until the next weekly sample was below the SSV or if the GM of the previous five maximum weekly values was equal to or greater than $126 \mathrm{MPN} / 100 \mathrm{~mL}$ (Missouri Attorney General's Office, 2010). Of the 20 beaches monitored by the MDNR state-wide beach monitoring program, GGB and PB1 have among the largest frequency of closures. During the 2009 through 2011 recreational seasons, GGB was closed for 12 weeks and PB1 was closed 10 weeks because $E$. coli concentrations exceeded either the SSV or the 30-day GM (fig. 2).

\section{Site Description}

The study area includes the two main public beaches (GGB and PB1) at LOSP and adjacent coves on the Grand Glaize arm of the Lake of the Ozarks in central Missouri (fig.1). In addition, a small beach at a group campground called Camp Rising Sun Beach (RS-B) and a site where Grandglaize Creek (locally referred to as Grand Glaize Creek) enters the lake (site SWB) were sampled to establish background levels at less populated areas within LOSP. The Lake of the Ozarks is underlain by karstic, dolostone bedrock with many springs, sinkholes, and losing streams. Soils on the steep slopes are thin, rocky, and generally poorly suited for 


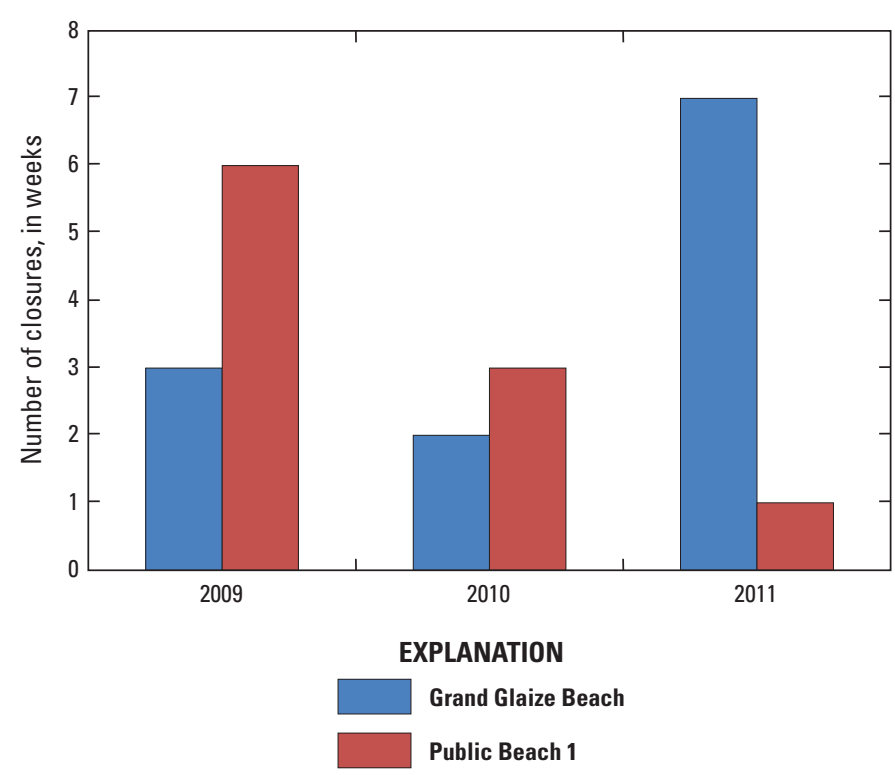

Figure 2. Number of beach closures at Grand Glaize Beach (GGB) and Public Beach 1 (PB1), Lake of the Ozarks State Park, 2009-11.

traditional on-site septic systems (Vandike and others, 1985). The Lake of the Ozarks, created with the construction of Bagnell Dam on the Osage River in 1931, has, at normal stage, a surface area of approximately 94 square miles, 1,150 miles (mi) of shoreline, and a total volume of 2 million acre-feet (Ameren, 2012). Much of the lake has intensely developed shoreline ranging from older 1950s-style seasonal homes to large resorts, and septic systems likely do not meet the minimum construction standards, as they were installed before construction standards were implemented (Missouri Attorney General's Office, 2010).

Flow in the Grand Glaize arm is from the southeast to the northwest where Bagnell Dam regulates lake discharge. The Lake of the Ozarks and LOSP are popular recreation destinations for the Midwest, and the MDNR estimated an average yearly park attendance of 1.3 million visitors between 2000 and 2011, and during 2011, the park hosted an all-time high of 2.2 million visitors (Missouri Department of Natural Resources, 2012a). In addition to the two public swimming beaches, LOSP also has several other beaches at group recreational areas that are not open to the public, such as Camp Rising Sun beach, that are not part of the MDNR beach monitoring program.

\section{Grand Glaize Beach}

GGB, located at the upper end of a narrow cove about $1,600 \mathrm{feet}$ (ft) long and $300 \mathrm{ft}$ wide, is roughly $12 \mathrm{mi}$ downstream, or northwest, from the mouth where Grand Glaize
Creek enters the Lake of the Ozarks. During summer months, the small crescent shaped beach has about $250 \mathrm{ft}$ of shoreline, is $50 \mathrm{ft}$ deep, and is located between two small intermittent tributaries referred to in this report as the west and east tributaries. The west tributary extends about $0.6 \mathrm{mi}$ west of GGB to a ridge, includes developed areas along State Highway 54, and has a drainage area of about 143 acres, 39 of which are mixed retail development, parking areas, and streets (fig. 3). The remaining 104 acres drain undeveloped heavily wooded slopes and park area. A sanitary survey conducted as part of this investigation during fall 2011 identified several potential sources for human-associated fecal contamination from wastewater systems within the west tributary watershed, including a vault toilet at a nearby picnic area and septic systems at a seasonal residence and maintenance workshop (fig. 4). A bathhouse, marina, and boat privy pumpout station at the marina also were identified, although outside the west tributary drainage area. The picnic area vault toilet is located approximately $500 \mathrm{ft}$ west of the beach. The seasonal residence, located approximately $750 \mathrm{ft}$ west of the beach, had a septic system but had not been occupied since spring 2010; and the maintenance workshop, located approximately $1,200 \mathrm{ft}$ northwest from GGB, had a septic system that was used daily. Septic tanks at the seasonal residence and maintenance workshop were located within $100 \mathrm{ft}$ of the west tributary or small branches of the west tributary, and during May 2012, the seasonal residence and maintenance workshop were connected to a centralized sewer system (fig. 3) The septic tank and laterals at the maintenance workshop were removed. The septic tank at the seasonal residence also was removed. Also within the west tributary watershed is a centralized pressure main that runs from the marina and bathhouse at GGB along the west tributary and connects to a City of Osage Beach sanitary sewer main adjacent to State Highway 54.

The east tributary drains about 18 acres that, except for 2.6 acres of asphalt parking lot adjacent to the beach, is densely wooded area north of the beach. No potential humanassociated sources were identified during the sanitary survey within the east tributary watershed except the centralized sanitary sewer main that runs from the marina to the beach bathhouse (fig. 3).

GGB has a bathhouse with showers that is connected to the centralized sanitary sewer system through a pump station adjacent to the bathhouse. A floating swimming boom separates the swimming area at the beach to the west from the boating area to the east (fig. 4). During the recreational season, normal water depths in the swimming area range from less than $3 \mathrm{ft}$ in the tributary inlets on either side of the beach to a maximum of about $10 \mathrm{ft}$ near the middle of the swimming boom. Mowed grassy areas separate the beach from the bathhouse and parking areas, and the beach is used most heavily during summer and holiday weekends, especially Memorial Day, Independence Day, and Labor Day when likely more than 100 visitors use the beach (fig. 5).

The marina adjacent to GGB consists of a concession area, fueling station, boat privy pumpout station, small 


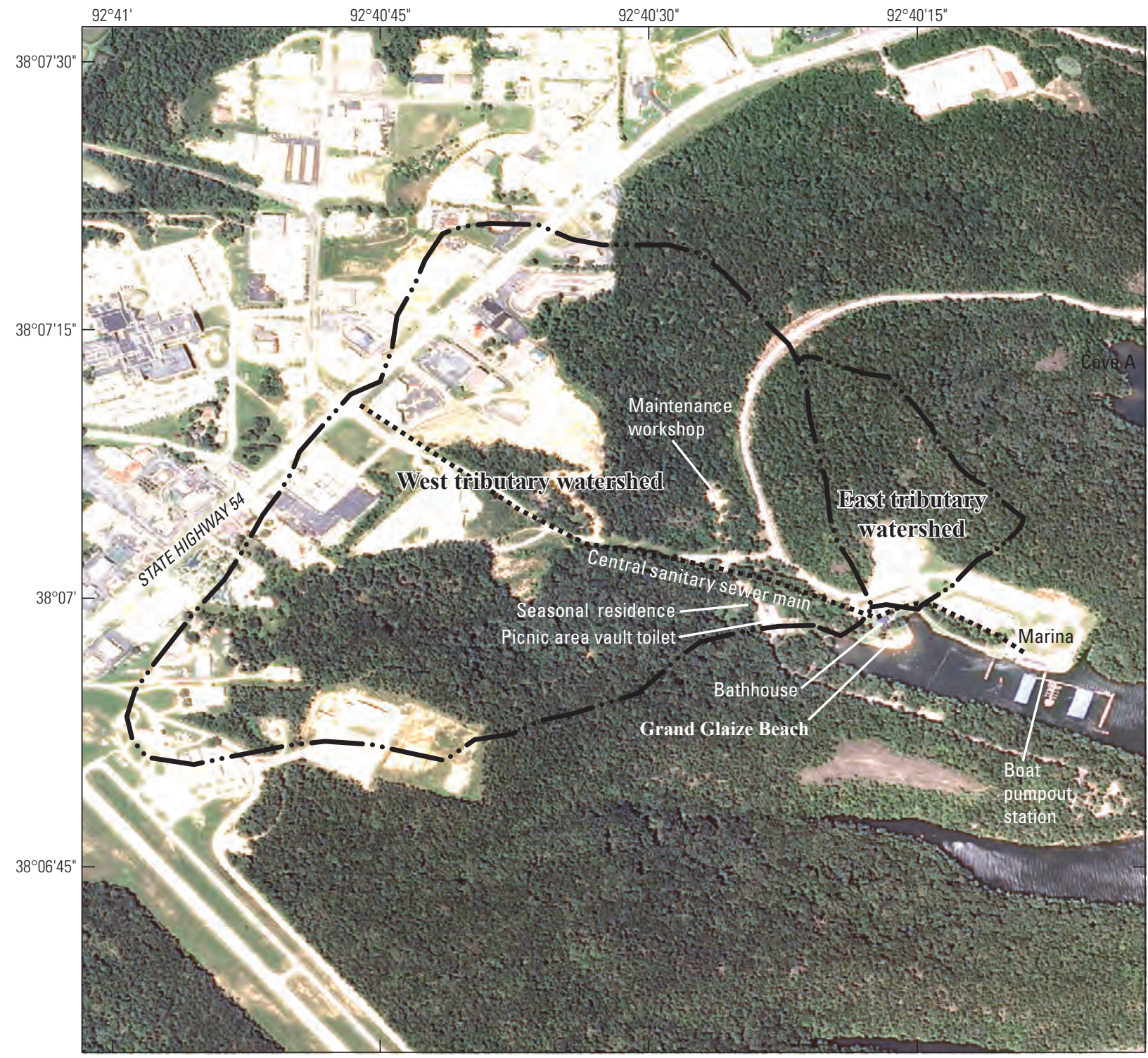

Base from U.S. Department of Agriculture, 2012 National Agriculture Imagery Program

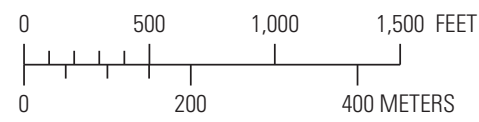

EXPLANATION

Watershed boundary

Figure 3. Known wastewater systems in the vicinity of Grand Glaize Beach (GGB) and watershed areas of tributaries to GGB cove, Lake of the Ozarks State Park, Missouri. 


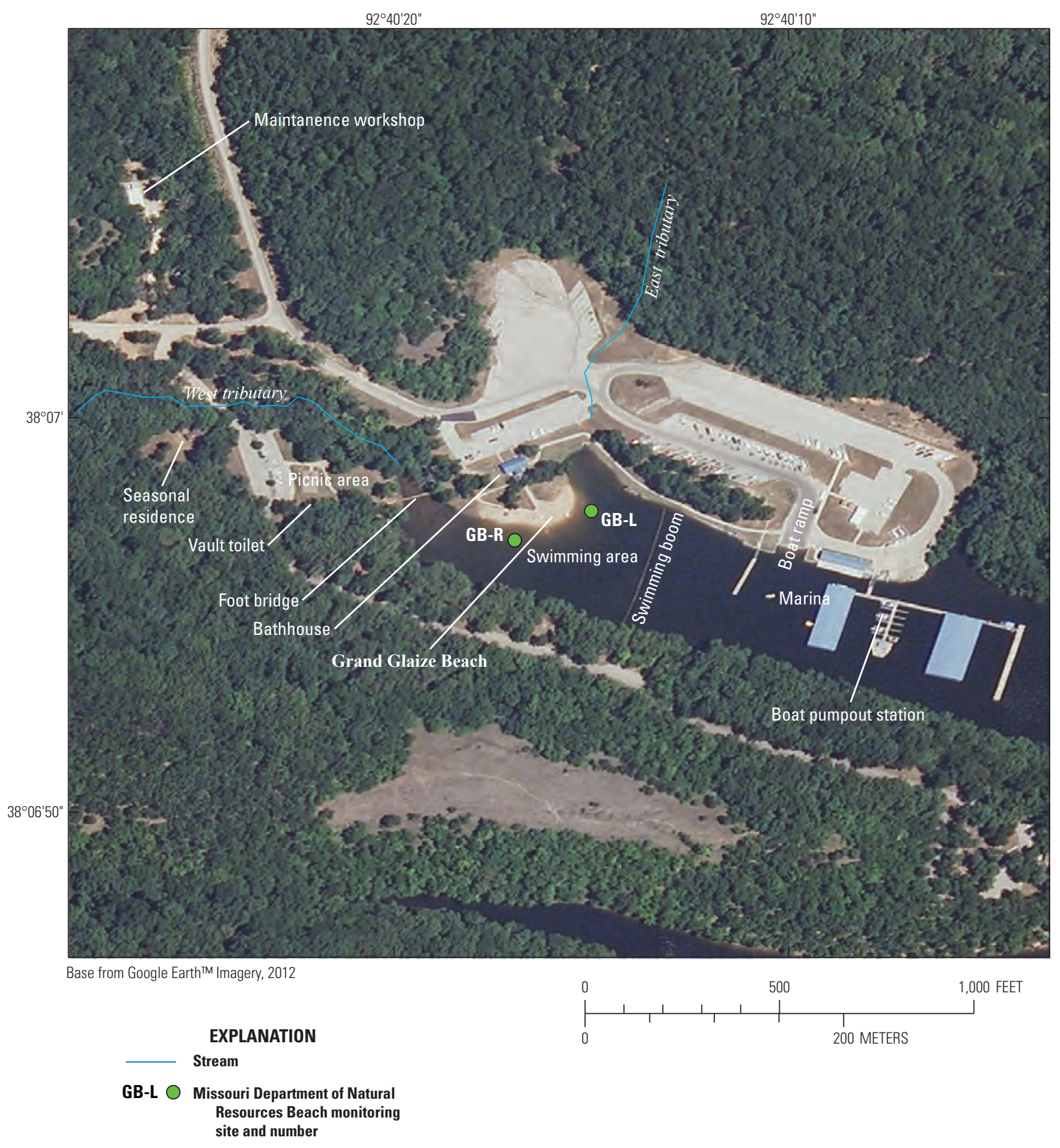

Figure 4. Major features and Missouri Department of Natural Resources (MDNR) beach monitoring locations in the vicinity of Grand Glaize Beach (GGB), Lake of the Ozarks State Park, Missouri. 


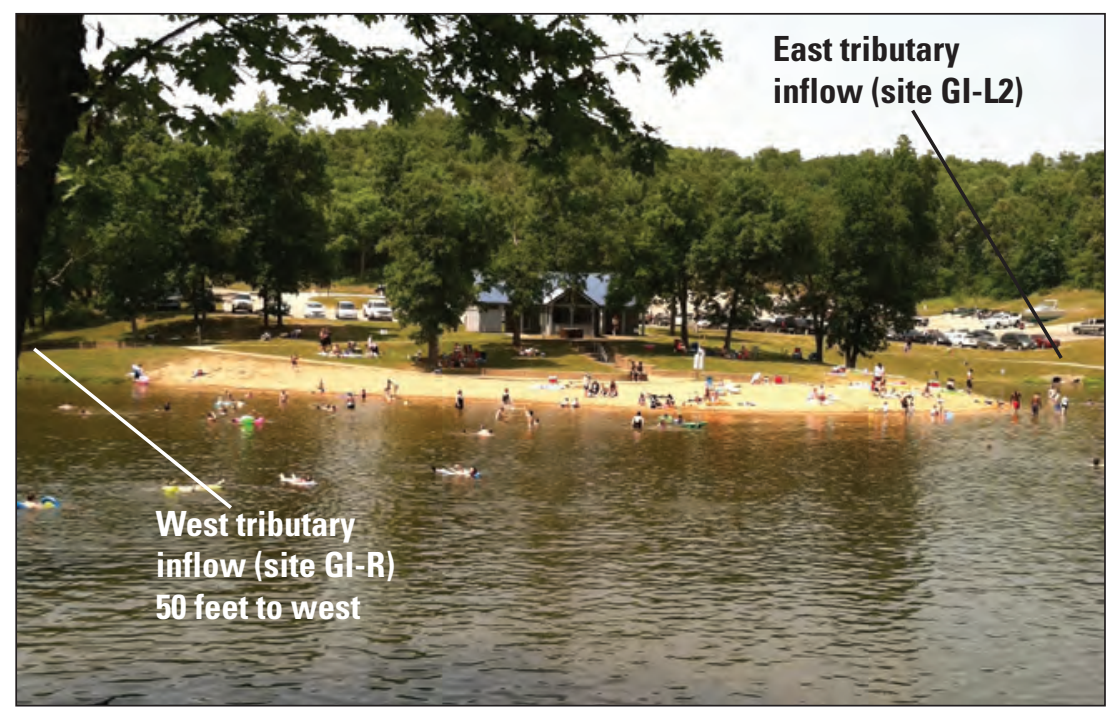

Grand Glaize Beach (GGB);

looking northwest;

Saturday of Memorial Day weekend, 5-26-2012.
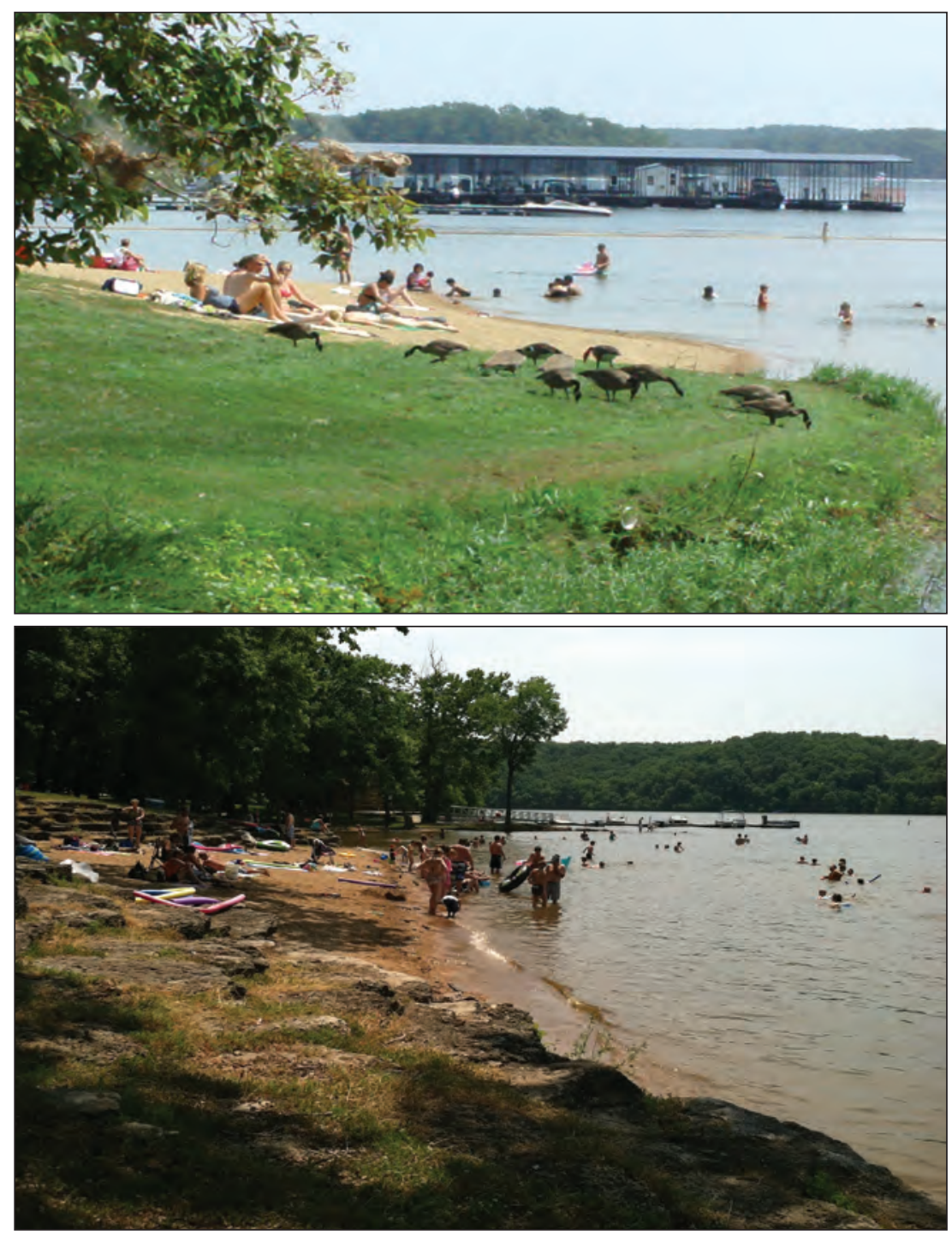

Public Beach 1 (PB1):

looking south;

Labor Day, 9-3-2011.

Figure 5. Grand Glaize Beach (GGB) and Public Beach 1 (PB1) during selected holidays at Lake of the Ozarks State Park, Missouri, 2011-12. 
courtesy dock next to a boat ramp, large boat dock capable of accommodating 50 boats, and more than 3 acres of asphalt parking capable of accommodating several hundred vehicles and trailers (fig. 4). During the recreational season, boat traffic is moderate (approximately 10 boats per hour) and peaks at mid-day. During the nonrecreational season, several fishing derbies are held at the marina, and several hundred boats use the marina boat ramp.

In addition to humans and pets, wild animals including Canada geese, deer, vultures, raccoons, rabbits, armadillos, and other small animals often are seen at GGB or in the immediate vicinity. The MDNR prohibits dogs from beaches, and they must be on leashes in the park. Geese have been a known nuisance at GGB for several years, and during 2011-12 park staff often noted a group of approximately 40 geese frequenting GGB in the evening and early morning around 0700 hours before park staff would arrive to groom the beach (fig. 6). Smaller numbers of geese also would occasionally visit the beach during daylight hours when the beach was occupied and graze in adjacent grassy areas or forage for food scraps left by visitors (fig. 5). Deer frequent the mowed grassy areas between the parking lots and the woods to the north within the east tributary watershed, and deer scat can be found in this region, but deer rarely frequent the beach area.

During the recreational season, park staff generally groomed GGB daily by dragging a metal pole behind a small tractor to remove hazardous materials such as glass and to smooth the sand of tracks from birds and bathers (fig. 6). This raking process, although protecting the public and leaving the beach smooth and more aesthetically pleasing, buried smaller objects including feces from geese within the sand, which has been reported to increase $E$. coli concentrations in sediment (Kinzelman and others, 2004). During July 2012, the raking method was replaced with a walk behind beach cleaner that was designed to collect and remove litter and small debris from the sand. Park staff noted that although very effective at litter removal, goose droppings often broke up and fell back into the sand rather than being retained in the machine's collection hopper. The sand at GGB is replaced periodically and is trucked in from a quarry north of the Lake of the Ozarks.

Besides providing recreation, the Lake of the Ozarks is a power generation facility, and lake levels are maintained primarily for those purposes. Lake levels fluctuate approximately $6 \mathrm{ft}$ throughout the year with higher stages occurring during the recreational season and lower stages occurring during January through April and October through December during the off-season (fig. 7). Because of extremely shallow slopes on the western side of GGB, the shoreline in the west tributary inlet may recede as much as $300 \mathrm{ft}$ during lower lake stages.
In contrast, the slope from the middle to the eastern side of the beach is steeper and the shoreline recedes less than about $50 \mathrm{ft}$ during lower lake stages. Lake levels were near normal for the 2011 recreational season (May-September), but lake levels were below normal during the late summer (July-August) in 2012 .

\section{Public Beach 1}

Public Beach 1 (PB1) is located about eight miles southeast and upstream from GGB on the Grand Glaize arm of the lake near Kaiser, Missouri (fig. 1). This beach is located on the northwest side of a ridge that extends southwest and is bordered on three sides by the lake (fig. 8). Unlike GGB, PB1 is located on the main arm of the lake, not inside of a sheltered cove. The narrow $40 \mathrm{ft}$ deep by $250 \mathrm{ft}$ wide beach is located at the base of a steep hill with an 8 to $10 \mathrm{ft}$ high bedrock exposure separating the beach from a sloped hillside to the east (fig. 5). Uphill from the beach are picnic areas, a playground, and a bathhouse. The beach is exposed to waves from boat traffic that tend to wash away finer sediment leaving the beach with a coarser grain-size distribution than GGB. The bathhouse and adjacent asphalt parking area are on the hillside about $300 \mathrm{ft}$ east of the beach. Except for a grassy area between the beach and bathhouse where deer and deer scat frequently are observed, the area is thickly wooded. Approximately $350 \mathrm{ft}$ south of PB1 is a small marina with a fueling station, boat ramp, and small dock, and approximately $300 \mathrm{ft}$ north of PB1 are several small fishing docks. Extending about $0.4 \mathrm{mi}$ along the lakeshore south of the marina and about $0.65 \mathrm{mi}$ northeast along the ridge east of PB1 is a large (more than 100 acres) campground with more than 180 campsites, several shower houses, a concession area, and several vault toilets. A horse stable is located approximately $1 \mathrm{mi}$ northeast of PB1, and runoff from the horse stable enters an unnamed tributary that enters the lake about 0.50 mi north (downstream) from PB1. The beach and campground bathhouses, marina, horse stable, office, and campground concession are connected to a localized sanitary sewer system that feeds to a wastewater treatment plant located at the mouth of a small tributary along the lake shore about 0.25 mi northeast of PB1. Because PB1 is on the upper end of the Grand Glaize arm of the lake, much of the lake surrounding the beach and campground is relatively shallow (less than 15-20 ft deep). Shallow water depths and runoff from Grand Glaize Creek that enters the lake only $3 \mathrm{mi}$ from PB1 contribute to greater turbidity in the lake around PB1 as is evident by tan colored water in a 2012 aerial photograph (fig. 8 inset). 


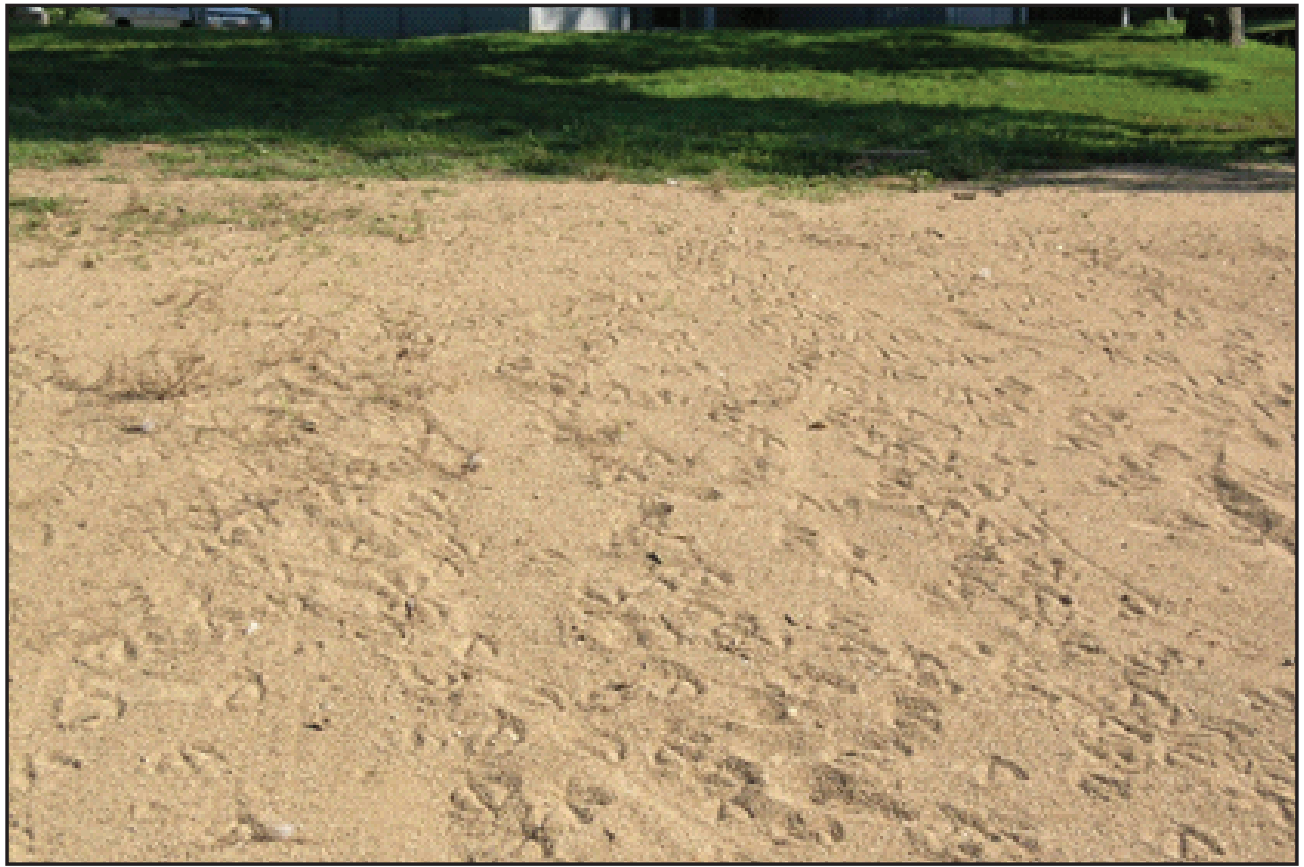

Goose tracks on beach in the early morning before park workers have groomed the beach.

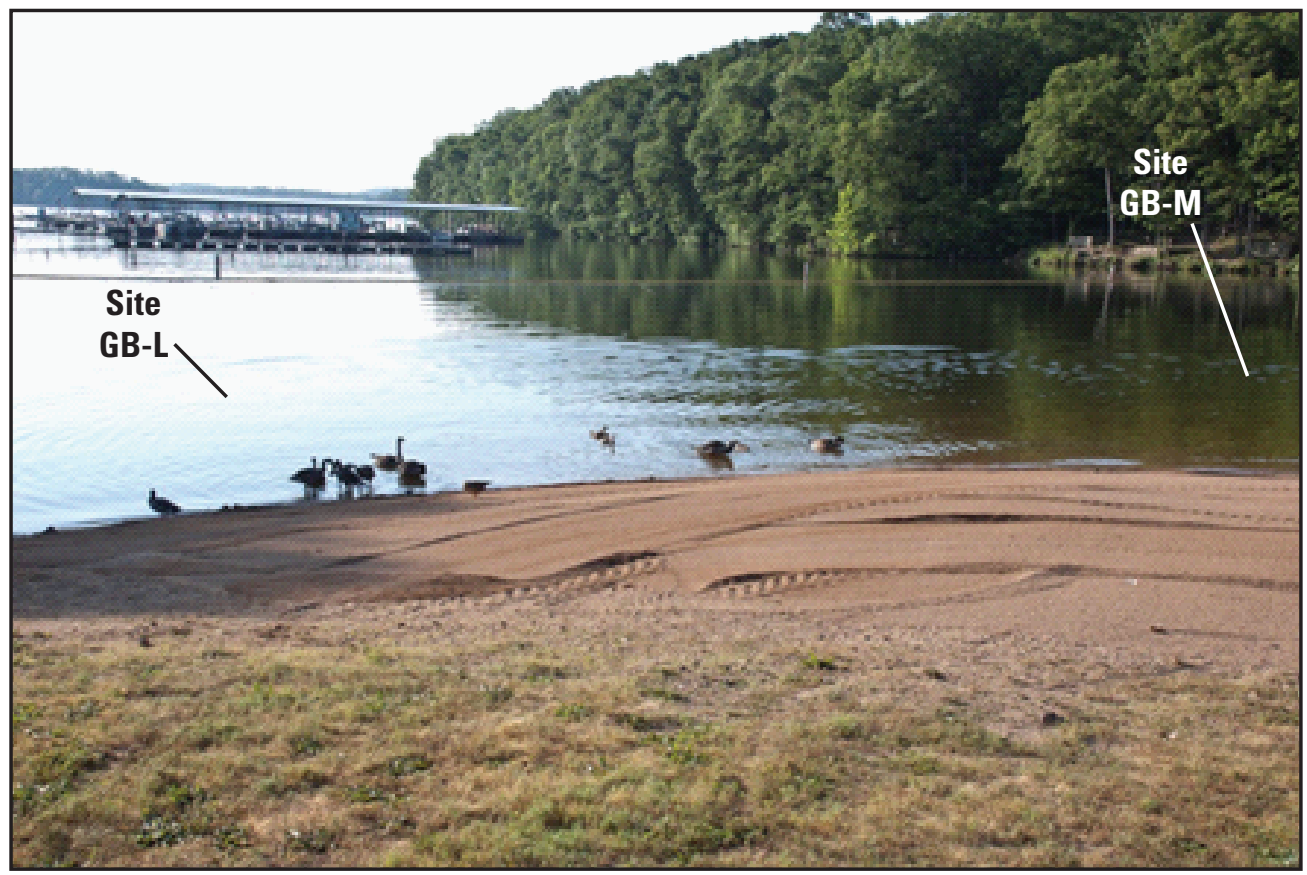

Geese returning in the early morning just after beach grooming, May 27, 2012.

Figure 6. Geese activity at Grand Glaize Beach (GGB), May 2012. 


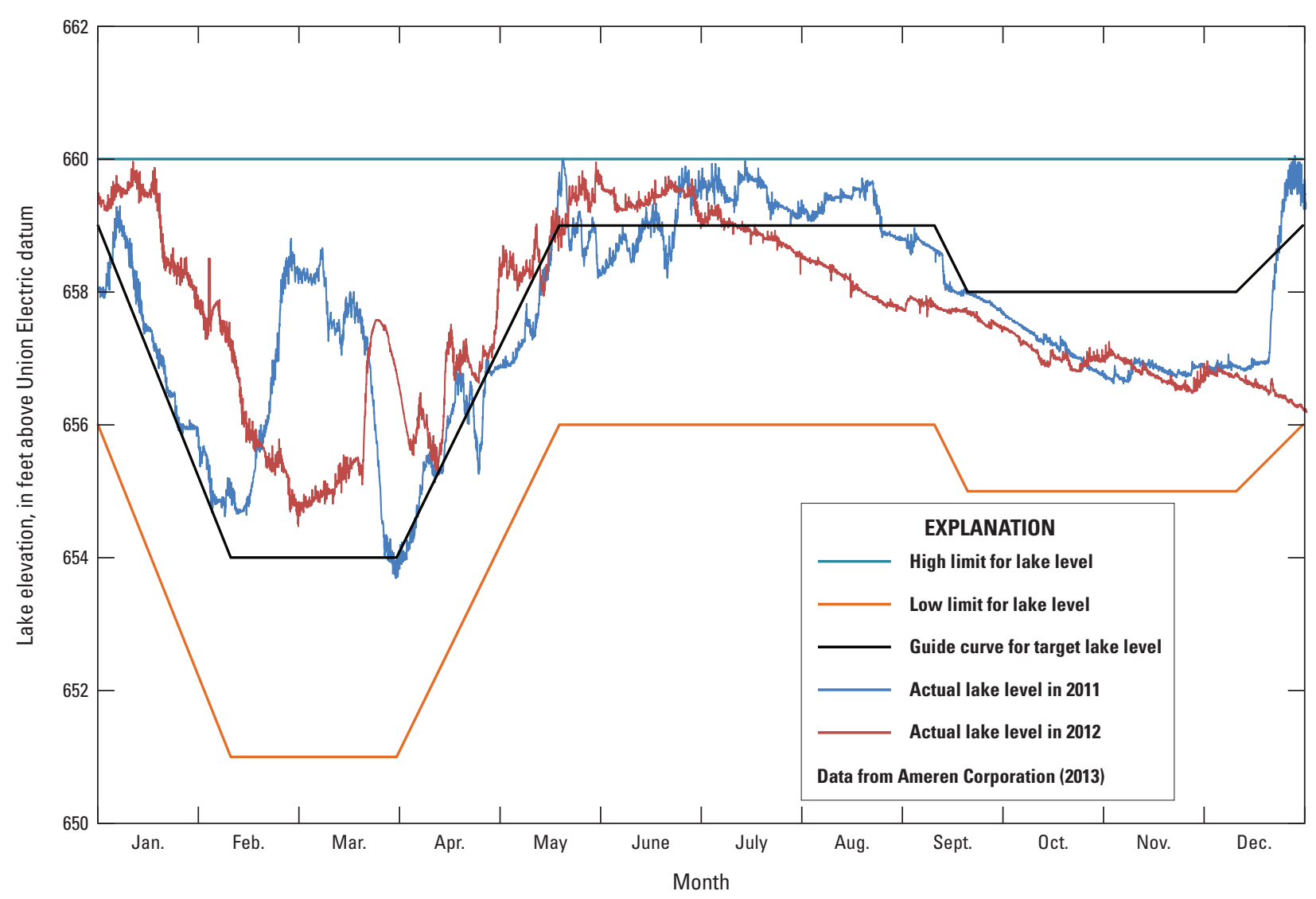

Figure 7. Curves for high and low lake level limits, target lake level, and actual lake levels, Lake of the Ozarks, Missouri, 2011-12. 


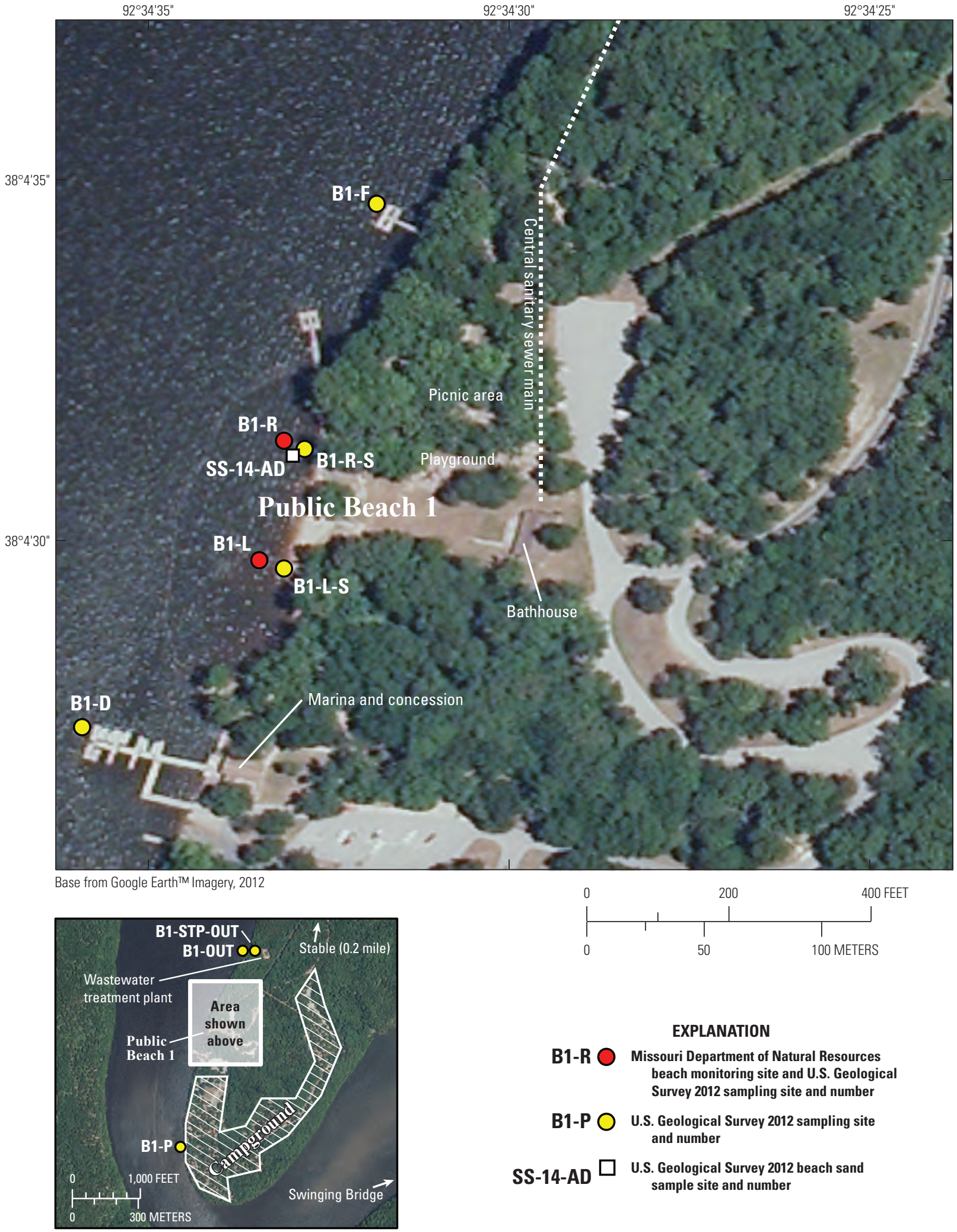

Figure 8. Major features, Missouri Department of Natural Resources beach monitoring locations, and 2012 U.S. Geological Survey sampling locations in the vicinity of Public Beach 1 (PB1), Lake of the Ozarks State Park, Missouri. 


\section{Methods of Study}

This report presents data collected during two field studies - a reconnaissance study conducted during late-summer and fall 2011 and an intense monitoring study conducted during the 2012 recreational season from a total of 36 locations (table 1). During 2011, reconnaissance sampling of 14 sites for 17 days was done at GGB, GGB cove, and nearby coves, which was used to design an expanded and more intensive monitoring program at GGB, PB1, and vicinity for 45 days during the 2012 recreational season. Minimal sampling also was conducted on February 5, 2013, at GGB to supplement sediment and resuspended sediment data collected during the 2012 recreational season.

The MDNR beach closure criteria for E. coli is 126 and 235 colonies per 100 milliliters for the GM and SSV, respectively (Missouri Attorney General's Office, 2010); however, the reported units can be either CFU/100 mL or MPN/100 mL depending on which USEPA-approved analytical method is used to enumerate the $E$. coli. Because samples were sent to different labs, E. coli concentrations were analyzed using different methods and reported in different units. For samples analyzed at the USGS Missouri Water Science Center (MWSC), E. coli concentrations were determined using the membrane-filtration method (Myers and others, 2007), which reports $E$. coli in units of CFU/100 mL. For samples analyzed by the USGS Ohio Water Microbiology Laboratory (OWML) and MDNR, E. coli concentrations were determined using the Colilert Quanti-Tray $/ 2000^{\circledR}$ method (IDEXX Corp., Westbrook, Maine), which reports E. coli concentrations in MPN/100 mL.

\section{Site Selection and Sampling Frequency}

A USEPA tool for methodologically investigating fecal sources of contamination at public beaches is a sanitary survey, titled "Great Lakes Beaches Routine On-Site Sanitary Survey," which can be accessed at http://water.epa.gov/ type/oceb/beaches/sanitarysurvey_index.cfm. The USEPA tool was used to conduct a sanitary survey during the 2011 reconnaissance by USGS to identify potential sources of E. coli contamination.

During the 2011 reconnaissance, water samples were collected at several locations at GGB, GGB cove, and two coves north of GGB cove to determine baseline concentrations of E. coli at and in the vicinity of GGB (fig. 9). The two sampling locations at the beach were identical to the MDNR sample locations (sites GB-L and GB-R). GGB cove and the west tributary were sampled at seven different locations to assess spatial variability of $E$. coli concentrations throughout the cove and possible relations to stormwater runoff (sites GI-L, GI-R, GI-R7, GI-R8, and GI-R9) and boat traffic at the marina (sites GM-01 and GM-02). Samples also were collected from locations in two coves north of GGB cove, designated as cove A (sites CA-01, CA-02, and CA-03) and cove B (sites CB-01 and CB-02) to determine if E. coli concentrations at GGB cove were larger than other nearby undeveloped coves. Routine water samples typically were collected around noon every Tuesday, Thursday, and Saturday for 6 weeks from August 25, 2011, through October 3, 2011.

The 2012 intensive study, designed based on the results of the 2011 reconnaissance study, included sampling at GGB, PB1, and RS-B; began May 17, 2012 and ended October 3, 2012, with one additional sampling on February 5, 2013, to supplement sediment and resuspended sediment data. In addition to water samples, sediment and resuspended sediment samples were collected from GGB, and a sediment sample was collected from PB1. During 2012, all cove B sites and site CA-02 were excluded from the sampling sites list. Sites CA-01 and CA-03 were retained in the 2012 intensive monitoring, and additional sampling sites were added along the west tributary to GGB cove (sites GI-T-DS, GI-T, GI-T-N, and GI-T-US), the east tributary (site GI-L2), and the middle of the beach (site GB-M) between sites GB-L and GB-R (fig. 10). In addition, locations in ankle-deep water (sites GB-L-S, GB-M-S, and GB-R-S) corresponding to the beach sites were sampled during some trips, as was a small spring (site CASPG) discovered in 2012 near the upper end of cove A.

Public Beach 1 and vicinity were sampled at eleven locations during the 2012 intensive study (fig. 8). Sampling sites included two sites at the beach (sites B1-L and B1-R) identical to MDNR sampling locations in addition to locations at the PB1 marina boat dock (site B1-D), a fishing dock north of PB1 (site B1-F), and along the lakeshore near the upper end of the campground south of PB1 at campsite 173 (site B1-P). Samples also were collected at the lakeshore near the wastewater treatment plant north of PB1 (site B1-OUT) and once from treated effluent discharging from the plant (site B1-STPOUT). Sampling from a swimming dock at Camp Rising Sun Beach (site RS-B) as well as a site where Grand Glaize Creek enters the lake at what is called Swinging Bridge (site SWB) was done to establish background levels at less populated areas within LOSP (fig. 1). In addition, samples were collected from ankle-deep water at the beach sites (site B1-L-S and B1-R-S).

Sampling during the 2012 recreational season was organized into one of three sampling trips referred to as routine, intensive, and runoff trips in this report. Each sampling trip generally took place on a single day, except for some runoff trips that occurred during the late night and early morning hours. On average, trips were conducted twice a week with about four sampling trips during each week between May and July. The routine sampling trips consisted of as many as 29 locations at GGB, GGB cove, cove A, PB1, and, occasionally, RS-B and CA-SPG. Routine sites were sampled generally between 1000 and 1500 hours.

Intensive sampling trips consisted of 21 sites and the collection of 3 to 5 rounds of samples each day from GGB and GGB cove and at least 1 round of samples from PB1, cove A, and RS-B. The main purpose of the intensive sampling events was to monitor how E. coli concentrations and beach use vary 


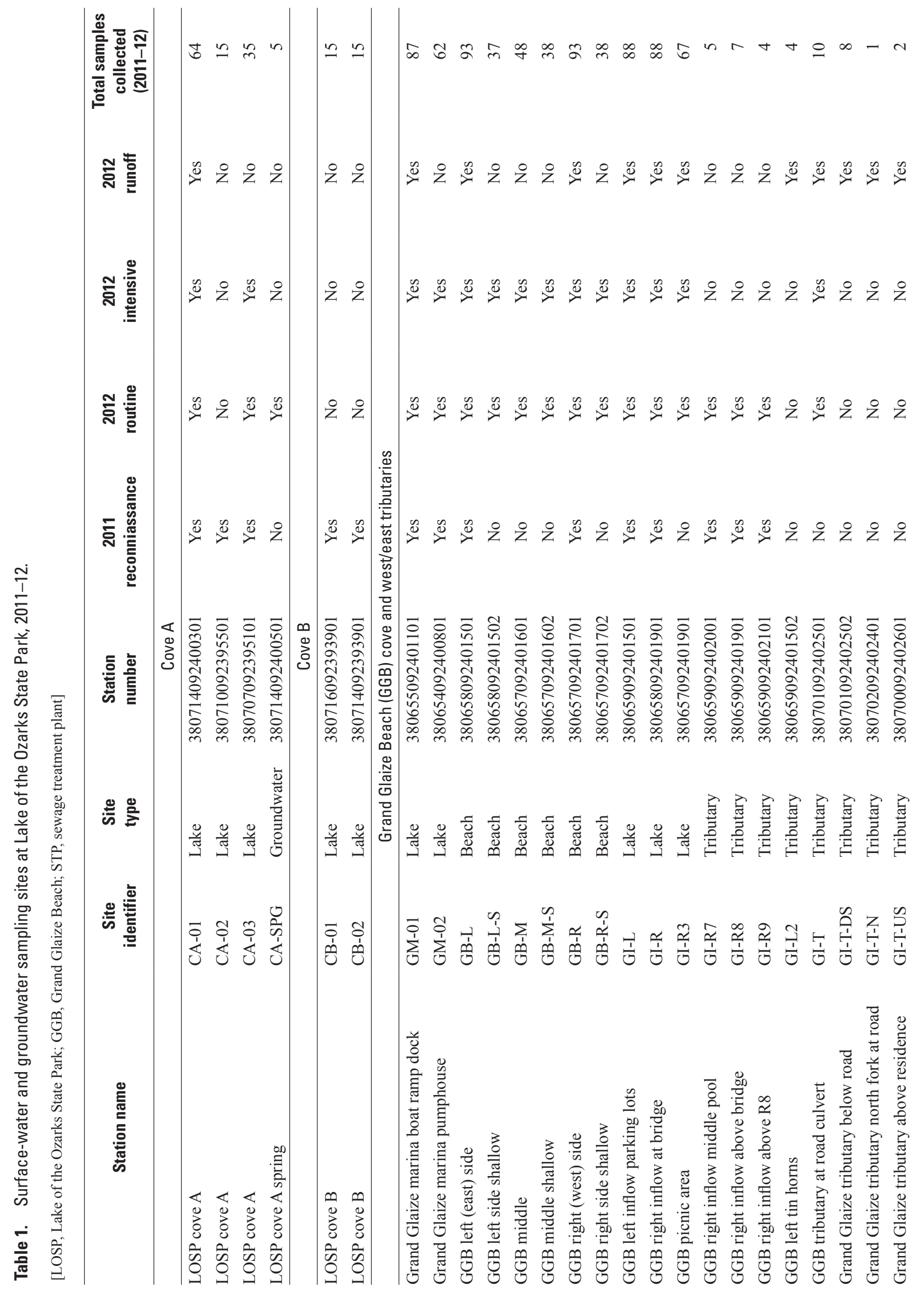




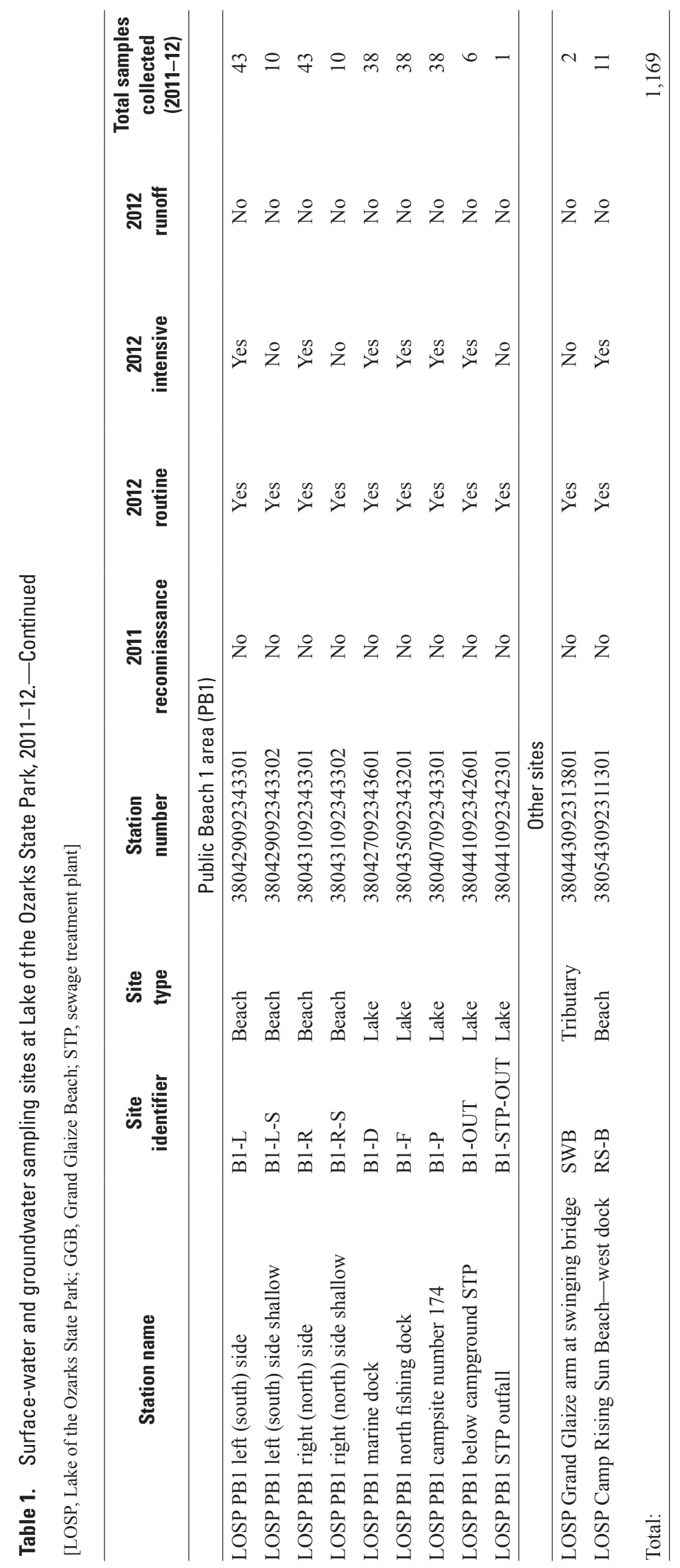




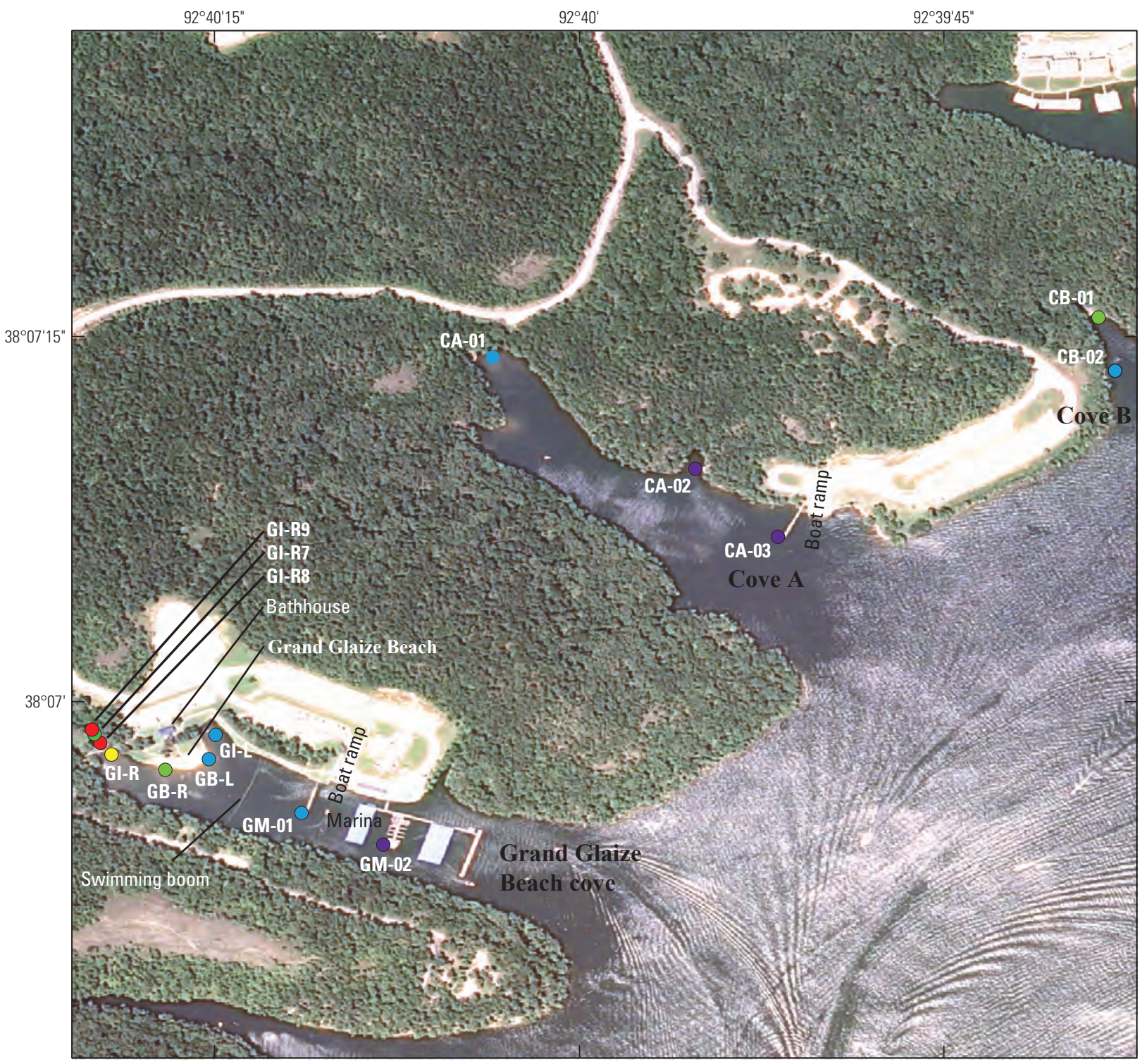

Base from U.S. Department of Agriculture, 2012 National Agriculture Imagery Program

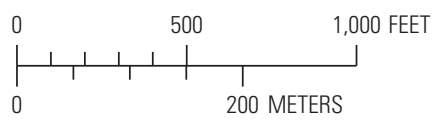

\section{EXPLANATION}

GI-R9 2011 sampling site and name

$\begin{array}{ll} & \begin{array}{c}\text { Average Escherichia coli concentration, } \\ \text { in colony-forming units per } 100 \text { milliliters }\end{array} \\ & \text { Greater than }(>) 1,000 \\ 0 & >235-1,000 \\ - & >25-235 \\ - & >10-25 \\ \text { L Less than or equal to } 10\end{array}$

Figure 9. Average Escherichia coli (E. coli) concentrations in samples from 2011 sites from Grand Glaize Beach (GGB) cove, cove A, and cove B, Lake of the Ozarks State Park, Missouri. 


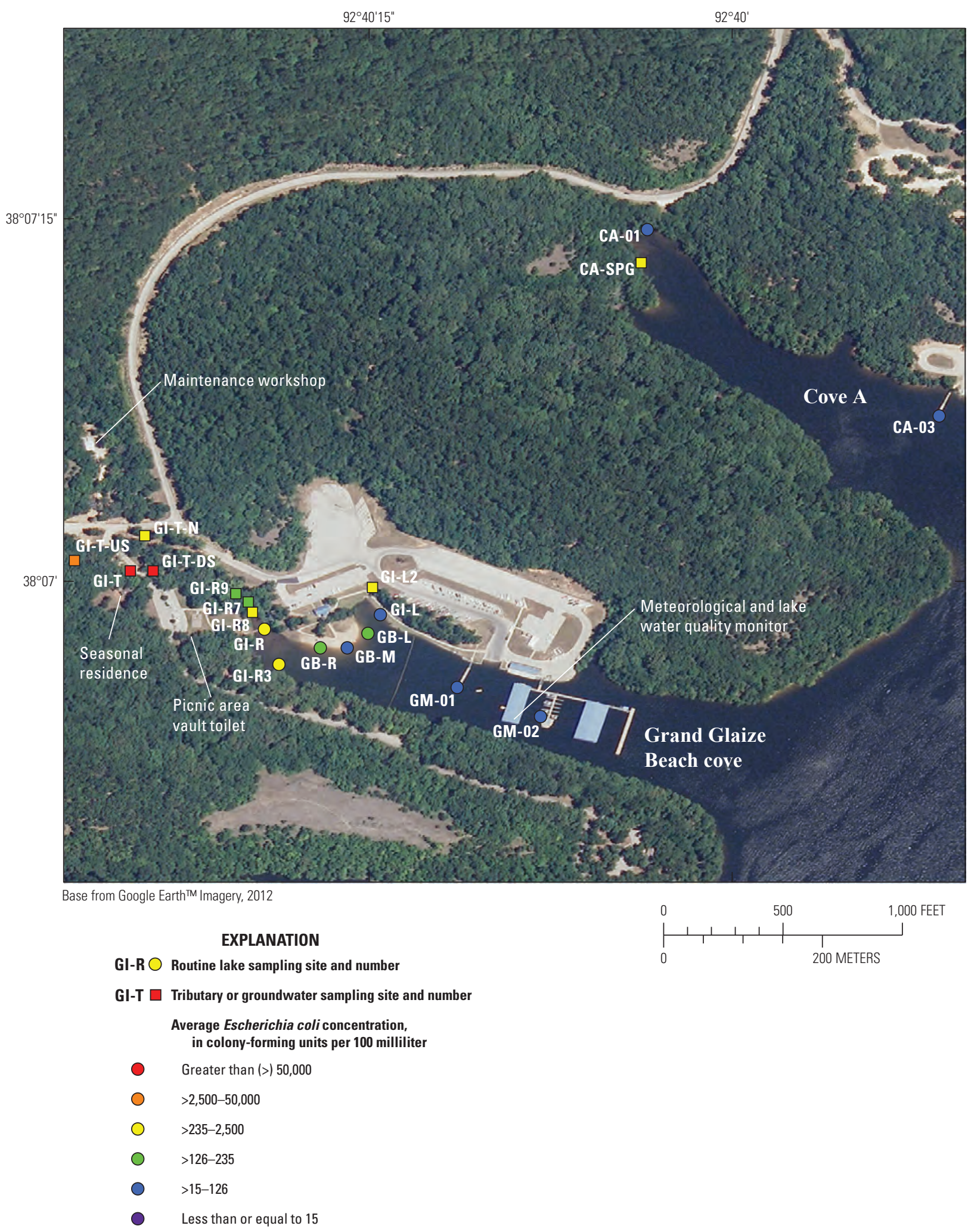

Figure 10. Location and average Escherichia coli (E. coli) concentration in water samples collected during 2012 from Grand Glaize Beach (GGB) cove, tributaries, and cove A, Lake of the Ozarks State Park, Missouri. Locations of shallow water samples at beach (GB-R-S, GB-M-S, and GB-L-S) not shown. See figure 11 for specific location of these sites. 
throughout the day at GGB. Intensive sampling events were conducted on and around low-traffic weekdays, high-traffic weekends, and the three major holidays during the recreational season in 2012 including Memorial Day (May 28), Independence Day (July 4), and Labor Day (September 3).

Runoff sampling events focused on capturing the effect of stormwater runoff. Sampling during these runoff events occurred at as many as 12 locations at GGB, GGB cove, the west and east tributaries, and, when possible, site CA-01. On several occasions, precipitation was not enough to cause substantial flow from the west tributary into GGB cove but did, however, cause local runoff from streets, impervious areas, and sidewalks that formed pools in the west tributary. During these events sampling locations in the west and east tributaries (sites GI-T, GI-T-DS, GI-T-N, GI-T-US, and GI-L2), GGB (sites GB-L and GB-R), GGB cove (sites GM-01, GI-L, GI-R, and GI-R3), and cove A (site CA-01) were sampled when pooling or flow was observed (fig. 10). Of the 45 sampling trips conducted during 2012 at LOSP, 31 were routine events, 10 were intensive events, and 4 were runoff events.

\section{Sample Collection and Analysis}

A total of 1,353 surface-water, sediment, resuspended sediment, and MST samples were collected and analyzed during the 2011-13 duration of the project. Water samples were analyzed for E. coli, and field measurements were made at the time of sample collection. Turbidity was measured from a split sample from the bacteria sample bottle in the USGS MWSC laboratory, Rolla, Mo. Resuspended sediment samples were collected at 12 different locations in GGB cove, 3 of which were collected on a regular basis. Sediment samples were collected and analyzed for E. coli at 11 locations at GGB and 1 site at PB1. MST samples of water and sediment were collected mainly at GGB and PB1, but also were collected from GGB cove and tributary sites and sent to the USGS OWML for analysis. Data from all surface and groundwater sites are available in the USGS National Water Information System (NWIS) as well as online at URL http://mo.water.usgs.gov/. Data not in the NWIS include sediment and resuspended sediment samples and MST data generated by the OWML.

\section{Water Samples}

Water samples were collected for E. coli and turbidity analysis using sterilized, $250-\mathrm{mL}$ polypropylene bottles. Samples generally were collected in waist-deep water and collected using an established grab-sampling technique approximately 6 to 12 in. below water surface at arm's length to minimize sample contamination (Myers and others, 2007). Water-quality properties including specific conductance, water temperature, $\mathrm{pH}$, dissolved-oxygen concentration, and, occasionally, air temperature were recorded concurrently with water sample collection on either a YSI 85 or YSI 556 MPS field meter (YSI Incorporated, Yellow Springs, Ohio).
At beach locations, the number of bathers in the water, the number of bathers on the shore, and the total number of bathers at the beach (sum of bathers in the water and bathers on the shore) were noted at the time of sample collection, as well as other notes including observations of litter, animals, or animal scat on the beach. Samples from pooled water in tributaries were collected similarly to routine water samples at beach locations.

Enumeration of $E$. coli was done using standard USGS membrane-filtration procedures for fecal indicator bacteria (Myers and others, 2007) using Difco Modified mTEC agar (Becton, Dickerson and Company, Franklin Lakes, New Jersey). All samples were processed within 6 hours of collection either on-site or at the USGS MWSC laboratory. When the number of $E$. coli colonies on the plates was excessively large (more than approximately 200) the plates were sectioned visually into quarters, and one quarter was counted and multiplied by four. Because these counts were outside of the ideal range of 20-80 colonies per plate, the concentrations were qualified as estimates. Turbidity was measured with a Hach 2100P portable turbidimeter that was calibrated with known standards according to manufacturer's guidelines (Hach Company, 2008). Selected water samples also were sent overnight to the OWML for E. coli enumeration using the Colilert QuantiTray $/ 2000^{\circledR}$ method (IDEXX Corp., Westbrook, Maine) and for MST marker analyses using quantitative polymerase chain reaction (qPCR).

\section{Sediment and Resuspended Sediment Samples}

Sediment samples (imported beach sand above and below the shoreline; native, finer-grained sediment; and a mixture of both) were collected and analyzed for $E$. coli from the swash zone (the beach region where wave action constantly inundates beach sands), following sediment collection methods used by the USGS Ohio Water Science Center (WSC; Francy and Darner, 1998) with the exception that only single samples were collected. Nearshore sediment (sediment near the shoreline of GGB) samples were collected on May 31, June 25, June 27, and October 3 in 2012 and February 5 in 2013 at equally spaced locations across GGB (fig. 11). All samples were collected in sterile, $120-\mathrm{mL}$ wide-mouth polypropylene jars. Foreshore (FS) samples (samples collected above the shoreline) from the swash zone were collected approximately 2-ft inland from the shoreline, and ankle-deep (AD) samples were collected about 1 to $2 \mathrm{ft}$ from the shoreline (fig. 12). For foreshore samples, the top 2 in. of dry sand was scraped away and the underlying upper 2 in. of moist sand was sampled. Sediment samples were collected at waist-deep (WD) locations on May 31, 2012, at the same locations as routine water samples at GGB (sites GB-L, GB-M, and GB-R) and on October 3 at waist-deep locations (sites SS-11-AD, SS-12-AD, and SS-13-AD) near GI-R3 and an ankle-deep location (site SS10-AD) near GI-R (fig. 11). For waist-deep sediment samples, the collector waded to the sample location, submerged the capped jar to the lake bottom, removed the cap, and scooped 


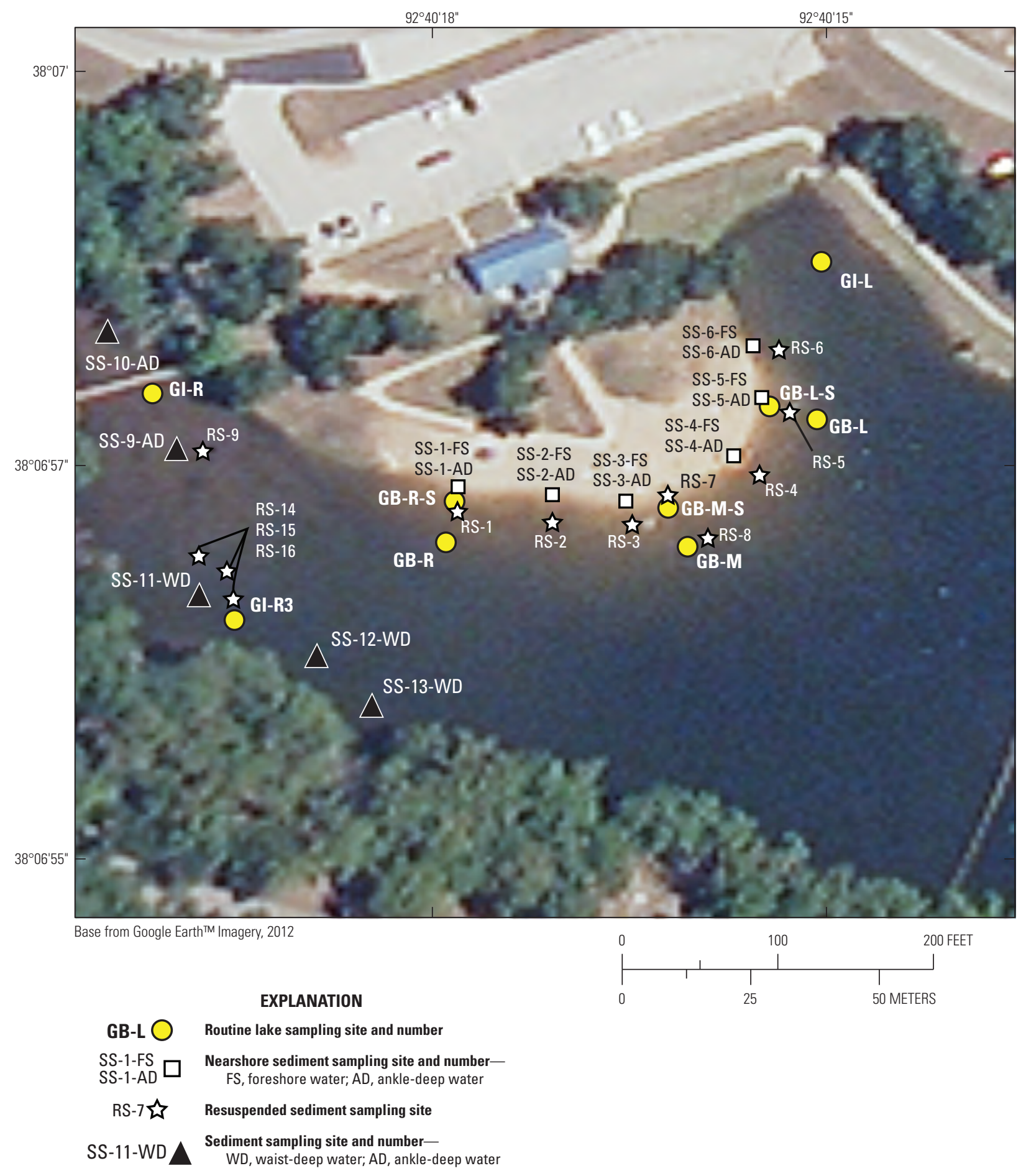

Figure 11. Locations of sediment and resuspended sediment samples collected at Grand Glaize Beach (GGB) and adjacent swimming area, 2012-13. 


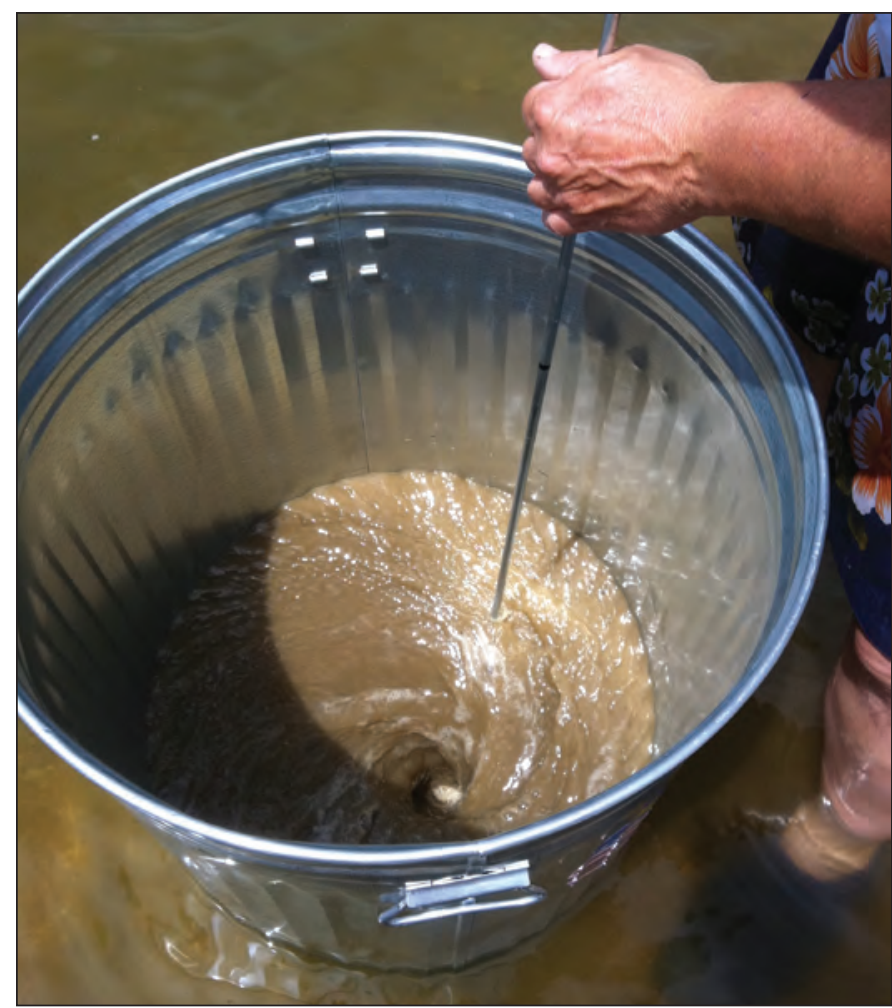

Resuspension of sediments, June 7, 2012, Grand Glaize Beach.

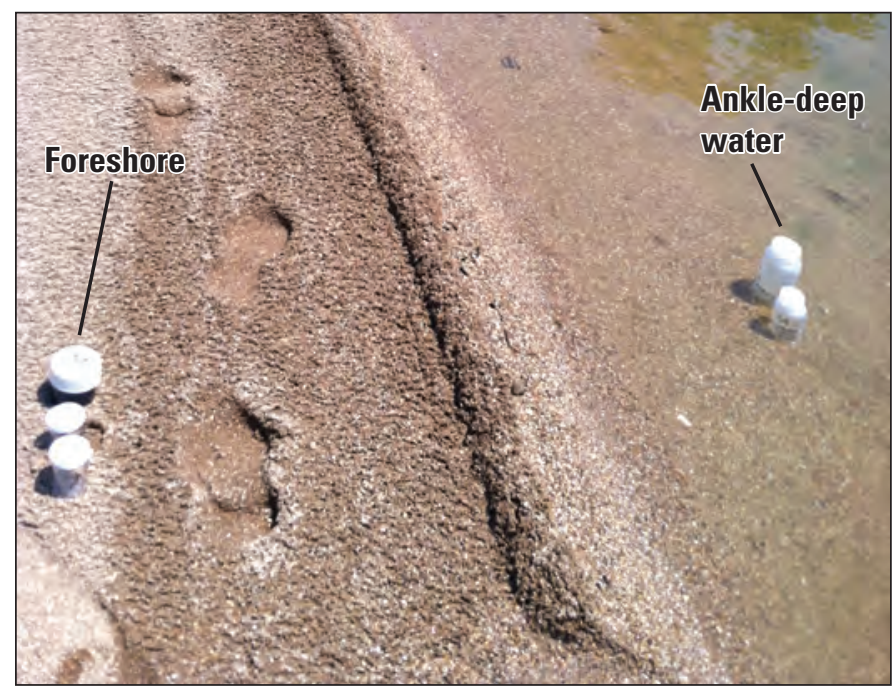

Relative location of foreshore and ankle-deep sediment to edge of water.

Figure 12. Resuspended sediment sample and foreshore and ankle-deep nearshore sediment sample collection, 2012-13. lakebed sediment. The cap was placed back on the jar before returning the jar to the surface to prevent loss of sediment.

Sediment samples were processed at the USGS MWSC laboratory by first emptying each sample onto a separate sheet of aluminum foil then folding the foil diagonally corner to corner clockwise. This procedure was replicated three times and a sterilized micro spatula was used to further homogenize the sample and transfer 20-30 subsamples [50 grams (g) total] to a sterile, $250-\mathrm{mL}$ polypropylene bottle. After adding $200 \mathrm{~mL}$ of sterile phosphate buffer solution to the bottle, the sample was mixed for 45 minutes (min) on a wrist-action shaker. After shaking, the bottles were removed and allowed to settle for $1 \mathrm{~min}$, allowing any large particles to settle, and then the suspensions were analyzed for $E$. coli using the membrane-filtration technique. For sediment samples, the filtered volumes were much smaller than water samples, varying from $0.1 \mathrm{~mL}$ to $10 \mathrm{~mL}$. The remaining sediment samples that were not used in enumeration were dried at 105 Celsius $\left({ }^{\circ} \mathrm{C}\right)$ for 24 hours to determine percent dry weight, and $E$. coli concentrations in colony-forming units per gram of dry weight $\left(\mathrm{CFU} / \mathrm{g}_{\mathrm{DW}}\right)$ were then calculated based on established methods (Francy and Darner, 1998). Particle-size distributions of samples collected on October 3, 2012, were determined using established methods (Guy, 1977), which included drying the samples for several days at room temperature and then passing them through 1-millimeter $(\mathrm{mm})$ and 0.063-mm sieves. Selected sediment samples also were sent overnight to the OWML for E. coli enumeration using the Colilert Quanti-Tray $/ 2000^{\circledR}$ method (IDEXX Corp., Westbrook, Maine) and for MST marker analyses using qPCR.

Resuspended sediment samples were collected from as many as 12 locations at GGB during 3 occasions on June 7, 2012; September 22, 2012; and February 5, 2013 to assess the potential for sediment at GGB to act as a sink for E. coli (fig. 11). Samples were collected using a 30-in diameter, metal cylinder, and to prevent cross-contamination, the inner surface was sprayed with methanol and flame-sterilized before each use (fig. 12). The cylinder was lowered into approximately 2-ft deep water (approximately 10-30 ft from shore) and slowly pushed several inches into the sediment. Once secured in the sediment, the water inside the cylinder was sampled in the same fashion as routine water samples. A cordless drill with a 3-ft paint mixer attachment was then used to disturb the sediment and uniformly mix it into the water column by mixing the top couple inches of sediment. The water was mixed for 45 seconds and then allowed to settle for 30 seconds before sampling. On June 7, 2012, six equally spaced resuspended sediment samples were collected along GGB (sites RS-1 through RS-6). In addition, two resuspended sediment samples were collected in the middle of GGB near location GB-M — one at the edge of the water (site RS-7) and the other 
in 4-ft deep water (site RS-8). On September 22, 2012, three resuspended sediment samples were collected near sites GB-L, GB-M, and GB-R at sites RS-1, RS-3, and RS-5 as well as three near site GI-R3 at sites RS-14, RS-15, and RS-16 and one near site GI-R at site RS-9. On February 5, 2013, two resuspended sediment samples were collected near sites GB-L and GB-R at sites RS-1 and RS-5 (fig. 11). All resuspended sediment samples were processed and analyzed for E. coli and turbidity at the USGS MWSC using the same methods as water samples. Selected resuspended sediment samples also were sent to the OWML for $E$. coli enumeration using the Colilert Quanti-Tray $/ 2000^{\circledR}$ method (IDEXX Corp., Westbrook, Maine) and for MST marker analyses using qPCR.

\section{Microbial Source Tracking Samples}

A total of 72 water samples, 19 sediment samples, and 10 fecal source samples were collected and shipped overnight on ice to the OWML for MST using qPCR analysis. Water samples were collected in sterile 500-mL deoxyribonucleic acid (DNA)-free bottles, sediment samples were collected in sterile $250-\mathrm{mL}$ polypropylene jars, and fecal source samples were collected in sterile $50-\mathrm{mL}$ centrifuge tubes. Once received at the OWML, water samples were filtered through a 0.4 -micrometer, $47-\mathrm{mm}$ polycarbonate filter (Whatman, Florham Park, N.J.). The average volume of water filtered was $60 \mathrm{~mL}$, with as little as $5 \mathrm{~mL}$ and as much as $120 \mathrm{~mL}$ filtered, depending on the rate at which the filter clogged. The filter was aseptically folded and placed into a 2-mL screw-cap tube containing $0.3 \mathrm{~g}$ of acid-washed, glass beads (Sigma-Aldrich Corp., St. Louis, Mo.). Filters were frozen and stored at $-70{ }^{\circ} \mathrm{C}$ until further processing. For water samples collected during weekends or holidays, filtering was done onsite (May 26, 2012) or transported to the USGS MWSC laboratory and filtered within 6 hours and the filters placed in a standard freezer $\left(-20^{\circ} \mathrm{C}\right)$ until they were shipped on dry ice to the OWML. The May 26, 2012, MST filters processed at the field site were not frozen immediately, but were placed in an ice chest for about 10 hours before they were transported to the USGS MWSC laboratory and frozen.

The sediment samples were processed at the OWML using the method described in Francy and Darner (1998). Briefly, a composite of three sediment samples was made by mixing equal proportions in a sterile container. Approximately $20 \mathrm{~g}$ of sample was added to $200 \mathrm{~mL}$ of phosphate-buffered saline solution and the bottle was put on a wrist-action shaker for $45 \mathrm{~min}$. After shaking, the bottle was allowed to settle for 30 seconds and the liquid phase was poured into a sterile $500-\mathrm{mL}$ polypropylene bottle. An average of $30 \mathrm{~mL}$ of the liquid-phase of the sample was filtered as described above and stored at $-70{ }^{\circ} \mathrm{C}$ until further processing.

For fecal source samples, approximately $0.25 \mathrm{~g}$ of wetweight material was added to a $50-\mathrm{mL}$ centrifuge tube with $10 \mathrm{~mL}$ of phosphate-buffered saline. The tube was vortexed until the sample was completely mixed. Either $1 \mathrm{~mL}$ or $0.1 \mathrm{~mL}$ of the sample was filtered as described above and stored at $-70{ }^{\circ} \mathrm{C}$ until further processing.

The proportion dry weight was calculated for all sediment and fecal samples by weighing approximately $25 \mathrm{~g}$ of sample immediately and again after the sample completely dried. The ratio of the two measurements was used to calculate the concentrations of either $E$. coli or MST markers per gram dry weight.

For the extraction of genetic materials, filters were thawed at room temperature and 350 microliter of GeneRite lysis buffer was added to each tube. The tubes were processed in a bead beater (BioSpec Products, Inc., Bartlesville, Oklahoma) at maximum speed for $2 \mathrm{~min}$ and centrifuged for $1 \mathrm{~min}$ to separate the DNA extract from the beads and the filter. The supernatant was collected in a sterile $1.5-\mathrm{mL}$ microcentrifuge tube and processed according to the manufacturer's instructions in the GeneRite DNA-EZ extraction kit (GeneRite, North Brunswick, N.J.), except without the use of a prefilter. The final DNA extracts were stored at $4{ }^{\circ} \mathrm{C}$ until qPCR was run within 1 week.

Water, sediment, and fecal source samples were analyzed using qPCR for four MST markers:

- General fecal contamination, Bacteroides marker (GenBac, Dick and Field, 2004; U.S. Environmental Protection Agency, 2010)

- Human-associated, Bacteroides marker (HF183, Seurinck and others, 2005)

- Ruminant-associated, Bacteroides marker (BoBac, Layton and others, 2006)

- Waterfowl-associated, Helicobacter marker (GFD, Green and others, 2012)

The human-associated marker is intended to only react with the genetic material of Bacteroides from the intestinal tracts of humans; the ruminant-associated marker is designed to react with the genetic material of Bacteroides from animals that fall within the ruminant family (for example, cattle, deer, sheep, goats); and the waterfowl-associated marker is intended to react only with the genetic material of Helicobacter from waterfowl (for example, gulls, Canada Geese, ducks, chickens). It was not known if the waterfowl-associated marker would react to Helicobacter genetic material from vultures; therefore, source samples of vulture scat were collected for that purpose.

Analyses for qPCR were run on an Applied Biosystems StepOne Plus or Model 7500 thermal cycler (Applied Biosystems, Foster City, California). For the quantification of MST markers, standard curves were established for each assay using known quantities of the DNA marker that was inserted into an $E$. coli plasmid. The number of gene copies in the plasmid was calculated using the DNA concentration, as determined by the PicoGreen assay (Invitrogen, Carlsbad, Calif.) and the molecular weight of the plasmid. Quantities of the MST markers in the water, sediment, and fecal samples were determined 
using the standard curve. Sample results were reported as copies/100 mL for water samples and copies/gram dry weight $\left(\mathrm{g}_{\mathrm{DW}}\right)$ for sediment and fecal samples.

For each MST marker assay, a lower detection limit was established and defined as the 95-percent confidence interval around detections in blank samples. If results for environmental samples are lower than the detection limit, they are reported as below detection limit (BDL). Sample results that are greater than the detection limit, but less than the lower limit of quantification in the standard curve, are reported with an "E" to denote that it is an estimated value.

\section{Collection of Ancillary Data}

Ancillary environmental data were collected by USGS and other sources, including lake stage and meteorological data. Hourly lake stage at Bagnell Dam at the Lake of the Ozarks, recorded by Ameren (Ameren Corporation, 2013) and served on the World Wide Web at URL http://apps.ameren. com/HydroElectric/Reports/Osage/, was used in statistical analyses. A meteorological station was constructed at GGB marina that measured wind speed, wind direction, air temperature, and relative humidity, using a MET-SET sensor (Sutron Corporation, Sterling, Virginia); precipitation with a rain gauge tipping bucket (Texas Electronics, Inc., Dallas, Texas); and water temperature and specific conductance with a YSI 600R water-quality sonde, all recorded at 15 -min intervals. Precipitation data from 2009-12 were obtained from the National Oceanic and Atmospheric Administration (NOAA) at Lee C. Fine Memorial Airport in Kaiser, Mo. (National Climatic Data Center, 2013a) and used to supplement data collected from the GGB marina meteorological station.

To estimate flow into GGB cove from the normally dry west tributary during runoff events, a Levelogger Edge ${ }^{\mathrm{TM}}$ pressure transducer (Solinst Canada Ltd., Georgetown, ON, Canada) was installed at site GI-T (fig. 10). Discharge was measured manually during selected runoff events using a YSI FlowTracker, and the measurements were used to develop a rating curve to estimate discharge of the west tributary during runoff events (Rantz and others, 1982). Two YSI 6600 sondes were temporarily deployed at sites GB-R and GI-R during August 31 through September 2, 2012, to record the effects of anticipated runoff from the remnants of Hurricane Isaac. The sondes measured and recorded specific conductance, turbidity, and water temperature at 15 -min intervals.

\section{Quality Assurance}

Quality-assurance and quality-control (QA/QC) practices were followed as described in Myers and others (2007). Daily filter blanks were run during each of the 62 sampling events and consisted of processing $100 \mathrm{~mL}$ of sterile phosphate buffer solution through the filter system. All filter blanks were below the detection level (less than $1 \mathrm{CFU} / 100 \mathrm{~mL}$ ), verifying the sterility of all membrane-filtration equipment and materials. To capture sample and analytical variability of $E$. coli concentrations and turbidity, concurrent replicates were collected and analyzed. Because of the frequency and density of sampling and limited personnel, the goal of collecting 1 sample replicate per visit was not met, and replicates were collected and processed on 29 of the 62 sampling trips (47 percent of trips) made to Lake of the Ozarks State Park. On an individual sample basis, 2.5 percent of the 1,169 routine surface-water samples were duplicate samples with an average relative percent difference (RPD) of 42 percent with a range of 0 to 143 percent in nontransformed $E$. coli concentration and an average RPD of 27 percent with a range of 2 to 69 percent in turbidity values. The RPD is calculated as the absolute difference between values of each replicate pair divided by their average value and multiplied by 100 .

For MST analyses, all samples were analyzed by qPCR in duplicate, and each analytical run included a 6-point standard curve and a no-template qPCR blank. In addition to the qPCR blanks, eight filtration blanks from the USGS MWSC and OWML were analyzed, and each batch of sample extractions included an extraction blank (four in total) to test for crosscontamination in the extraction and qPCR processes. Qualitycontrol samples indicated four low-level detections in blanks that were incorporated into the lower detection limit calculated by the OWML for each assay. Inhibition of the qPCR by the sample matrix was measured for each sample by seeding part of the sample extract with the plasmid-based standard and comparing the value to the same quantity of standard seeded into molecular-grade water. Multiple dilutions were run for those samples that exhibited inhibition.

\section{Statistical Methods}

All E. coli concentration data were $\log _{10}$-transformed, and the Shapiro-Wilk test (Shapiro and Wilk, 1965) was used to test normality. Escherichia coli data from 2011 were normally distributed; therefore qualifiers were removed and linear regression analysis was done using SYSTAT 13 (SPSS, Inc., Chicago, Illinois) to identify significant (p-value less than 0.05 ) explanatory variables. In contrast, E. coli data from 2012 were non-normally distributed and left-censored due to lower detection limits; therefore, qualifiers were removed from the left-censored data and nonparametric tests were conducted.

Boxplots were constructed to display the distribution of data at multiple sites (Helsel and Hirsch, 1992). Boxplots indicate the 25th, 50th, and 75th percentiles of the data as well as extreme values. The median, which is plotted as a horizontal line between the 25th and 75th percentile, provides a description of data symmetry as a symmetric dataset would have a median exactly half-way between the 25th and 75th percentiles. Averages, although skewed by small or large numbers in the dataset, were used to preserve the effect of extreme values and have been used frequently by USGS Ohio WSC (Francy and others, 2006). 
Kruskal-Wallis tests (Kruskal and Wallis, 1952) were used to investigate differences between two or more groups of data at a significance level of alpha $(\alpha)=0.05$. When two or more groups were reported to be significantly different (p-value less than 0.05), the Dwass-Steel-Critchlow-Fligner's pairwise comparison test (Dwass, 1960; Steel, 1960; Critchlow and Fligner, 1991) was used to establish significance between groups. Pairwise correlations between E. coli and environmental variables were examined using Spearman's rank correlation coefficient rho ( $\rho$; Spearman, 1904). The Wilcoxon signedrank test (Wilcoxon, 1945), a nonparametric paired t-test, was used to determine statistical difference between paired data. Trends were analyzed using the Mann-Kendall test (Mann, 1945), which when significant (p-value less than 0.05), tests whether a downward or upward trend is present. Logistic regression was used to investigate the likelihood of variables to cause exceedances of the E. coli standard.

\section{Occurrence and Origin of Escherichia coli in Water and Sediments}

The following discussion presents a review of historical MDNR beach monitoring data from LOSP and possible relations with general hydrologic conditions in the region, as well as results of water tracing done by the MDNR as part of this combined cooperative investigation of bacterial contamination at LOSP swimming beaches. This is followed by a presentation of the fall 2011 spatial reconnaissance of $E$. coli at GGB, GGB cove, and vicinity. The final discussion in this section presents results of the 2012 intensive study done at GGB and PB1, which was designed based on results from the 2011 spatial reconnaissance and a MDNR dye trace.

\section{Summary of Missouri Department of Natural Resources Investigations at Lake of the Ozarks State Park}

Correlation between historical E. coli concentrations at GGB and PB1 collected by the MDNR and precipitation or streamflow in the region was determined to provide insight into the temporal variation of $E$. coli at each beach and possible causes of contamination. In addition, water tracing of wastewater systems at GGB and PB1 were conducted to assess any potential hydrologic connection between human-associated E. coli sources and bathing areas at each beach.

\section{Examination of Historical Beach Monitoring Data}

During 2009, GGB was closed 18 percent of the recreational season (three closures in 17 weeks), and E. coli concentrations were negatively correlated with date (Julian date)
(Spearman's $\rho=-0.627$; $p$-value $=0.007$ ) and positively correlated with 24-hour precipitation $(\rho=0.481$; $p$-value $=0.051)$ measured at the NOAA weather station at Lee C. Fine Memorial Airport in Kaiser, Mo. about 6 mi southeast of GGB (fig. 1). During 2010, GGB was closed 13 percent of the recreational season (two closures in 16 weeks) with the largest single sample concentration occurring on the Monday following the July 4th weekend, one of the highest beach use days of the recreational season. Escherichia coli concentrations were positively correlated with 48 -hour precipitation at the NOAA weather station $(\rho=0.450 ; p$-value $=0.010)$ and negatively correlated with date $(\rho=-0.435$; $p$-value $=0.013)$. Closures in the 2011 recreational season (fig. 13) were widely publicized because GGB was closed for 39 percent of the recreational season (seven closures in 18 weeks) with five of the closures occurring in consecutive weeks. During 2011, E. coli concentrations were positively correlated with the average previous 7 -day discharge $(\rho=0.501 ; p$-value $=0.002)$ of the Niangua River at Tunnel Hollow Dam near Macks Creek (USGS streamgage number 06923950 , fig. 1), a major tributary to the Lake of the Ozarks and a surrogate for hydrologic conditions in the study area. During the recreational seasons, E. coli concentrations were significantly larger $(p$-value $=0.002)$ on the right side of the beach compared to the left during 2010 and 2011 and significantly trended downward during the 2009 and 2010 recreation seasons at GGB $(p$-value $=0.031)$; however, no trend was observed in 2011.

In contrast to GGB, historical MDNR monitoring data indicate a downward trend in beach closures at PB1. During 2009, PB1 was closed 29 percent of the recreational season (five closures in 17 weeks) with all five closures occurring in consecutive weeks at the beginning of the recreational season. During 2009, E. coli concentrations were positively correlated with 24-hour precipitation at the NOAA weather station $(\rho=0.411 ; p$-value $=0.101)$ and negatively correlated with date $(\rho=-0.760 ; p$-value $=0.000)$. In 2010 (fig. 14), PB1 was closed 19 percent of the recreational season (three closures in 16 weeks), and E. coli concentrations were positively correlated with the average Niangua River discharge 1 day before sampling $(\rho=0.506$; $p$-value $=0.006)$ and negatively correlated with date $(\rho=-0.402 ; p$-value $=0.023)$. During 2011, PB1 was closed only 6 percent of the recreational season (one closure in 18 weeks), and $E$. coli concentrations were positively correlated with the average Niangua River discharge one day before sampling $(\rho=0.789 ; p$-value $=0.000)$ and negatively correlated with date $(\rho=-0.793 ; p$-value $=0.000)$ and lake elevation $(\rho=-0.598$; $p$-value $=0.000)$. Similar to GGB, E. coli concentrations significantly trended downward during the 2009 (p-value $=0.001)$ and 2011 ( $p$-value $=0.0003$ ) recreational seasons; however, no significant trend was determined in 2010. In addition, there was no significant difference between $E$. coli concentrations at the left side and the right side of PB1 for any year or combination of years. 
Results of 2011 MDNR Water Tracing of Wastewater Systems at Grand Glaize Beach and Public Beach 1

As part of an effort to determine the origin of bacterial contamination at LOSP swimming beaches and supplement the 2011 spatial reconnaissance, the MDNR Geological Survey Program injected fluorescent dye at various locations in wastewater systems near GGB and PB1 during December 2011 to determine if there were hydrologic connections between these systems and the beaches or the lakeshore near the beaches (Pierce 2012a, 2012b). Particular attention was given to the wastewater systems in the west tributary at GGB in light of the large $E$. coli concentrations and low temperatures in water samples collected by USGS from pools in the lower end of the tributary the previous month.

At GGB fluorescent dye was injected into the centralized sewer pump station at the marina, the septic system at the maintenance workshop, and the vault toilet at the picnic area (fig. 4). No hydrologic connection with GGB was determined between the centralized collection system or the vault toilet (Pierce, 2012a). However, dye injected into the maintenance workshop septic system on December 1, 2011, was visually detected along a tributary immediately downstream from the workshop approximately 24 hours after several inches of rainfall fell on December 21, 2011. For the next several weeks, dye was detected in the west tributary and at several locations within GGB cove, including the beach itself (Pierce, 2012a).

At PB1, the beach bathhouse, marina, campground, and nearby residence at the stable are connected to a gravity sewer system that leads to a wastewater treatment plant located about 1,300 ft northeast of PB1, and there are also several vault toilets located in the campgrounds (fig. 8). Dye tracing of the wastewater systems at PB1 indicated a hydrologic connection between the permitted discharge from the wastewater treatment system and PB1, most likely caused by natural circulation of lake waters; however, there also was evidence of leakage in the gravity system, manholes, and vault toilets that could be hydrologically connected to PB1 (Pierce, 2012b).

\section{Results of 2011 USGS Spatial Reconnaissance of Escherichia coli at Grand Glaize Beach and Vicinity}

The 2011 spatial reconnaissance was designed to determine if GGB cove had significantly larger $E$. coli concentrations compared to other nearby coves in LOSP and the rest of the Lake of the Ozarks, as results from the 5-year LOWA lake-wide study had indicated (Missouri Department of Natural Resources, 2012b). In addition, information collected during the 2011 spatial reconnaissance was used to design an intensive sampling program during the 2012 recreational season. The 2011 sampling involved the collection of 207 water samples from 14 sites in GGB cove and 2 adjacent coves, cove A and cove B, north of GGB (fig. 9; table 1). Cove A is similar in size and shape to GGB cove and has a 110-acre watershed that drains a mostly wooded area with some developed areas in the upper watershed along State Highway 54. Cove B is smaller in size than GGB cove and cove A. Cove A and cove B are mostly undeveloped and have no swimming beaches, septic tanks, marinas, or picnic areas, making them reasonable background locations for comparison to GGB cove.

A comparison of all 2011 beach and lake samples from the three coves indicates that water samples from GGB cove contained significantly larger $E$. coli concentrations than the mostly undeveloped cove A $(\mathrm{p}$-value $=0.000)$ and cove $\mathrm{B}$ (p-value $=0.000$; fig. 15). The average $E$. coli concentration of the 125 samples from GGB cove (excluding 7 samples from pools in the west tributary) was $100 \mathrm{CFU} / 100 \mathrm{~mL}$ compared to an average of 6 (sample size $[n]=45)$ and $24 \mathrm{CFU} / 100 \mathrm{~mL}$ $(n=30)$ from cove A and cove B, respectively. In all three coves, the average $E$. coli concentrations were largest at shallow water sites at the upper ends of the coves near the inflows (sites CA-01, CB-01, GI-L, and GI-R) and were smallest at deeper water locations (sites CA-03, CB-02, and GM-02 ) furthest from the cove inflows. A comparison of the inflow sites at the upper end of each cove also indicated $E$. coli concentrations at the inflow site GI-R in GGB cove were significantly larger than the inflow sites in cove A (site CA-01; $\mathrm{p}$-value $=0.000)$, cove B (site CB-01; p-value $=0.000)$ and site GI-L (p-value $=0.008)$ in GGB cove. The average $E$. coli concentration at site GI-R (530 CFU/100 mL) was more than an order of magnitude larger than the average $E$. coli concentration at site CA-01 (11 CFU/100 mL) or site CB-01 (37 CFU/100 mL). Of the 13 samples from the 2011 reconnaissance that exceeded the SSV of $235 \mathrm{CFU} / 100 \mathrm{~mL}, 12$ were from site GI-R or pools in the lower reach of the west tributary (sites GI-R8 and GI-R9), and 1 sample was from site CB-01 (400 CFU/100 mL).

Significantly larger $E$. coli concentrations at the inflow sites in GGB cove compared to cove A and cove B indicate a probable local source of $E$. coli contamination within the upper part of GGB cove near or upstream from site GI-R that is not present in cove A or cove B. In addition, E. coli concentrations at sites near the marina (sites GM-01 and GM-02) were significantly smaller than sites near GGB $(\mathrm{p}$-value $=0.000)$. As the lake level declined during early-tomid-September 2011 (fig. 7), the lake shoreline receded past site GI-R, which became a gravel bar, and samples from the pool sites (sites GI-R7, GI-R8, and GI-R9) in the lower reach of the west tributary that enters GGB cove adjacent to GGB were substituted until they became dry by early October. Water samples collected from the pool sites contained large $E$. coli concentrations (20 to 4,800 CFU/100 mL), and free chlorine, measured using a Hach DR/2010 spectrophotometer (Hach Company, Loveland, Colo.) as part of a synoptic study, was detected in some samples, suggesting leakage from a water main, wastewater system, or both. 


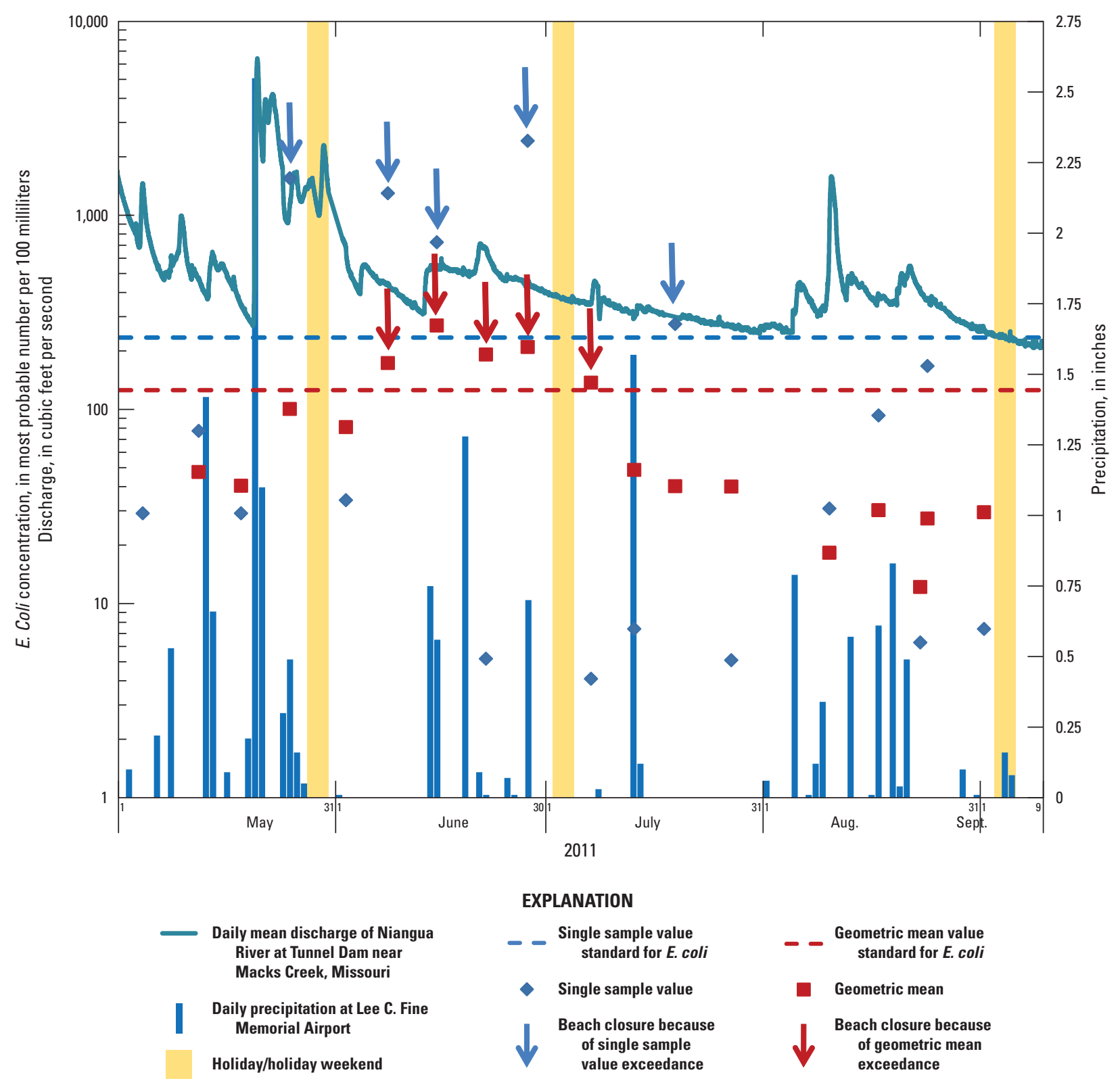

Figure 13. Weekly maximum Escherichia coli (E. coli) concentrations at Grand Glaize Beach (GGB) during the 2011 recreational season reported by the Missouri Department of Natural Resources (MDNR), daily mean discharge of the Niangua River at Tunnel Dam near Macks Creek, Missouri (USGS streamgage number 06923950), and daily precipitation recorded at a National Oceanic and Atmospheric Association station at Lee C. Fine Memorial Airport in Kaiser, Mo., 2011. 


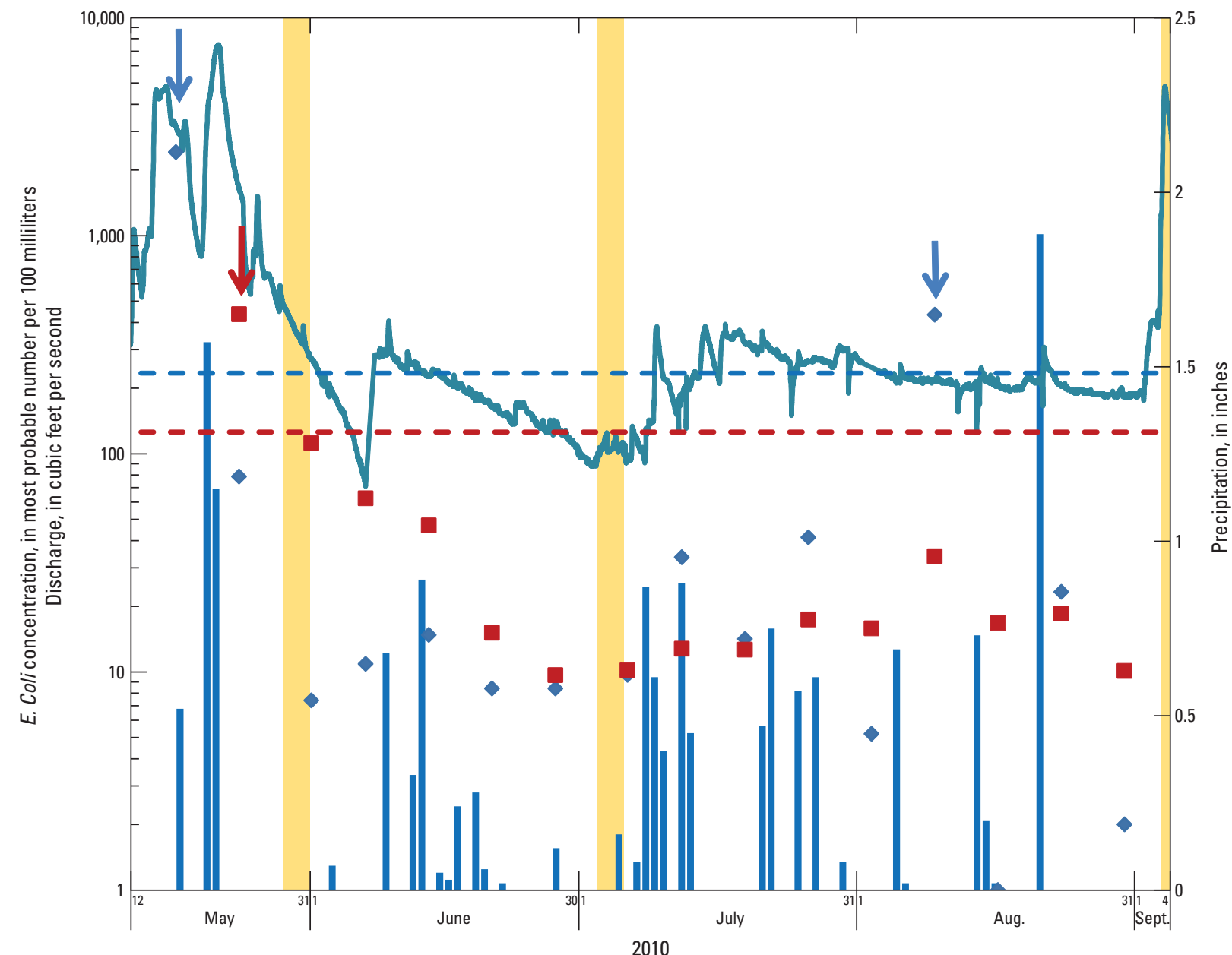

EXPLANATION
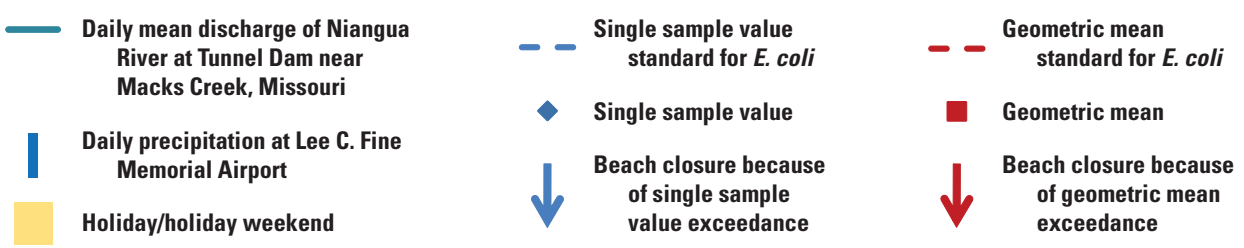

Figure 14. Weekly maximum Escherichia coli (E. coli) concentrations at Public Beach 1 (PB1) during the 2010 recreational season reported by the Missouri Department of Natural Resources (MDNR), daily mean discharge of the Niangua River at Tunnel Dam near Macks Creek, Missouri (USGS streamgage number 06923950), and daily precipitation recorded at a National Oceanic and Atmospheric Association station at Lee C. Fine Memorial Airport in Kaiser, Mo., 2010. 


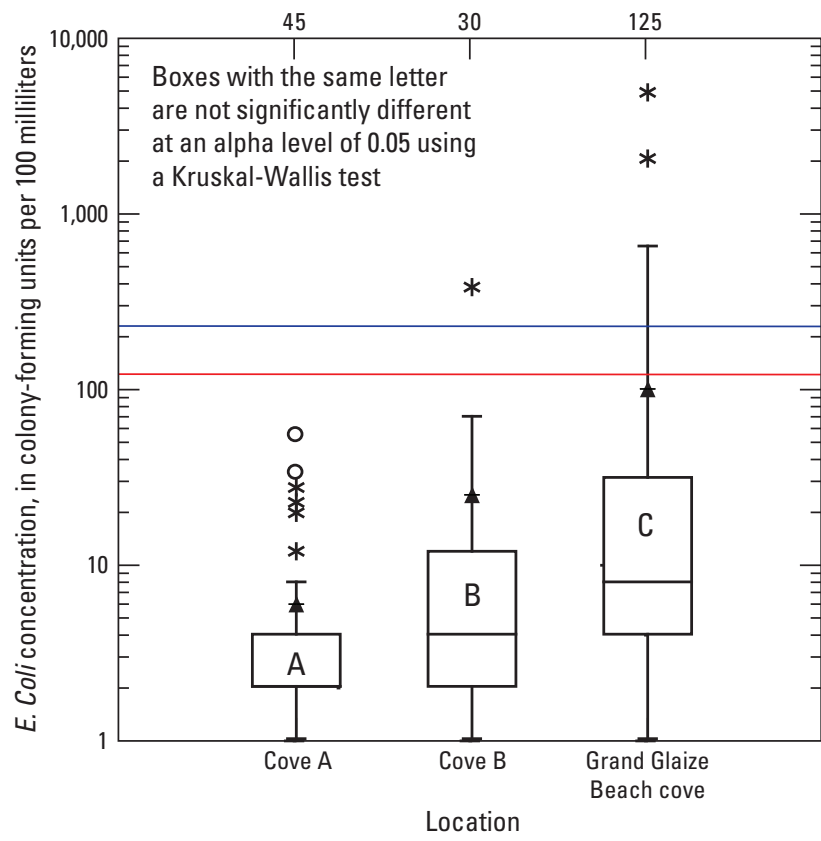

EXPLANATION

15 Sample size

Upper detached (greater than 3.0 times IQR)

* Upper outside (1.5 to 3 times IQR)

Upper adjacent (within 1.5 times IQR)

75th percentile Median Interquartile

25th percentile $\}$ range (IOR)

1 Lower detached (greater than 3.0 times IQR)

A Arithmetic average

- Geometric mean standard

_ Single sample value standard

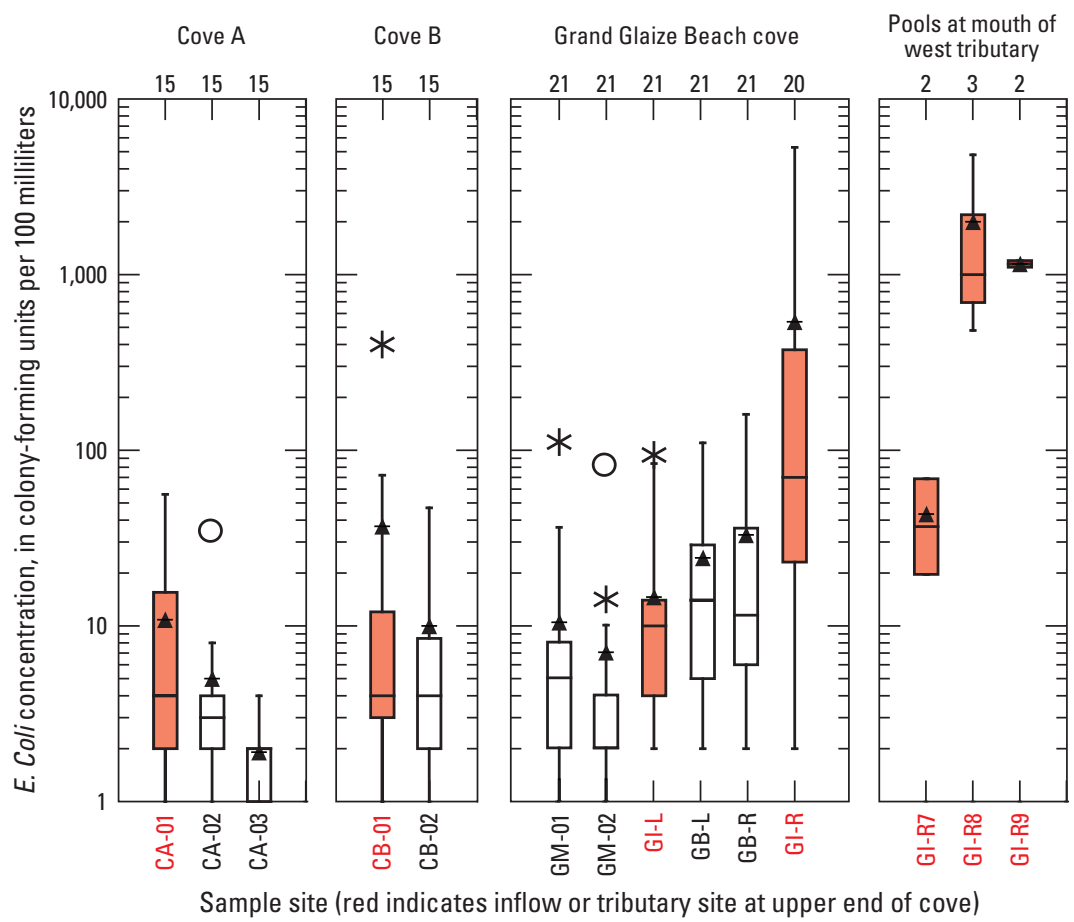

Figure 15. Concentrations of Escherichia coli (E. coli) in water samples collected during the 2011 reconnaissance from Grand Glaize Beach (GGB) cove, cove A, and cove B, Lake of the Ozarks State Park, Missouri. 
In addition to the largest average $E$. coli concentrations (45 to 2,100 CFU/100 mL), specific conductance values tended to be larger at site GI-R and pool sites (GI-R7, GI-R8, and GI-R9) and water temperatures tended to be lower at pool sites compared to other sites in GGB cove (fig. 16). The average temperature of $16.3{ }^{\circ} \mathrm{C}$ and specific conductance of 484 microsiemens per centimeter at 25 degrees Celsius $[\mu \mathrm{S} / \mathrm{cm}$ at $25^{\circ} \mathrm{C}$ ]) measured in the pool sites is similar to the average temperature $\left(14.1^{\circ} \mathrm{C}\right)$ and specific conductance $(444 \mu \mathrm{S} / \mathrm{cm}$ at $25^{\circ} \mathrm{C}$ ) of groundwater in the area based on 54 well and spring samples from Camden and Miller Counties contained in the USGS NWIS database, indicating shallow groundwater may be a source of the large $E$. coli concentrations at these sites. This area was a focus for follow-up dye traces of wastewater systems done by the MDNR in December 2011.

Using a stem-and-leaf plot to identify clusters of data (Helsel and Hirsh, 1992), lake elevation was categorized into less than and equal to $658.01 \mathrm{ft}$ and greater than $658.01 \mathrm{ft}$, and statistical tests indicated that $E$. coli concentrations at site GI-R were significantly larger at lower lake elevations $(\mathrm{p}$-value $=0.003)$. However, the large E. coli concentrations in the west tributary did not have a measurable effect on GGB during the period of sampling as no significant difference in E. coli concentrations were detected between beach sites GB-L and GB-R, most likely due to volumetric dilution by mixing with lake water between sites GB-R and GI-R and absence of runoff in the tributary during the sampling period. None of the samples collected during 2011 from the beach (sites GB-L or GB-R) exceeded the SSV limit of $235 \mathrm{CFU} / 100 \mathrm{~mL}$. A summary of $E$. coli concentrations at all sites during 2011 and 2012 is listed in table 2.

Because the 2011 reconnaissance sampling did not begin until late in the recreational season, the number of beach visitors was small except for the Saturday of Labor Day weekend (September 3, 2011) when 49 bathers visited the beach, and E. coli concentrations at GGB were the largest measured (100 CFU/100 mL at GB-L and $160 \mathrm{CFU} / 100 \mathrm{~mL}$ at GB-R) during the 2011 reconnaissance. Overall, E. coli concentrations during the 2011 reconnaissance at GGB were positively correlated with turbidity $(\rho=0.567 ; p$-value $=0.000)$ and the number of bathers in the water $(\rho=0.374$; $p$-value $=0.024)$. Because $E$. coli concentrations were normally distributed for 2011 beach samples, simple linear regression was used to indicate the total number of bathers was a significant explanatory variable for $E$. coli concentrations measured at GGB (p-value $=0.001$; adjusted $r^{2}=0.22$ ). No substantial precipitation (all precipitation events were less than 0.2 in.) was recorded at the NOAA station at Lee C. Fine airport during the 13-day period preceding Labor Day weekend, and E. coli concentrations in water samples collected two days prior were less than $30 \mathrm{CFU} / 100 \mathrm{~mL}$. The spike in E. coli concentration on September 3, 2011, is unrelated to runoff and appears to be related to beach use, indicating that the bathers themselves or their activity (such as bathers resuspending sediment) was the source of the observed spike in $E$. coli concentration.

\section{Occurrence of Escherichia coli at Grand Glaize Beach and Vicinity during 2012}

Based on the results from the 2011 reconnaissance that E. coli concentrations were significantly larger in GGB cove than adjacent coves and a hydrologic connection was established between a septic tank, the west tributary, and GGB through dye tracing, sampling sites in cove A and cove B were reduced and sampling locations and frequency at GGB and GGB cove were increased for the 2012 intensive study. In addition to routine surface-water-quality sampling, sediments in the swimming area were sampled throughout the recreational season. In an attempt to isolate runoff from other potential sources of $E$. coli at GGB, sampling was conducted during rainfall events. The trend of larger E. coli concentrations on high beach-use weekends observed in 2011 was further investigated by increasing sampling frequency during weekends, especially holiday weekends, and predicted high-traffic weekdays such as the week surrounding the July 4 holiday.

The average number of total bathers at GGB during 2012 sampling events was $21(n=71)$ and ranged between 0 and 125 with the maximum occurring on the Saturday of Memorial Day weekend (May 26, 2012). Bather counts followed a normal distribution peaking between 1200 and 1800 hours each day and typically were largest on Saturdays with the exception of July 4, 2012, which fell on a Wednesday. Goose and vulture feces were observed on and in the vicinity of GGB on many occasions throughout the recreational season with goose fecal matter observed mostly during the months of May and June, and vulture fecal matter primarily observed later in the summer. During the pre-dawn hours on June 25, 2012 , in response to nuisance complaints from the public and the perceived contribution of geese feces to increased $E$. coli concentrations at GGB, the MDNR caught and removed 30 of the estimated 40 geese that frequented GGB and released them in another region of the State. The MDNR also constructed a low fence along the shoreline and grassy areas near the beach to discourage geese from grazing. Although discouraging any remaining geese (none were observed at GGB after the relocation effort), vultures frequently were observed roosting on the posts supporting the fence later in the season. Deer fecal matter was observed along the shore near site GI-L on one occasion in August 2012 and raccoon prints were common along the shoreline near sites GI-R and GI-R7, especially later in the season as the lake level dropped.

\section{Routine and Intensive Surface-Water Sampling}

As in 2011, E. coli concentrations at sites in GGB cove (GM-01, GM-02, GI-L, GB-L, GB-M, GB-R, GI-R, and GI-R3; $n=501$; average $=380 \mathrm{CFU} / 100 \mathrm{~mL}$ ) were significantly larger than concentrations at sites in the cove A (CA-01 and CA-03; $n=69$; average $=89 \mathrm{CFU} / 100 \mathrm{~mL}$; 

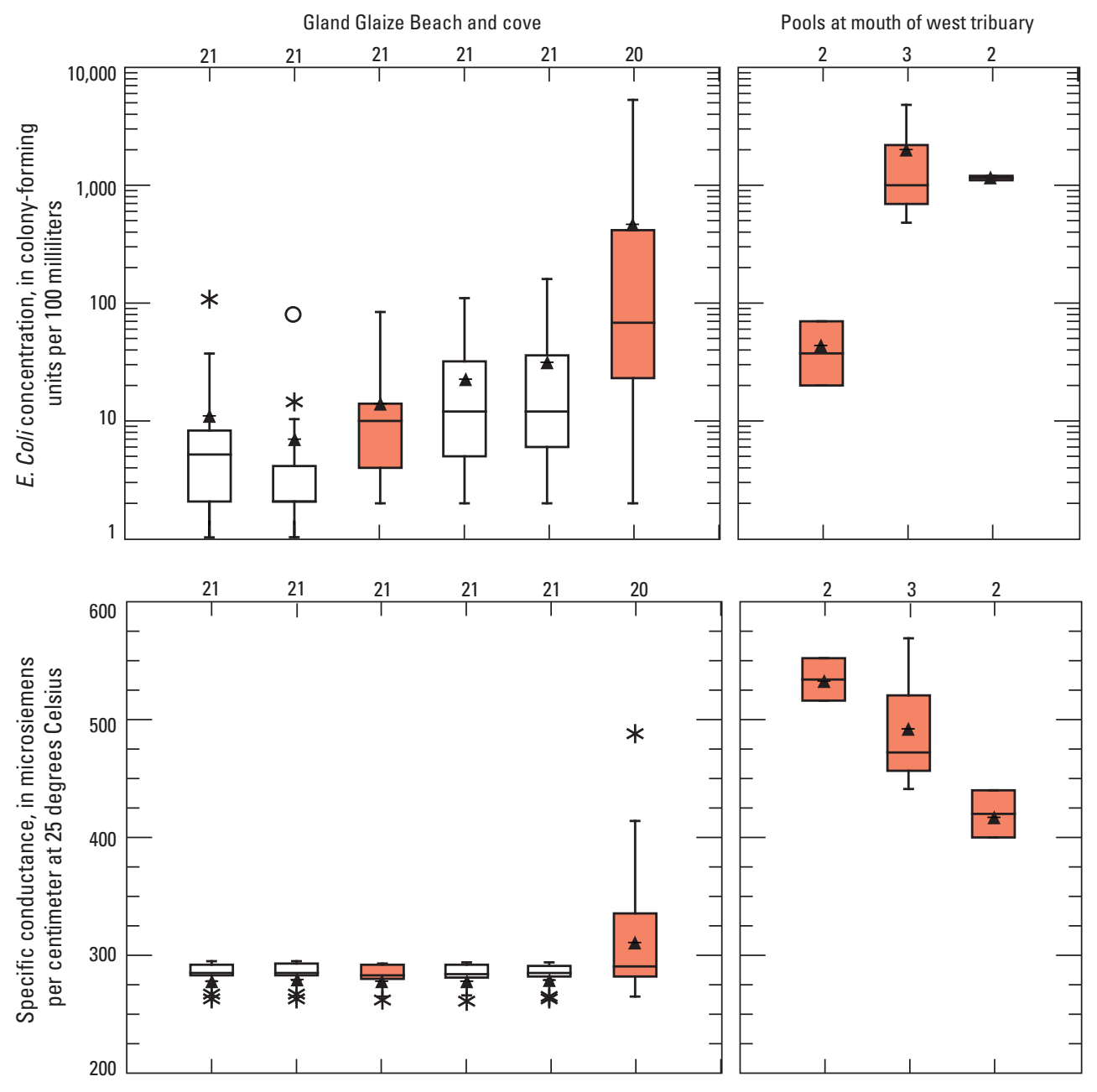

11 Sample size

Upper detached (greater than 3.0 times IQR)

* Upper outside (1.5 to 3 times IOR)

Upper adjacent (within 1.5 times IOR)

75th percentile

Median $\}$ Interquartile
25th percentile $\}$ range (IOR)

Lower detached (greater than 3.0 times IQR) $*$ Lower outside (1.5 to 3 times IOR)

$\star$ Arithmetic average

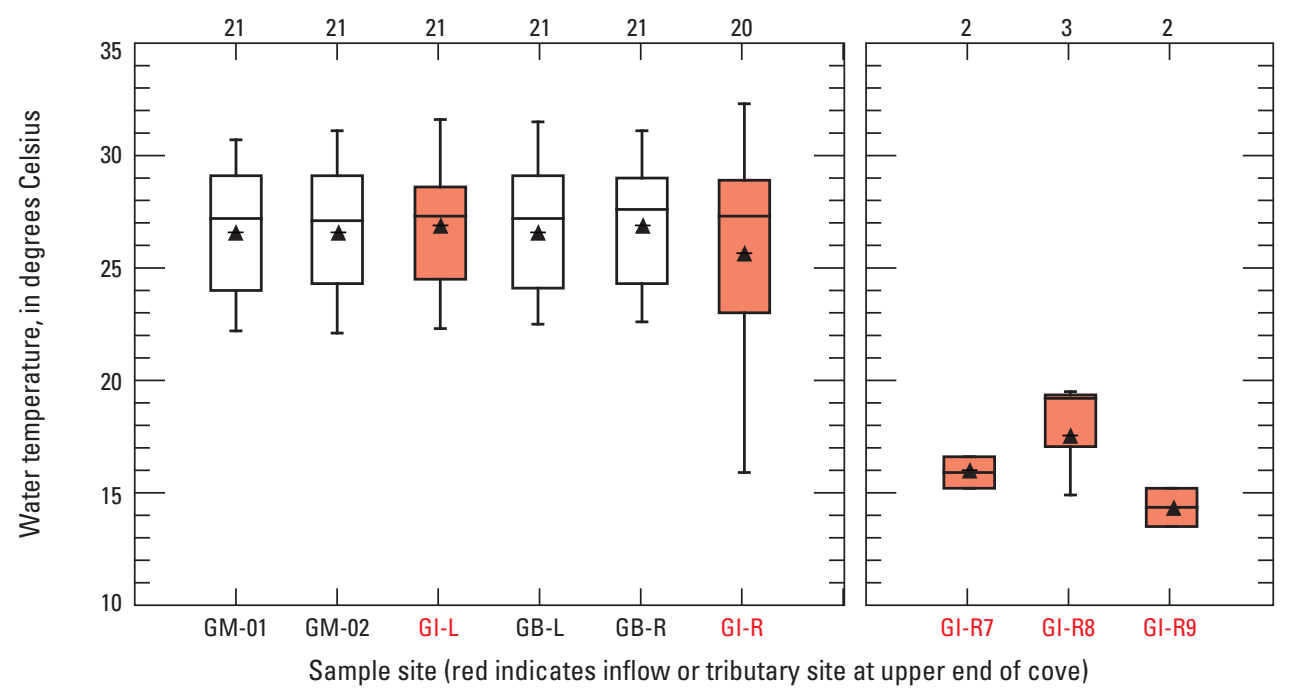

Figure 16. Concentrations of Escherichia coli (E. coli) and values of specific conductance and water temperature in water samples collected from Grand Glaize Beach (GGB) cove, 2011. 


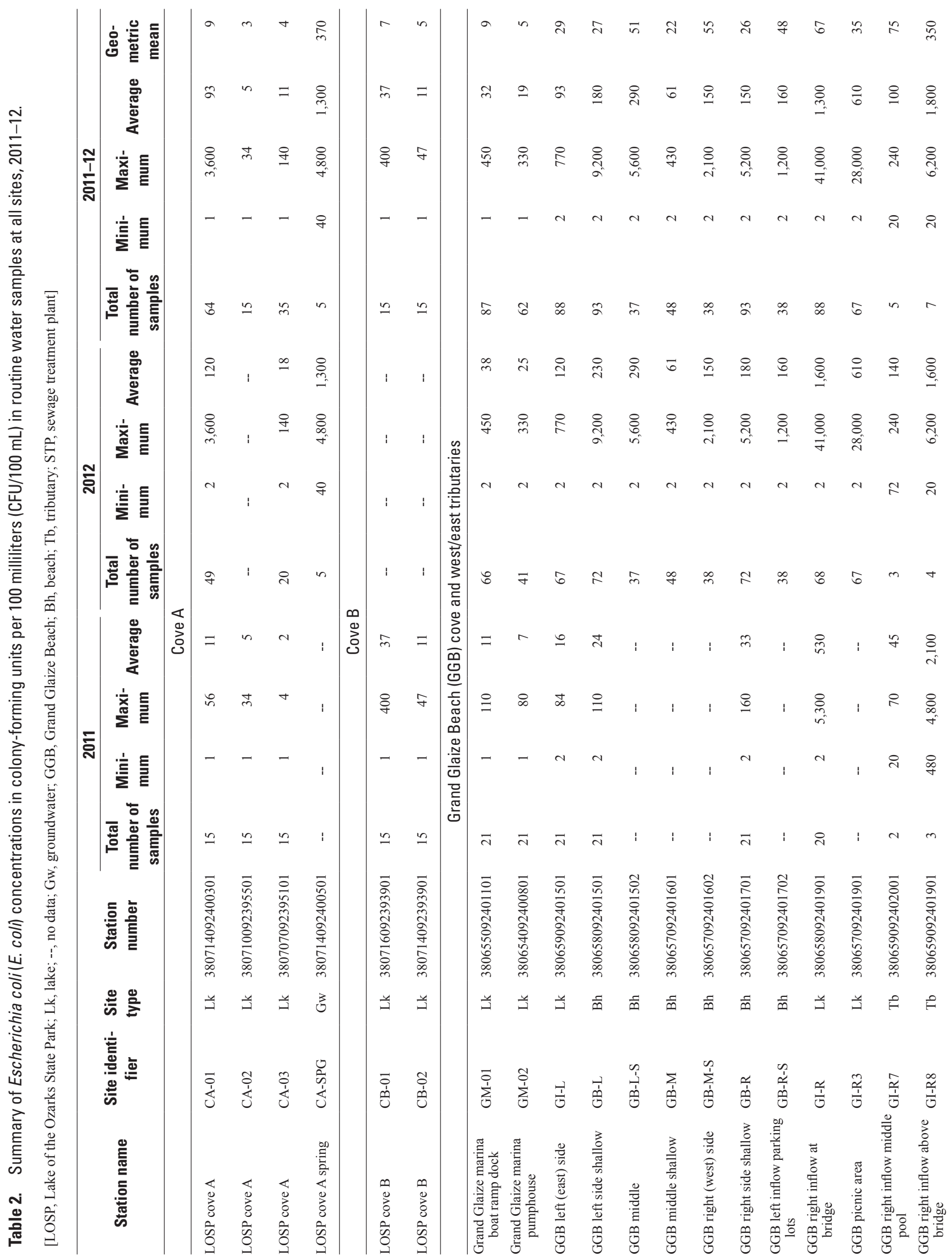




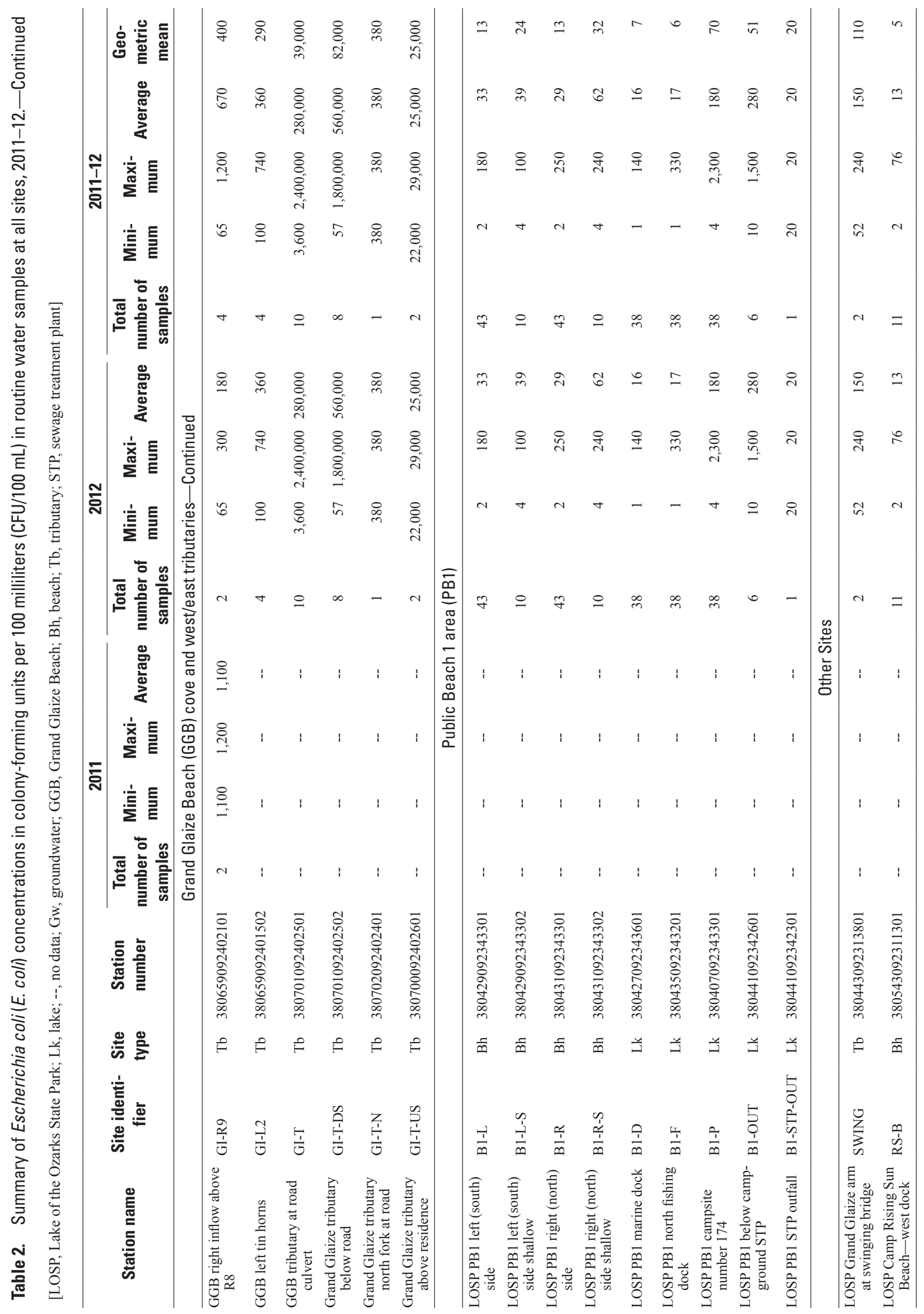


p-value $=0.000)$, and the sites with the largest concentrations were clustered at the upper end of GGB cove at site GI-R and sites along the west tributary upstream from the beach (fig. 10). Escherichia coli concentrations at sites closest to the beach (sites GI-L, GB-L, GB-M, GB-R, GI-R, and GI-R3) also were significantly larger than locations farthest from the beach (sites GM-01 and GM-02; p-value $=0.000$ ) in deeper water, indicating that the source of $E$. coli contamination during nonrunoff conditions may be localized in the upper end of GGB cove (fig. 17). Escherichia coli concentrations in ankle-deep water at GGB (sites GB-L-S, GB-R-S, and GB-M-S) were significantly larger than waist-deep water (sites GB-L, GB-M, and GB-R; p-value $=0.002$ ), likely due to wave transport and accumulation of $E$. coli onto nearshore sediment, which are easily resuspended. A similar distribution of E. coli concentrations in nearshore samples was observed at Lake Erie beaches (Francy and others, 2006).

Overall, concentrations of $E$. coli in water samples from GGB (sites GB-L, GB-M, and GB-R) trended downward $(p$-value $=0.008)$ and occasionally spiked starting from the beginning of the season until Hurricane Isaac arrived at the end of the recreational season (fig. 18). The spikes generally were associated with high-use days best illustrated by the first and largest spike of the season that occurred on May 26, 2012 (Saturday of Memorial Day weekend). Beginning at 0930 hours with only 4 bathers at the beach, the average $E$. coli concentration at sites GB-L and GB-R was $50 \mathrm{CFU} / 100 \mathrm{~mL}$ and turbidity was 3.4 Nephelometric Turbidity Units (NTU); whereas during the afternoon with 125 bathers, the largest number observed during 2012, E. coli concentrations reached $9,200 \mathrm{CFU} / 100 \mathrm{~mL}$ at site GB-L and $5,200 \mathrm{CFU} / 100 \mathrm{~mL}$ at site GB-R and turbidity increased to 15 NTU at site GB-L and 16 NTU at site GB-R. Based on the increase in $E$. coli concentration with an increase in the total number of bathers on May 26, sampling at GGB was intensified after Memorial Day from three to as many as five sampling events per day on high-use weekends and holidays to capture daily variation at a finer scale.

Looking at all days sampled during 2012, E. coli concentrations in water samples from sites GB-L and GB-R significantly increased with an increase in the total number of bathers at the beach ( $p$-value $=0.000, n=188$ ). For this test, the total numbers of bathers at the beach were placed into three groupings of $0-5,6-50$, and greater than 50 bathers. Multiple comparison tests indicated significant differences in E. coli concentrations between all three total bather groupings ( $\mathrm{p}$-value $=0.000$ ). Similar testing on the significance of turbidity on E. coli concentrations did not indicate a significant difference in $E$. coli at larger values of turbidity when grouping turbidity into less than 7, 7-10, and greater than 10 NTU. Although the significant positive relation between bather count and E. coli concentration at GGB indicates a human-associated source of $E$. coli contamination is likely, this relation alone does not indicate the mechanism and specific origin of the contamination. With the strong association between $E$. coli concentrations and bathers at the beach, it is expected that $E$. coli concentrations at GGB would vary with time of day as did bather counts. As expected, E. coli concentrations at GGB were correlated with time of day $(\rho=0.504$; $\mathrm{p}$-value $=0.000)$ and were largest in the middle of the day (p-value $=0.000 ; n=192)$ when sample time was placed into three groups representing morning (0000-1259 hours; average bather count $=6)$, mid-day (1300-1759 hours; average bather count $=46)$ and evening $(1800-2359$ hours; average bather count $=16$ ). Concentrations of $E$. coli at GGB also were correlated to wave height $(\rho=0.411 ; p$-value $=0.000)$, previous 48-hour precipitation measured at GGB $(\rho=0.318$; $\mathrm{p}$-value $=0.000)$, and turbidity $(\rho=0.296$; $p$-value $=0.000)$. The correlation between $E$. coli concentration and wave height is probably related more to time of day because boat traffic and the number of bathers at the beach (the origin of most larger waves at GGB) peaked during the afternoon hours.

After Memorial Day, the first high-use day of the season, subsequent spikes in the daily average of the maximum E. coli concentrations at sites GB-L and GB-R decreased in amplitude with time during the 2012 recreational season when comparing high-use days defined as more than 50 bathers such as May 26, June 9 , and July 4 . On these days maximum turbidity values and the maximum total numbers of bathers were similar or larger than May 26, yet the averages of the maximum E. coli concentrations were nearly an order of magnitude smaller (fig. 18). For example, on May 26 the maximum turbidity was $16 \mathrm{NTU}$, and there were 125 bathers, and on July 4 the maximum turbidity was 23 NTU with 117 bathers yet the average of the maximum E. coli concentrations on July 4 $(620 \mathrm{CFU} / 100 \mathrm{~mL})$ was more than an order of magnitude smaller than on May 26 (7,200 CFU/100 mL). Furthermore, more than 60 bathers were at the beach on the afternoons of the nonholiday weekends of June 9, June 16, June 23, and June 30, yet averages of the maximum E. coli concentrations were less than 1,000 CFU/100 mL (fig. 18). Based on this observed decline despite steady bather activity and turbidity on high use days during the recreational season and the strong correlation between turbidity and total number of bathers ( $\rho=0.637)$, bather activity, rather than the bathers themselves, may be an important component of the observed spikes in $E$. coli concentrations through resuspension and mobilization of E. coli-contaminated sediment.

During the 2012 study, one or more sets of samples were collected from GGB on 45 days between May 17 and October 3, 2012. Fifteen of these 45 days were on a weekend (Friday and Saturday) or holiday (Memorial Day and the Tuesday, Wednesday, and Thursday surrounding July 4) and the remaining 30 days were on weekdays (Sunday through Thursday). Sunday was treated as a weekday because the average Sunday bather counts of 12 was more comparable to Monday-Thursday (average of 7 total bathers) than to weekends and holidays (average of 50 total bathers). Using the daily maximum E. coli values from the two MDNR sites at GGB (sites GB-L and GB-R) to compare against the SSV of $235 \mathrm{CFU} / 100 \mathrm{~mL}$, 9 of the 45 days sampled by the USGS exceeded the SSV, and there were significantly more exceedances $(p$-value $=0.018)$ 


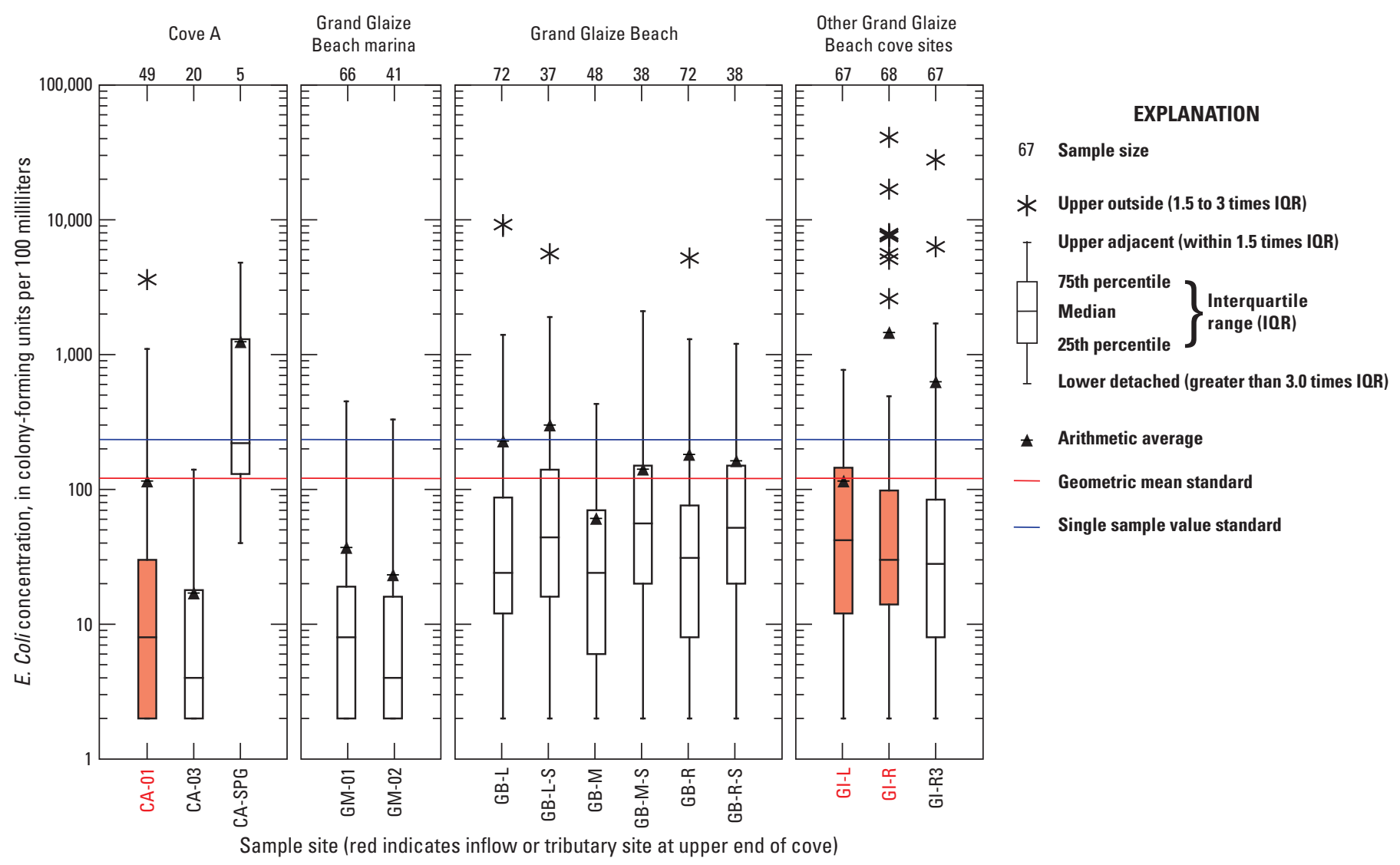

Figure 17. Concentrations of Escherichia coli (E. coli) in water samples collected during 2012 from Grand Glaize Beach (GGB) cove and cove A, Lake of the Ozarks State Park, Missouri. 


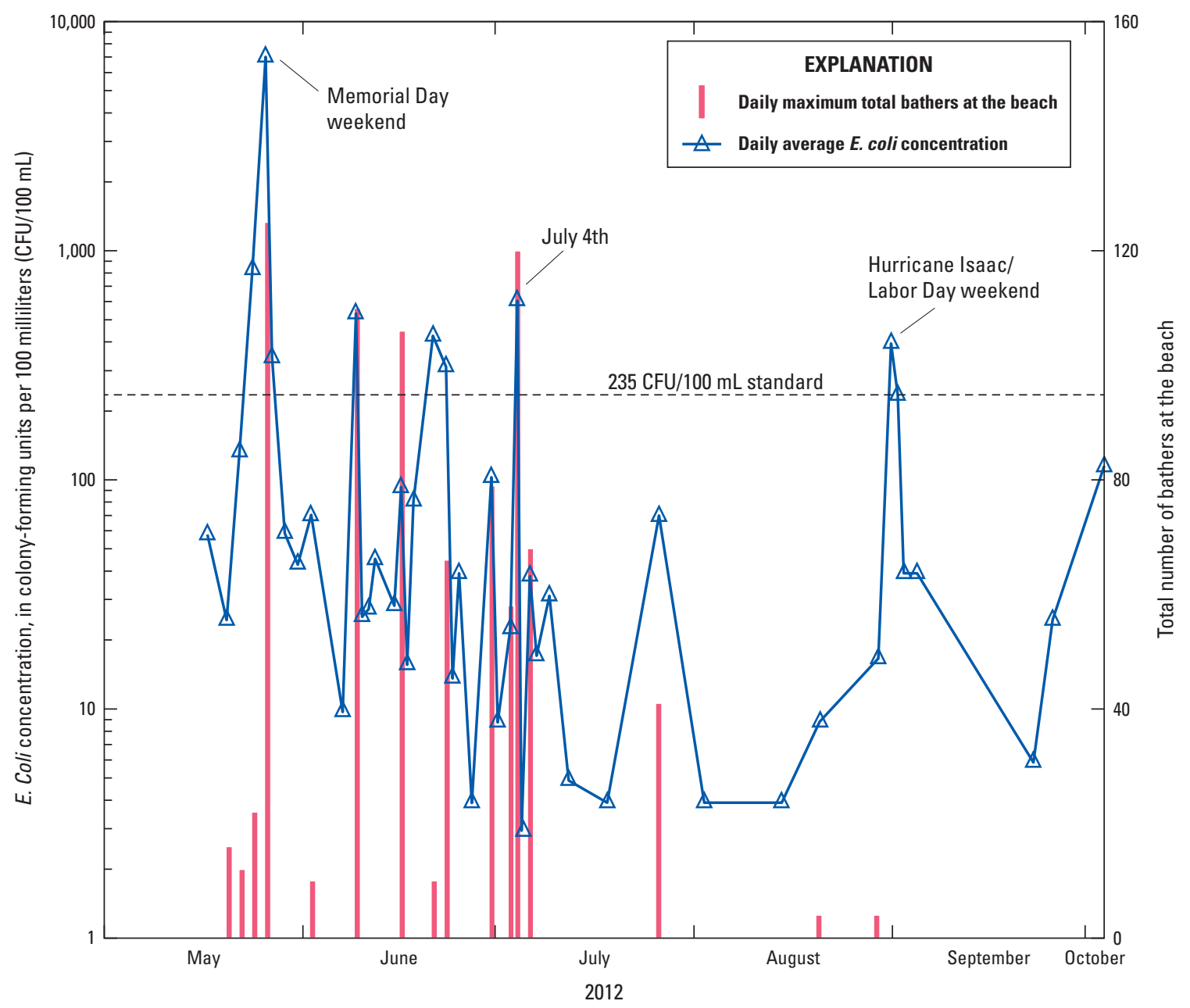

Figure 18. Temporal variation of the daily average of the maximum Escherichia coli (E. coli) concentrations at GB-L and GB-R and the daily maximum total number of bathers at the beach at Grand Glaize Beach (GGB), 2012. 
on weekends $(n=6)$ than weekdays $(n=3)$. The six weekend exceedances occurred on one Friday, four Saturdays, and on July 4. Weekday exceedance occurred on the Sunday of Memorial Day weekend and on two Thursdays.

The likelihood of exceeding a SSV during a day also can be presented as a function of maximum total number of bathers that day. Using the daily maximum total number of bathers at the beach as the independent variable and the occurrence or lack of an exceedance as the dependent variable, logistic regression indicates a significant relation between total bather count and likelihood of exceeding the SSV ( $p$-value $=0.005$ ). Data from 3 days were excluded in the logistic model: May 24,2012 , when the beach was disturbed because of grading and spreading of more than 30 cubic yards of sand; and the 2-day period of Hurricane Isaac runoff (August 31 and September 1). This relation also is apparent when comparing the probability of exceeding the SSV standard with the total number of bathers. Of the days with more than 100 bathers, 3 of 4 ( 75 percent) exceeded the standard; of the days with more than 50 bathers, 4 of 8 ( 50 percent) exceeded the standard; and of the days with more than 25 bathers, 4 of 11 (36 percent) exceeded the standard. The probably of exceeding the SSV standard is 24 percent ( 4 of 17 days) when the total number of bathers at the beach is more than 10 .

Routine MDNR beach monitoring samples are collected early in the week (Monday, Tuesday, or, on rare occasion, Wednesday) when beach use is generally small compared to weekends/holidays, which typically occur 3 to 5 days after and 2 to 4 days before MDNR sampling. Because of this large period of time between MDNR sampling and beach use, a comparison was made using USGS daily maximum concentrations from the two GGB sites (GB-L and GB-R) to determine the accuracy of weekly 2012 MDNR monitoring results to correctly forecast SSV exceedances on days that the USGS sampled (fig. 19). Weekly 2012 MDNR routine monitoring at GGB began the week of April 30 and lasted through August 27,2012 , and the results were used as the predictor for the following Thursday and subsequent 6 days until the next Thursday when new results were released and beach closure decisions made. The USGS collected samples on 40 days covering 16 weeks of the 18 -week MDNR monitoring period. Of the 40 days sampled by the USGS, 31 days ( 77.5 percent) were correctly predicted by MDNR monitoring; however, 7 days (17.5 percent) were false negatives (MDNR weekly sample did not exceed the SSV, but a USGS sample on 1 or more days that week did), and 2 days ( 5 percent) were false positives (MDNR sample exceeded the SSV, but USGS samples that week did not). Separating the results into weekdays and weekend/holiday groups, false negatives were more frequent on weekends and holidays (36.4 percent) during high-use days than weekdays (10.3 percent) during low-use days, indicating that samples collected at the beginning of the week are not good predictors for SSV exceedances on weekends and holidays. These indications along with other studies (Boehm and others, 2002; Doyle and others, 1992) and the variation of E. coli concentrations measured at GGB on single days during this study indicate that fecal bacteria concentrations at public swimming beaches vary by orders of magnitude not only dayby-day but also within a given day making weekly forecasting potentially problematic and inaccurate.

\section{Runoff Sampling}

During 2012, Missouri weather included the worst drought in 30 years, which lead to the designation of all Missouri's 114 counties as Primary Natural Disaster areas by the U.S. Agriculture Secretary (U.S. Department of Agriculture, 2012). This lack of rainfall allowed for the isolation of stormwater runoff from other potential sources of $E$. coli contamination. Three of five minor rainfall events were sampled by USGS MWSC, and none were substantial enough to generate surface flow into GGB cove from the west tributary until the first major rainfall event, Hurricane Isaac, on August 31, 2012, at the end of the recreational season.

The first minor rainfall event occurred on May 31, 2012, with 0.73 in. of rainfall in 1 hour recorded at the NOAA station in Kaiser, Mo. A pressure transducer at GI-T indicated that there was no measurable runoff in the west tributary from this event, and no runoff was observed at 0735 hours when the field team arrived at GGB; however, the shallow pool at site GI-T-DS immediately downstream from the road crossing was noticeably larger than the previous week and appeared slightly turbid indicating possible local runoff from the road or immediate area (fig. 10). The E. coli concentration on May 31, $2012(69,000 \mathrm{CFU} / 100 \mathrm{~mL})$ at GI-T-DS was substantially larger compared to the concentration on May 23, $2012(57 \mathrm{CFU} / 100 \mathrm{~mL})$, indicating that either local runoff or shallow subsurface flow affected GI-T-DS.

Sampling of localized runoff in the west tributary during the second minor runoff event on June 11, 2012, allowed for identification of a substantial $E$. coli source in the vicinity of the seasonal residence. During this event, the marina meteorological station recorded a short period of rainfall ( 0.43 inch in 1.5 hours) that produced only localized runoff at sites GI-T and GI-L2 (fig. 10). Localized runoff at site GI-T from adjacent areas including the road and nearby excavated septic tank at the seasonal residence contributed to GI-T, and, within an hour, seeped beneath the road to site GI-T-DS, whereas localized runoff from the parking lot north of GGB entered GGB cove at site GI-L2. Escherichia coli concentrations in local runoff samples collected before noon at sites GI-T $(10,000 \mathrm{CFU} / 100 \mathrm{~mL})$ and GI-T-DS $(980,000 \mathrm{CFU} / 100 \mathrm{~mL})$ were substantially larger than at sites GI-T-N $(380 \mathrm{CFU} / 100 \mathrm{~mL})$ and GI-L2 $(320 \mathrm{CFU} / 100 \mathrm{~mL})$ indicating a substantial source of $E$. coli in the immediate vicinity of sites GI-T-DS and GI-T. At 1255 hours on the same day, a small slug of runoff from upper reaches of the west tributary finally reached site GI-T causing a peak discharge of about 0.02 cubic feet per second $\left(\mathrm{ft}^{3} / \mathrm{s}\right)$ at 1305 hours that decreased to less than 1 gallon per min $\left(0.002 \mathrm{ft}^{3} / \mathrm{s}\right)$ by around 1400 hours. The total volume of runoff was estimated at $44 \mathrm{ft}^{3}$, which collected in a bedrock-bottom pool about $300 \mathrm{ft}$ downstream 
Contingency table comparing MDNR beach status with USGS samples

\begin{tabular}{|c|c|c|c|}
\hline $\begin{array}{c}\text { MDNR status on } \\
\text { day of USGS } \\
\text { sample }\end{array}$ & $\begin{array}{l}\text { Number of days } \\
\text { of USGS sample }\end{array}$ & $\begin{array}{c}\text { Days a USGS } \\
\text { sample result } \\
\text { did not exceed } \\
\text { SSV }\end{array}$ & $\begin{array}{c}\text { Days a USGS } \\
\text { sample result } \\
\text { did exceed } \\
\text { SSV }\end{array}$ \\
\hline \multicolumn{4}{|c|}{ All samples } \\
\hline Open & 38 & 31 & 7 \\
\hline Closed & 2 & 0 & 2 \\
\hline Total & 40 & 31 & 9 \\
\hline \multicolumn{4}{|c|}{ Weekdays } \\
\hline Open & 28 & 25 & 3 \\
\hline Closed & 1 & 0 & 1 \\
\hline Total & 29 & 25 & 4 \\
\hline \multicolumn{4}{|c|}{ Weekends } \\
\hline Open & 10 & 6 & 4 \\
\hline Closed & 1 & 0 & 1 \\
\hline Total & 11 & 6 & 5 \\
\hline
\end{tabular}

\section{EXPLANATION}

\section{MDNR sample did not exceed SSV \\ \. MDNR sample exceeded SSV \\ Maximum value of USGS samples' exceeded SSV \\ Maximum value of USGS samples did not exceeded SSV \\ --- Lag period between MDNR sample collection and beach posting \\ Beach open/MDNR projected period ${ }^{3}$ of SSV non-exceedance based on weekly sample \\ Beach closed/MDNR projected period of SSV exceedance based on weekly sample \\ Minor rainfall event, daily total less than 0.20 inches (red outline indicates daily rainfall greater than 1.5 inches).}

'USGS samples were collected at identical locations as MDNR samples at at left and right side (sites GB-L and GB-R) of Grand Glaize Beach (GGB). USGS exceedances are based on the maximum Escherichia coli (E. colli) concentration of multiple samples measured on each day.

${ }^{2}$ An E. coli concentration greater than or equal to 235 colonies per 100 milliliters constitutes an exceedance of the SSV and subsequent beach closure. The date of beach status posting is assumed as Thursday of each week.

${ }^{3}$ The date of beach status posting is assumed as Thursday of each week.

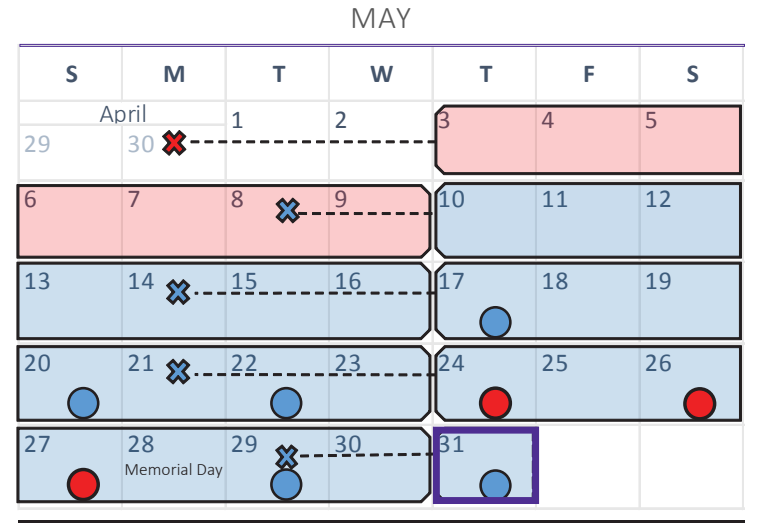

JUNE

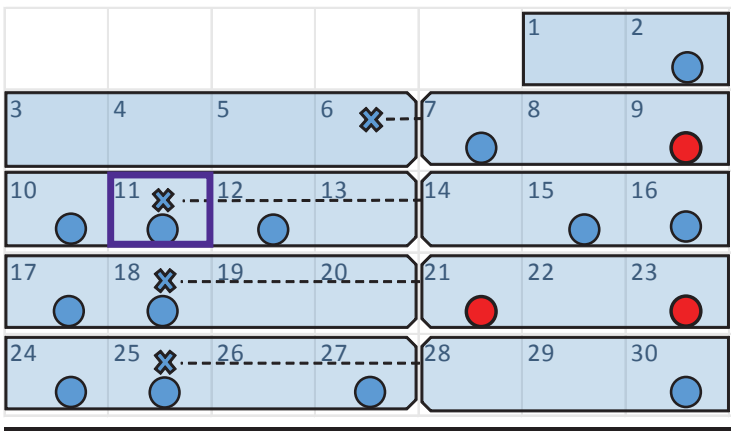

JULY
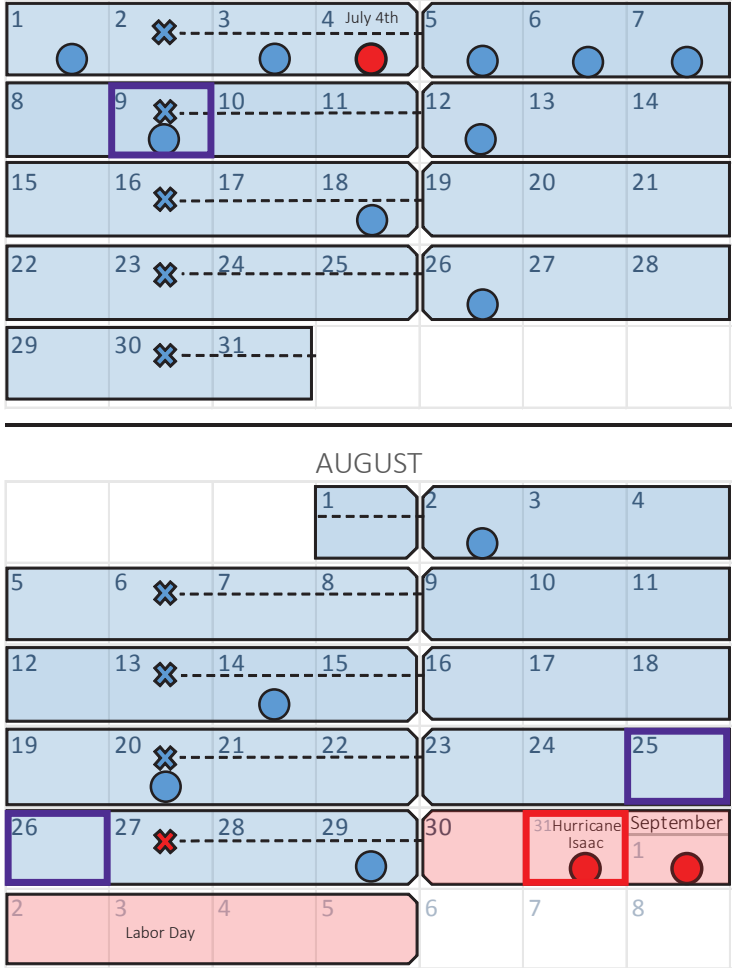

Figure 19. The number of days sampled during the 2012 recreational season by the U.S. Geological Survey (USGS) with or without an exceedance of the single sample value (SSV) standard and the beach status of Grand Glaize Beach (GGB) on those days based on weekly Missouri Department of Natural Resources (MDNR) routine testing, 2012. 
from site GI-T-DS where it never directly entered GGB cove at site GI-R but throughout the next day gradually seeped into the rock and cobble streambed. Water samples collected at site GI-T contained $71,000 \mathrm{CFU} / 100 \mathrm{~mL}$ of E. coli near the discharge peak at 1310 hours and $44,000 \mathrm{CFU} / 100 \mathrm{~mL}$ at 1507 hours. Escherichia coli concentrations in water samples collected the next day (June 12, 2012) from pools of water in the west tributary also varied from $22,000 \mathrm{CFU} / 100 \mathrm{~mL}$ in a pool upstream from the seasonal residence (site GI-T-US) to $11,000 \mathrm{CFU} / 100 \mathrm{~mL}$ at site GI-T and $660,000 \mathrm{CFU} / 100 \mathrm{~mL}$ at site GI-T-DS. The substantially larger $E$. coli concentrations at site GI-T-DS compared to sites GI-T-US and GI-T are consistent with raw sewage (Bergier and Wlodyka-Bergier, 2013) and septic contaminated soils disturbed and exposed during the recent excavation or shallow infiltration moving through these soils.

A third minor rainfall event ( 0.76 inch in 3.5 hours) on July 9, 2012, produced only localized runoff from the seasonal residence and septic tank excavation area and from a ditch along the road. Water samples collected from the east and west tributaries indicated that there were substantially smaller $E$. coli concentrations in the east tributary at site GI-L2 $(290 \mathrm{CFU} / 100 \mathrm{~mL})$ than from the west tributary downstream from the seasonal residence at sites GI-T $(2,400,000 \mathrm{CFU} / 100 \mathrm{~mL})$ and GI-T-DS (920,000 CFU/100 mL) further indicating the presence of raw sewage related to contamination from septic contaminated soils disturbed during removal of the septic tank at the seasonal residence in early May 2012, or shallow groundwater in the vicinity of the seasonal residence septic tank excavation are likely sources (fig. 10). The fact that the seasonal residence had not been used since 2010 indicates that $E$. coli in the former tank or soils and shallow groundwater within the drain field have remained viable for nearly 2 years.

Before the arrival of Hurricane Isaac, two minor rainfall events with no discernible runoff occurred on August 25 (0.19 inch in 1.5 hours) and August 26 (0.42 inch in one-half hour). Although no associated runoff in the west tributary at site GI-T was measured, runoff from the east tributary into GGB cove is likely because there is a large amount of impervious parking areas in the east tributary. The E. coli concentration in a MDNR beach sample at site GB-L the following morning (730 MPN/100 mL) was much larger than at GB-R (29 MPN/100 mL) and was the first sample all season to exceed the standard. The geese had not inhabited the beach since the end of June so entrainment of goose fecal matter is an unlikely source. The only major rainfall event causing surficial flow into GGB cove from west tributary during the 2012 recreational season occurred on August 31, 2012, as remnants of Hurricane Isaac made their way through the Midwestern United States during Labor Day weekend. Leading up to this event, E. coli concentrations at GGB at sites GB-L and GB-R on August 29 were small ( 6 to $24 \mathrm{CFU} / 100 \mathrm{~mL}$ ), and only 2.50 in. of precipitation had been recorded at the meteorological station at GGB between June 3 and August 30, 2012 with a maximum 15 -min intensity of 0.26 in.
On August 31, 2012, major rainfall (1.81 inches in 19 hours) with a maximum 15 -min intensity of 0.38 in. occurred at GGB cove with most of the rainfall (1.26 in.) falling during a 2-hour period between 0715 and 0915 hours (fig. 20). Sampling of this event included deployment of a continuous water-quality monitor (CWQM) at sites GI-R and GB-R to document the effect of runoff from the west tributary on GGB; the CWQMs were installed between 0815 and 0845 hours (fig. 10). Results from the first set of samples from GGB cove indicated small specific conductance $(114 \mu \mathrm{S} / \mathrm{cm}$ at $\left.25^{\circ} \mathrm{C}\right)$ and large $E$. coli concentrations $(770 \mathrm{CFU} / 100 \mathrm{~mL})$ at site GI-L, suggesting runoff from the east tributary. Flow in the west tributary at site GI-T started around 0800 hours, lasted until 0250 hours the following day, peaked at around $3.73 \mathrm{ft}^{3} / \mathrm{s}$ at GI-T at 0839 hours, and transported about $20,000 \mathrm{ft}^{3}$ of runoff into GGB cove. Flow from the west tributary entering GGB cove at site GI-R was directed toward the south bank of the cove near site GI-R3, bypassing GGB and moving towards the swimming boom (fig. 21). From its initial deployment at 0815 hours, the CWQM at site GI-R recorded small specific conductance (about $80 \mu \mathrm{S} / \mathrm{cm}$ at $25^{\circ} \mathrm{C}$ ) and large turbidity ( $650 \mathrm{NTU})$ values indicative of rainfall runoff (fig. 20). These values gradually stabilized at about $300 \mu \mathrm{S} / \mathrm{cm}$ at $25^{\circ} \mathrm{C}$ and $3.5 \mathrm{NTU}$ by the following afternoon. The CWQM at site GB-R recorded a stable specific conductance of about $270 \mu \mathrm{S} / \mathrm{cm}$ at $25^{\circ} \mathrm{C}$ throughout Hurricane Isaac; however, the turbidity increased slightly from about 3 to 7 NTU around 1400 hours on September 1 and subsequently increased at site GI-R, indicating potential counter-clockwise recirculation of west tributary runoff back towards GGB.

Dye tracing and hydrodynamic flow modeling of GGB cove was done as part of a Missouri S\&T master's thesis and indicated that flow inside GGB cove was dispersion dominated during low-wind velocity conditions and advection dominated during high-wind conditions. Recirculation patterns during Hurricane Isaac potentially could transport E. coli-contaminated sediments from the west tributary out towards the swimming boom and the marina and back to GGB (Wilson, 2013).

Escherichia coli concentrations ( 24 and $30 \mathrm{CFU} / 100 \mathrm{~mL}$ ) and turbidity (1.3 and 1.4 NTU) values at sites GB-L and GB-R in initial water samples collected at about 0840 hours on August 31 were comparable to samples collected on August 29 (10 and $24 \mathrm{CFU} / 100 \mathrm{~mL}$ and 1.4 to $2.1 \mathrm{NTU}$ ) indicating that any runoff from the beach itself or surrounding area had not yet affected E. coli concentrations at the beach. Sheet runoff from the beach caused small erosional features in the sand that were observed when the CWQM was deployed at GB-R around 0845 hours. By about 1030 hours E. coli concentrations in samples at sites GB-L and GB-R had increased to between 45 and $240 \mathrm{CFU} / 100 \mathrm{~mL}$ (average of $150 \mathrm{CFU} / 100 \mathrm{~mL}$ ), and concentrations peaked at 380 to $430 \mathrm{CFU} / 100 \mathrm{~mL}$ (average of $410 \mathrm{CFU} / 100 \mathrm{~mL}$ ) at around 1430 hours. Turbidity concentrations did not increase and remained less than 2.0 NTU, whereas specific conductance values decreased slightly to $268 \mu \mathrm{S} / \mathrm{cm}$ at $25^{\circ} \mathrm{C}$ from $273 \mu \mathrm{S} / \mathrm{cm}$ at $25^{\circ} \mathrm{C} 2$ days before. The increase in E. coli 

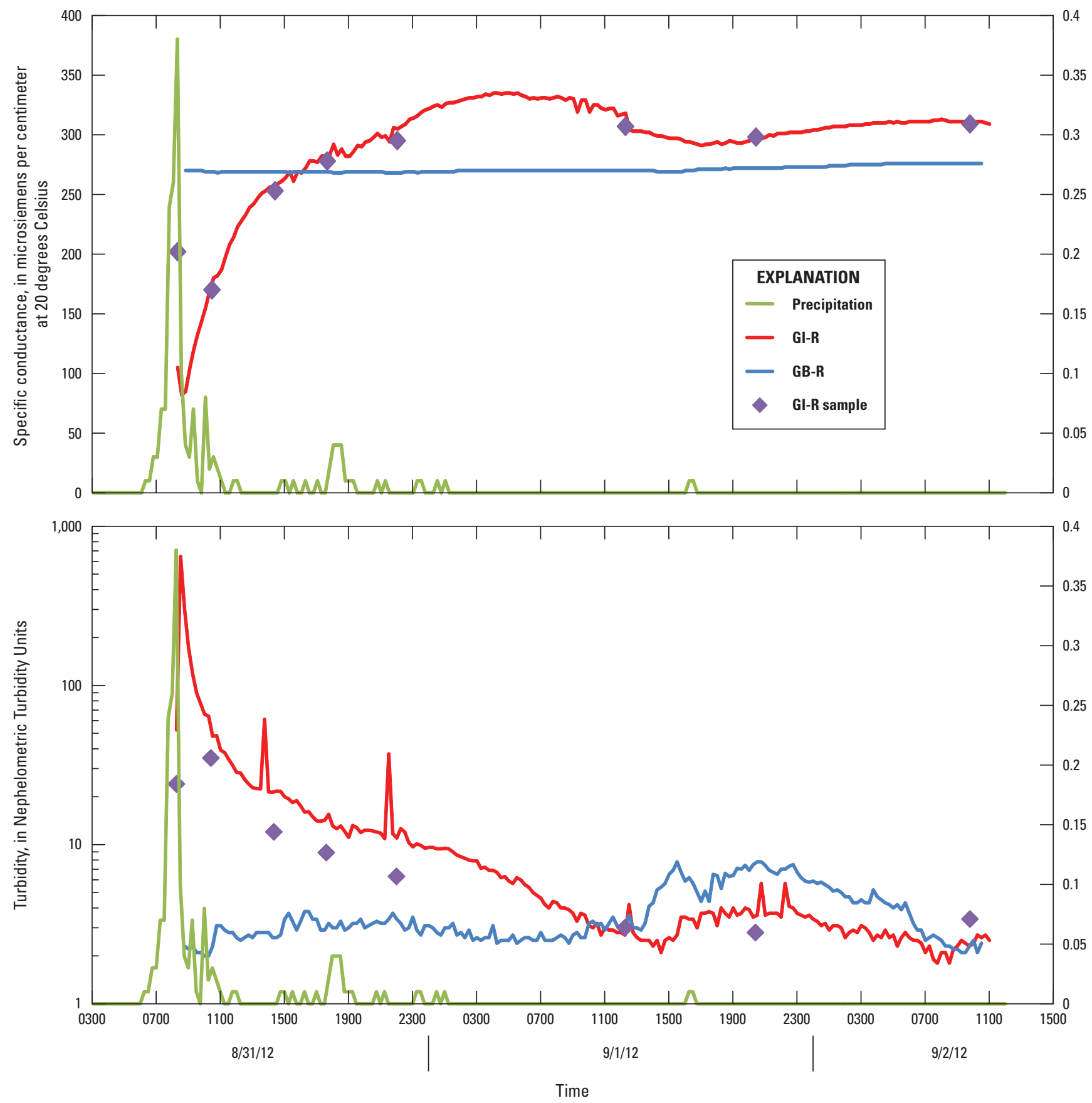

Figure 20. Continuous specific conductance and turbidity at sites GI-R and GB-R during Hurricane Isaac showing potential recirculation of tributary runoff back toward Grand Glaize Beach (GGB), 2012. 


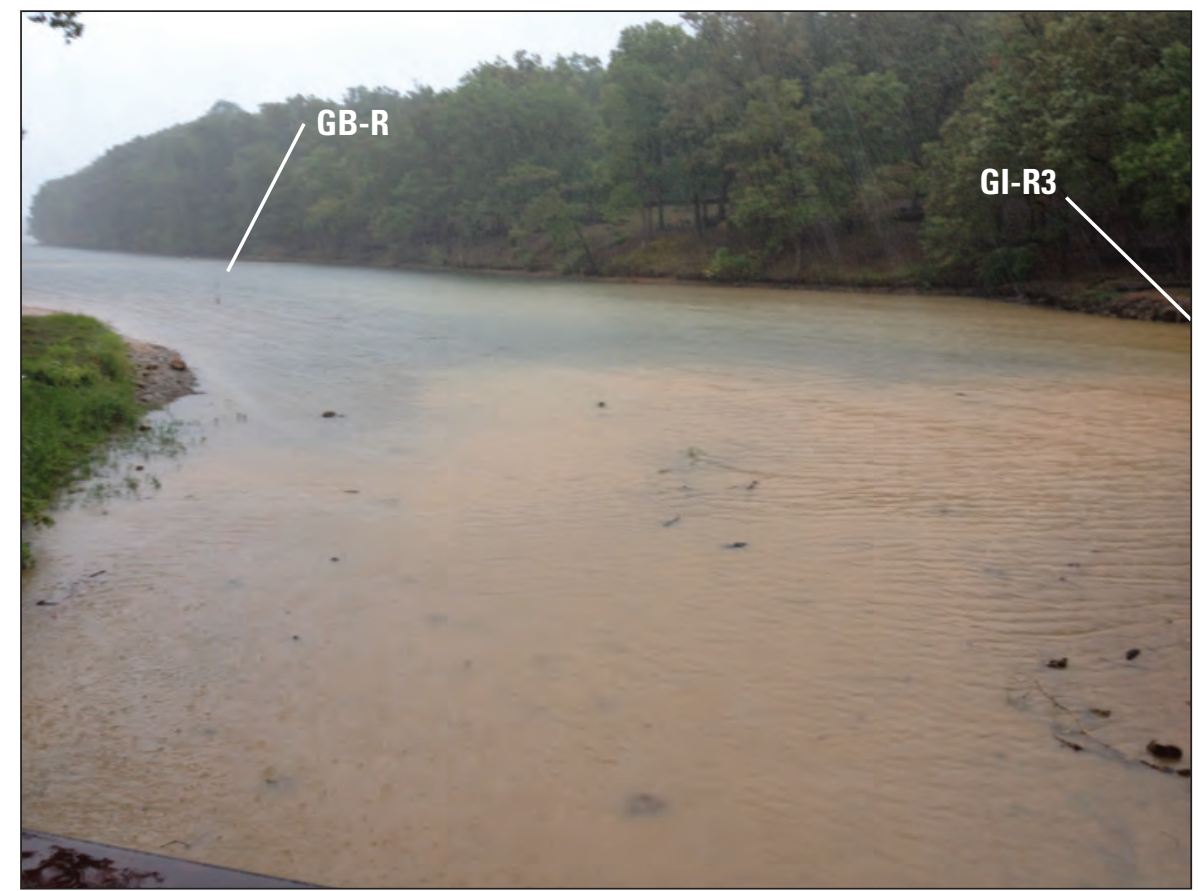

August 31, 2012, at 0910, looking southeast from foot bridge at site GI-R. Note plume of turbid water along south bank opposite of beach and continuous water quality monitor (CWOM) at site GB-R.

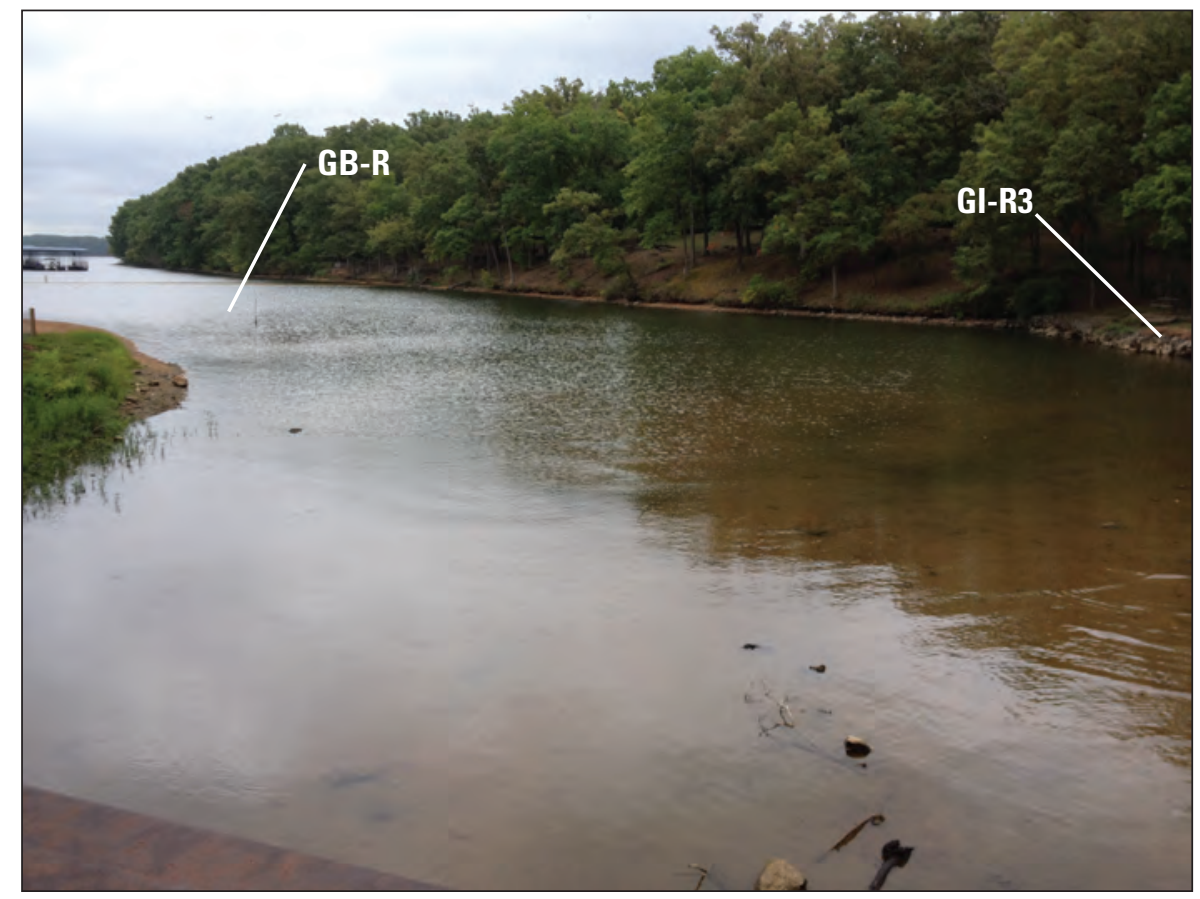

September 2, 2012, at 0949, looking southeast from foot bridge at site GI-R.

Figure 21. Turbidity plume from Hurricane Isaac runoff from the west tributary into Grand Glaize Beach (GGB) cove, August 31 and September 2, 2012. 
concentrations, steady turbidity, and slight decrease in specific conductance in samples from sites GB-L and GB-R was probably caused by sheet runoff from the beach itself (observed earlier that morning), dilution effect from low specific conductance rainfall falling directly on the lake, and possibly runoff from the east tributary. Escherichia coli concentrations gradually began decreasing in samples from sites GB-L and GB-R averaging 350 and $270 \mathrm{CFU} / 100 \mathrm{~mL}$ in samples collected at about 1745 and 2130 hours on August 31 to $120 \mathrm{CFU} / 100 \mathrm{~mL}$ in samples collected around noon on September 1. The average concentrations then increased to $240 \mathrm{CFU} / 100 \mathrm{~mL}$ (range of 180 to $300 \mathrm{CFU} / 100 \mathrm{~mL}$ ) in samples collected at about 2030 hours on September 1. The increase in E. coli concentrations the evening of September 1 coincides with the increase in turbidity recorded by the CWQM at sites GB-R and GI-R that began at about 1400 hours that afternoon and is most likely caused by the arrival of the runoff plume from the west tributary that was gradually circulating counterclockwise in the cove.

Runoff samples collected at GI-T on August 31, 2012, had $E$. coli concentrations as large as $150,000 \mathrm{CFU} / 100 \mathrm{~mL}$ at the onset of flow that decreased to $3,600 \mathrm{CFU} / 100 \mathrm{~mL}$ at 2206 hours on August 31 (fig. 22). Specific conductance values also were small at sites GI-R and GI-R3 (average of $163 \mu \mathrm{S} / \mathrm{cm}$ at $25^{\circ} \mathrm{C}$ ) around 1030 hours following peak discharge in the west tributary, and water samples collected from GI-R and GI-R3 at 1030 hours had the largest E. coli concentrations of nontributary samples in GGB cove during the event resulting from west tributary runoff. Escherichia coli concentrations at sites GI-R, GI-R3, and GI-T were all within the same order of magnitude during the period after the first sample at peak flow in the west tributary. The trapezoidal rule, a numerical integration technique that approximates total volume and contaminant loading by discretizing the area under the discharge-time curve into trapezoids (Larson and Edwards, 2009), was used along with linear interpolation of samples collected at site GI-T to approximate E. coli loading into GGB cove from the west tributary during the Hurricane Isaac event. The estimated 20,000 cubic feet $\left(\mathrm{ft}^{3}\right)$ of runoff at site GI-T during August 31 through September 1, 2012, transported an estimated $2.9 \times 10^{11}$ colonies of $E$. coli to GGB cove. This loading is an important source of $E$. coli and, if uniformly mixed with the estimated $565,000 \mathrm{ft}^{3}$ of water inside the swimming area determined using bathymetric data collected as part of a master's thesis (Wilson, 2013) would result in an average $E$. coli concentration of about 1,800 CFU/100 mL. Field observation indicated that most of the runoff in the west tributary originated from areas upstream from the seasonal residence; therefore, most of the $E$. coli loading into GGB cove from the west tributary during this event likely also originated from areas upstream from the seasonal residence.

The measured E. coli concentrations at GGB during the Hurricane Isaac event (average of $230 \mathrm{CFU} / 100 \mathrm{~mL}$, maximum of $430 \mathrm{CFU} / 100 \mathrm{~mL}$ at site GB-R the afternoon of August 31,2012 ) were smaller than the average predicted concentration of $1,800 \mathrm{CFU} / 100 \mathrm{~mL}$ in GGB cove calculated from loading from the west tributary during the event. Because $E$. coli concentrations at sites GI-R and GI-R3 during the event were similar to concentrations measured in the west tributary and much larger than concentrations at GGB, and the observed turbidity plume from the west tributary influent was directed along the south shoreline away from the beach and towards the swimming boom, some sediment and associated E. coli, from the west tributary likely settled farther from the beach. The CWQM data indicate that recirculation probably transported some of the sediment loading from the west tributary back to the beach the next day where it could contribute to $E$. coli loading of nearshore sediments that later could be resuspended by bathers. Although runoff associated with Hurricane Isaac was substantial, the most intense 2-hour rainfall (1.26 in.) was smaller than the 2-hour rainfall at a 1-year recurrence interval (1.56 in.) in Kaiser, Mo. (National Oceanic and Atmospheric Association, 2013). The measured precipitation for May through August in Kaiser, Mo. (4.29 in.) also was well below the normal total (12.22 in.; National Climatic Data Center, 2013b). Because the total precipitation for the 2012 recreational season was below normal, runoff into GGB cove may be a more important source of $E$. coli contamination at GGB during a more typical year than during 2012.

\section{Sediment and Resuspended Sediment Sampling}

Sediment samples were collected on five occasions from May 31, 2012, to February 5, 2013. Samples were collected at the shoreline and, as a result, sampling locations shifted towards the mouth of the cove as lake levels dropped and the shoreline retreated. The largest shoreline retreat (approximately $33 \mathrm{ft}$ ) occurred in the middle of the beach where the slope is the shallowest, and the smallest retreat (approximately $21 \mathrm{ft}$ ) occurred at the sides of the beach at sites GB-L and GB-R (fig. 11).

Sediment samples collected at GGB had substantially larger concentrations of $E$. coli than sediment samples collected by the USGS Ohio WSC at beaches with similar usage and E. coli contamination on Lake Erie, Ohio (Francy and Darner, 1998; Francy and others, 2002, 2006). Escherichia coli concentrations in nearshore sediment samples from GGB were significantly larger in foreshore samples (samples collected above the shoreline) than in ankle-deep water (p-value $=0.004)$ likely because of the concentrating effect of waves continually transporting and depositing $E$. coli to foreshore locations (Francy and others, 2006). Escherichia coli concentrations also were significantly larger on the left and middle areas of the beach compared to the right (p-value $=0.011)$ side (fig. 23$)$, which may be related to deposition of geese fecal matter onto nearshore sediment from the flock of geese that frequented the left side of GGB each morning during early 2012 before they were relocated by the MDNR in late June. Sediment samples consisted mostly of sand-sized material and greater (greater than $0.063 \mathrm{~mm}$ ) with most samples having more than 40 percent coarse sand-sized material and greater (greater than $1.0 \mathrm{~mm}$ ) (table 3). Nearshore 


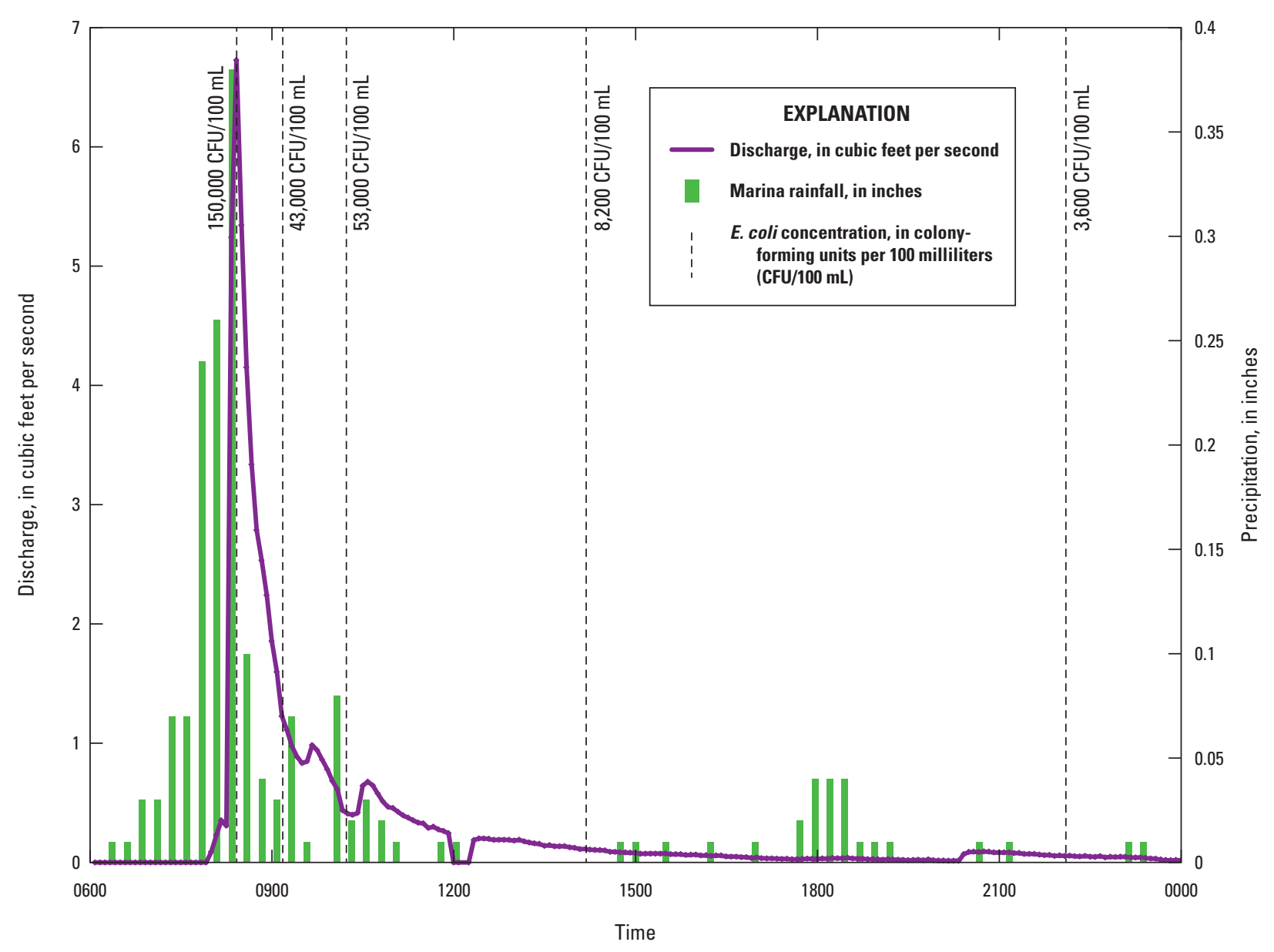

Figure 22. Discharge at GI-T in the west tributary, rainfall intensities, and Escherichia coli (E. coli) concentrations measured at GI-T during the Hurricane Isaac runoff event, 2012. 


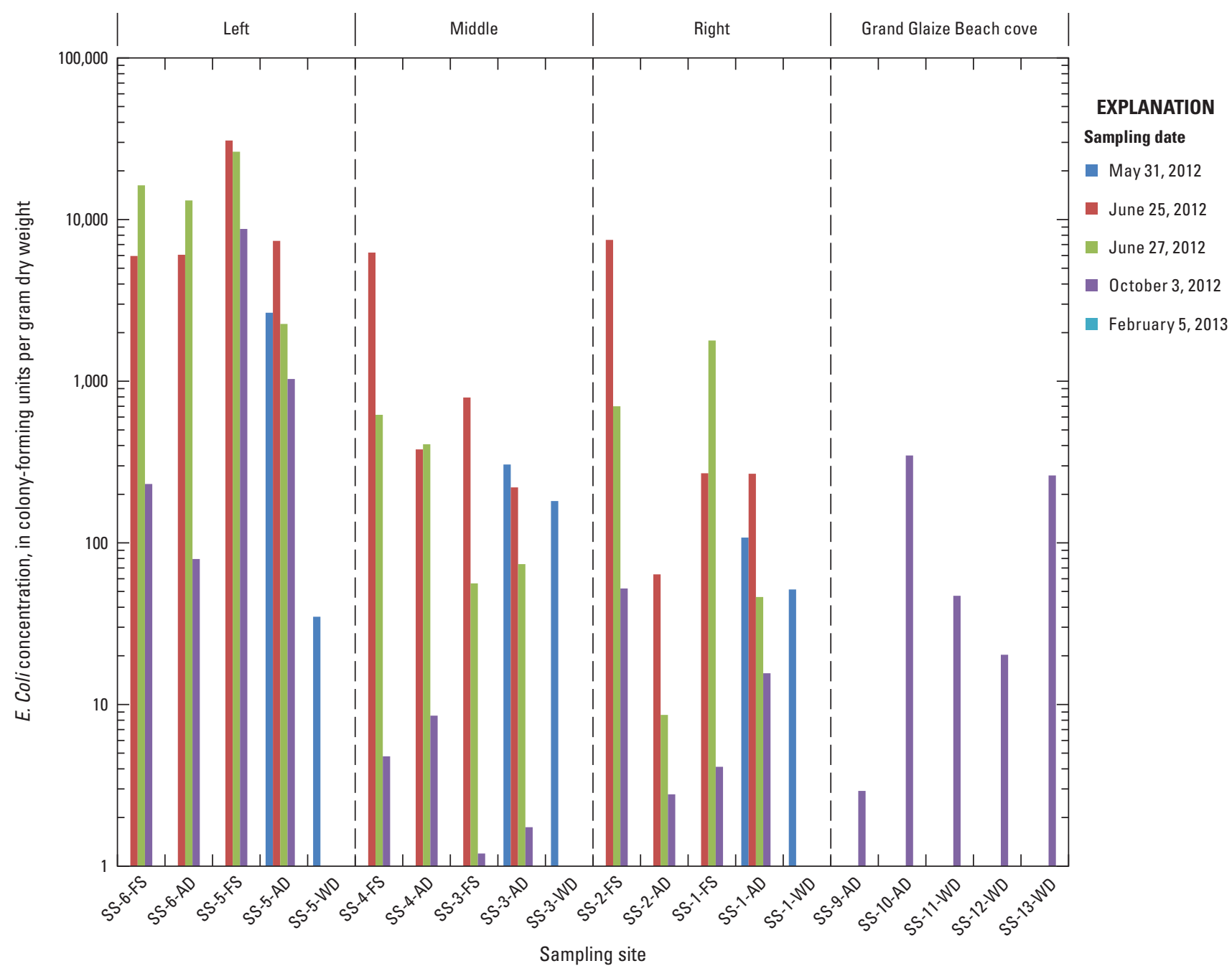

Figure 23. Escherichia coli (E. coli) concentrations in sediment samples collected at Grand Glaize Beach (GGB) between May 31, 2012, and February 5, 2013. Sample locations are arranged from the leftmost side to the rightmost side of GGB. Concentrations in samples collected on February 5, 2013, at SS-5-FS and SS-1-FS were less than 1 colony-forming units per gram dry weight. Sites ending in "FS" were sampled at foreshore locations, sites ending in " $A D$ " were sampled at ankle-deep locations, and sites ending in "WD" were sampled at waist-deep locations. 
Table 3. Grain-size distribution of sediment samples collected at Grand Glaize Beach (GGB) and GGB cove on October 3, 2012.

[mm, millimeter; SS, sediment sample; FS, foreshore; AD, ankle deep; WD, waist deep]

\begin{tabular}{|c|c|c|c|c|}
\hline \multirow[b]{2}{*}{ Beach area } & \multirow{2}{*}{$\begin{array}{c}\text { Site } \\
\text { (figure 11) }\end{array}$} & \multicolumn{3}{|c|}{ Grain size distribution, in percent } \\
\hline & & $\begin{array}{l}\text { Greater } \\
\text { than } 1 \mathrm{~mm}\end{array}$ & $1-0.063 \mathrm{~mm}$ & $\begin{array}{l}\text { Less than } \\
0.063 \mathrm{~mm}\end{array}$ \\
\hline Right & SS-1-FS & 40.6 & 54.4 & 5.0 \\
\hline Right & SS-1-AD & 40.7 & 58.3 & 1.0 \\
\hline Right & SS-2-FS & 49.8 & 48.8 & 1.4 \\
\hline Right & SS-2-AD & 54.4 & 44.7 & 0.9 \\
\hline Middle & SS-3-FS & 39.0 & 53.5 & 7.5 \\
\hline Middle & SS-3-AD & 53.6 & 45.1 & 1.3 \\
\hline Middle & SS-4-FS & 44.8 & 32.7 & 22.5 \\
\hline Middle & SS-4-AD & 58.5 & 39.2 & 2.3 \\
\hline Left & SS-5-FS & 52.5 & 32.0 & 15.5 \\
\hline Left & SS-5-AD & 63.2 & 27.7 & 9.1 \\
\hline Left & SS-6-FS & 51.4 & 45.4 & 3.2 \\
\hline Left & SS-6-AD & 49.3 & 47.1 & 3.6 \\
\hline GGB Cove & SS-10-AD & 68.7 & 24.1 & 7.2 \\
\hline GGB Cove & SS-9-AD & 66.0 & 25.1 & 8.9 \\
\hline GGB Cove & SS-11-WD & 22.6 & 36.6 & 40.8 \\
\hline GGB Cove & SS-12-WD & 78.1 & 17.3 & 4.6 \\
\hline GGB Cove & SS-13-WD & 92.0 & 5.0 & 3.0 \\
\hline
\end{tabular}

sediment sample locations on the left to the middle sides of the beach tended to have larger percentages of fine-grained (less than $0.063 \mathrm{~mm}$ ) sediments than the right side. This spatial distribution of fine-grained nearshore sediments likely is another contributing factor in larger $E$. coli concentrations on the left and middle sides of the beach as $E$. coli have been determined to survive longer in finer sediments (Burton and others, 1987; Howell and others, 1995).

Escherichia coli concentrations in nearshore sediment samples from GGB significantly decreased with time when averaging samples along the beach (sites SS-1 through SS-6) at foreshore and ankle-deep locations during sampling events in May and June 2012 (average $=4,300 \mathrm{CFU} / \mathrm{g}_{\mathrm{DW}}$ ) compared to samples in October 2012 and February 2013 $\left(\mathrm{p}\right.$-value $=0.000 ;$ average $=730 \mathrm{CFU} / \mathrm{g}_{\mathrm{DW}}$; table 4$)$. This decrease in $E$. coli concentrations likely is caused by an artifact of changing sampling locations as lake levels declined later in 2012 (fig. 7). Waist-deep locations (for example, site SS-1-WD) sampled on May 31 had smaller E. coli concentrations than foreshore and ankle-deep locations and likely coincided spatially with foreshore and ankle-deep sampling locations (for example, SS-1-FS and SS-1-AD) in October 2012 and February 2013, which may explain the apparent decline in E. coli concentrations in nearshore sediment with time.

During the winter and early spring, lake levels are lower and sediments that are normally under a few feet of water during the middle of the recreational season are exposed. During this period the beach is virtually unused and wildlife likely is more prevalent on the beach. Pre-season loading from wildlife fecal matter may explain large E. coli concentrations in nearshore sediment at the beginning of the season, but may be caused by other factors such as runoff.

Resuspended sediment samples were collected on three occasions at GGB. The difference in E. coli concentrations in the water column before and after mixing was intended to represent a worse-case scenario involving resuspension of sediments by bathers. The largest $E$. coli concentrations detected after mixing were measured on June 7, 2012, when resuspended sediment concentrations in the water column were roughly two to three orders of magnitude larger than before mixing (fig. 24; table 5). By September 22, 2012, concentrations before mixing were similar to the concentrations in June, but resuspended sediment concentrations were almost two orders of magnitude smaller. These results match results from the nearshore sediment samples as sampling locations for the resuspended sediment study tracked the shoreline as well. Overall, E. coli concentrations were significantly larger $(n=16, \mathrm{p}$-value $=0.017)$ after resuspending sediment, indicating that resuspended sediment can be an important source of $E$. coli in the water column. This significant increase in E. coli concentration in the water column supports the hypothesis that bathers resuspend $E$. coli-contaminated sediment, resulting in significantly increased $E$. coli concentrations in the water column.

\section{Occurrence of Escherichia coli at Public Beach 1 and Vicinity during 2012}

The 2012 intensive sampling at PB1 involved the collection of 240 water samples from 11 sites at PB1, RS-B, and Swinging Bridge (table 1; figs. 1 and 8). Sampling was conducted at PB1 from May 17 through September 4, 2012, and included routine water sampling and one sediment sample collected for MST analysis. The average number of total bathers at PB1 was smaller than at GGB, averaging 19 and ranged from 0 to $82(n=43)$. Similar to GGB, bather counts at PB1 followed a normal distribution, peaked between 1200 and 1500 hours, and were largest on Fridays, Saturdays, and holidays. Deer fecal matter was observed on many occasions on the hillside between the beach and the bathhouse. Several attempts were made to collect deer feces for MST analysis, but recently deposited samples could not be collected. Comparing daily maximum $E$. coli concentrations measured at sites B1-R and B1-L, which coincide with MDNR beach monitoring sites, to the 2012 MDNR standards, PB1 would have exceeded standards on only 1 of 34 days sampled during this study 
Table 4. Escherichia coli (E. coli) concentrations in sediment samples collected at Grand Glaize Beach (GGB) and GGB cove, 2012-13.

[USGS, U.S. Geological Survey; MWSC, Missouri Water Science Center; E. coli, Escherichia coli; CFU/g ${ }_{\mathrm{DW}}$, colonyforming units per gram dry weight; OWML, Ohio Water Microbiology Laboratory; MPN $/ \mathrm{g}_{\mathrm{DW}}$, most probable number per gram dry weight; SS, sediment sample; AD, ankle deep water; WD, waist deep water; --, no data; FS, foreshore; $<$, less than]

\begin{tabular}{|c|c|c|c|c|}
\hline $\begin{array}{c}\text { Site } \\
\text { identifier } \\
\text { (figure 11) }\end{array}$ & Date & $\begin{array}{c}\text { USGS MWSC } \\
\text { E. coli concentration } \\
\left.\text { (CFU } / \mathrm{g}_{\mathrm{DW}}\right) \text {, } \\
\text { membrane-filtration method }\end{array}$ & $\begin{array}{l}\text { USGS OWML } \\
\text { E. coli concentration } \\
\text { (MPN } / g_{\mathrm{DW}} \text { ), } \\
\text { Colilert }^{\circledR} \text { method }\end{array}$ & $\begin{array}{l}\text { Relative percent } \\
\text { difference } \\
\text { (RPD) }\end{array}$ \\
\hline SS-1-AD & $5 / 31 / 2012$ & 110 & 300 & 93 \\
\hline SS-1-WD & $5 / 31 / 2012$ & 51 & 58 & 13 \\
\hline SS-3-AD & $5 / 31 / 2012$ & 300 & -- & -- \\
\hline SS-3-WD & $5 / 31 / 2012$ & 180 & -- & -- \\
\hline $\mathrm{SS}-5-\mathrm{AD}^{\mathrm{a}}$ & $5 / 31 / 2012$ & 2,600 & 900 & 97 \\
\hline SS-5-WD & $5 / 31 / 2012$ & 35 & 130 & 115 \\
\hline SS-1-FS & $6 / 25 / 2012$ & 270 & 110 & 84 \\
\hline SS-1-AD & $6 / 25 / 2012$ & 270 & -- & -- \\
\hline SS-2-FS ${ }^{a}$ & $6 / 25 / 2012$ & 7,500 & 360 & 182 \\
\hline SS-2-AD & $6 / 25 / 2012$ & 64 & -- & -- \\
\hline SS-3-FS & $6 / 25 / 2012$ & 790 & 130 & 143 \\
\hline SS-3-AD & $6 / 25 / 2012$ & 220 & -- & -- \\
\hline $\mathrm{SS}-4-\mathrm{FS}^{\mathrm{a}}$ & $6 / 25 / 2012$ & 6,200 & 2,200 & 95 \\
\hline SS-4-AD & $6 / 25 / 2012$ & 380 & -- & -- \\
\hline SS-5-FS ${ }^{a}$ & $6 / 25 / 2012$ & 31,000 & 13,000 & 82 \\
\hline SS-5-AD & $6 / 25 / 2012$ & 7,400 & -- & -- \\
\hline SS-6-FS & $6 / 25 / 2012$ & 5,900 & 20,000 & 109 \\
\hline SS-6-AD & $6 / 25 / 2012$ & 6,100 & -- & -- \\
\hline SS-1-FS & $6 / 27 / 2012$ & 1,800 & -- & -- \\
\hline SS-1-AD ${ }^{a}$ & $6 / 27 / 2012$ & 46 & 1,500 & 188 \\
\hline SS-2-FS & $6 / 27 / 2012$ & 700 & -- & -- \\
\hline SS-2-AD & $6 / 27 / 2012$ & 9 & -- & -- \\
\hline SS-3-FS & $6 / 27 / 2012$ & 56 & -- & -- \\
\hline SS-3-AD ${ }^{\mathrm{a}}$ & $6 / 27 / 2012$ & 74 & 73 & 1 \\
\hline SS-4-FS & $6 / 27 / 2012$ & 620 & -- & -- \\
\hline SS-4-AD & $6 / 27 / 2012$ & 410 & -- & -- \\
\hline SS-5-FS & $6 / 27 / 2012$ & 26,000 & -- & -- \\
\hline SS-5-AD ${ }^{a}$ & $6 / 27 / 2012$ & 2,300 & 9,400 & 121 \\
\hline SS-6-FS & $6 / 27 / 2012$ & 16,000 & -- & -- \\
\hline SS-6-AD & $6 / 27 / 2012$ & 13,000 & -- & -- \\
\hline SS-1-FS & $10 / 3 / 2012$ & 4 & 4 & 0 \\
\hline SS-1-AD & $10 / 3 / 2012$ & 16 & -- & -- \\
\hline SS-2-FS & $10 / 3 / 2012$ & 52 & -- & -- \\
\hline SS-2-AD & $10 / 3 / 2012$ & 3 & -- & -- \\
\hline SS-3-FS & $10 / 3 / 2012$ & 1 & -- & -- \\
\hline SS-3-AD & $10 / 3 / 2012$ & 2 & 3 & 40 \\
\hline SS-4-FS & $10 / 3 / 2012$ & 5 & -- & -- \\
\hline SS-4-AD & $10 / 3 / 2012$ & 9 & -- & -- \\
\hline SS-5-FS ${ }^{a}$ & $10 / 3 / 2012$ & 8,800 & 16,000 & 58 \\
\hline
\end{tabular}


Table 4. Escherichia coli (E. coli) concentrations in sediment samples collected at Grand Glaize Beach (GGB) and GGB cove, 2012-13.-Continued

[USGS, U.S. Geological Survey; MWSC, Missouri Water Science Center; E. coli, Escherichia coli; CFU/g $\mathrm{g}_{\mathrm{DW}}$, colonyforming units per gram dry weight; OWML, Ohio Water Microbiology Laboratory; MPN $/ \mathrm{g}_{\mathrm{DW}}$, most probable number per gram dry weight; SS, sediment sample; $\mathrm{AD}$, ankle deep water; WD, waist deep water; --, no data; FS, foreshore; $<$, less than]

\begin{tabular}{|c|c|c|c|c|}
\hline $\begin{array}{c}\text { Site } \\
\text { identifier } \\
\text { (figure 11) }\end{array}$ & Date & $\begin{array}{c}\text { USGS MWSC } \\
\text { E. coli concentration } \\
\left(\mathrm{CFU} / \mathrm{g}_{\mathrm{DW}}\right) \text {, } \\
\text { membrane-filtration method }\end{array}$ & $\begin{array}{l}\text { USGS OWML } \\
\text { E. coli concentration } \\
\text { (MPN } / \mathrm{g}_{\mathrm{DW}} \text { ), } \\
\text { Colilert }^{\circledR} \text { method }\end{array}$ & $\begin{array}{l}\text { Relative percent } \\
\text { difference } \\
\text { (RPD) }\end{array}$ \\
\hline SS-5-AD & $10 / 3 / 2012$ & 1,000 & -- & -- \\
\hline SS-6-FS & $10 / 3 / 2012$ & 230 & -- & -- \\
\hline SS-6-AD & $10 / 3 / 2012$ & 80 & -- & -- \\
\hline SS-10-AD & $10 / 3 / 2012$ & 350 & 60 & 141 \\
\hline SS-9-AD & $10 / 3 / 2012$ & 3 & -- & -- \\
\hline SS-11-WDa & $10 / 3 / 2012$ & 47 & 18 & 89 \\
\hline SS-12-WD & $10 / 3 / 2012$ & 20 & -- & -- \\
\hline SS-13-WD & $10 / 3 / 2012$ & 260 & -- & -- \\
\hline SS-1-FS & $2 / 5 / 2013$ & $<1$ & 1 & -- \\
\hline SS-5-FS & $2 / 5 / 2013$ & $<1$ & $<1$ & -- \\
\hline Average: & & & & 92 \\
\hline
\end{tabular}

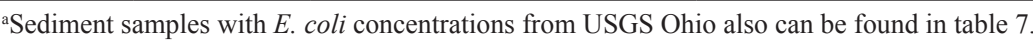

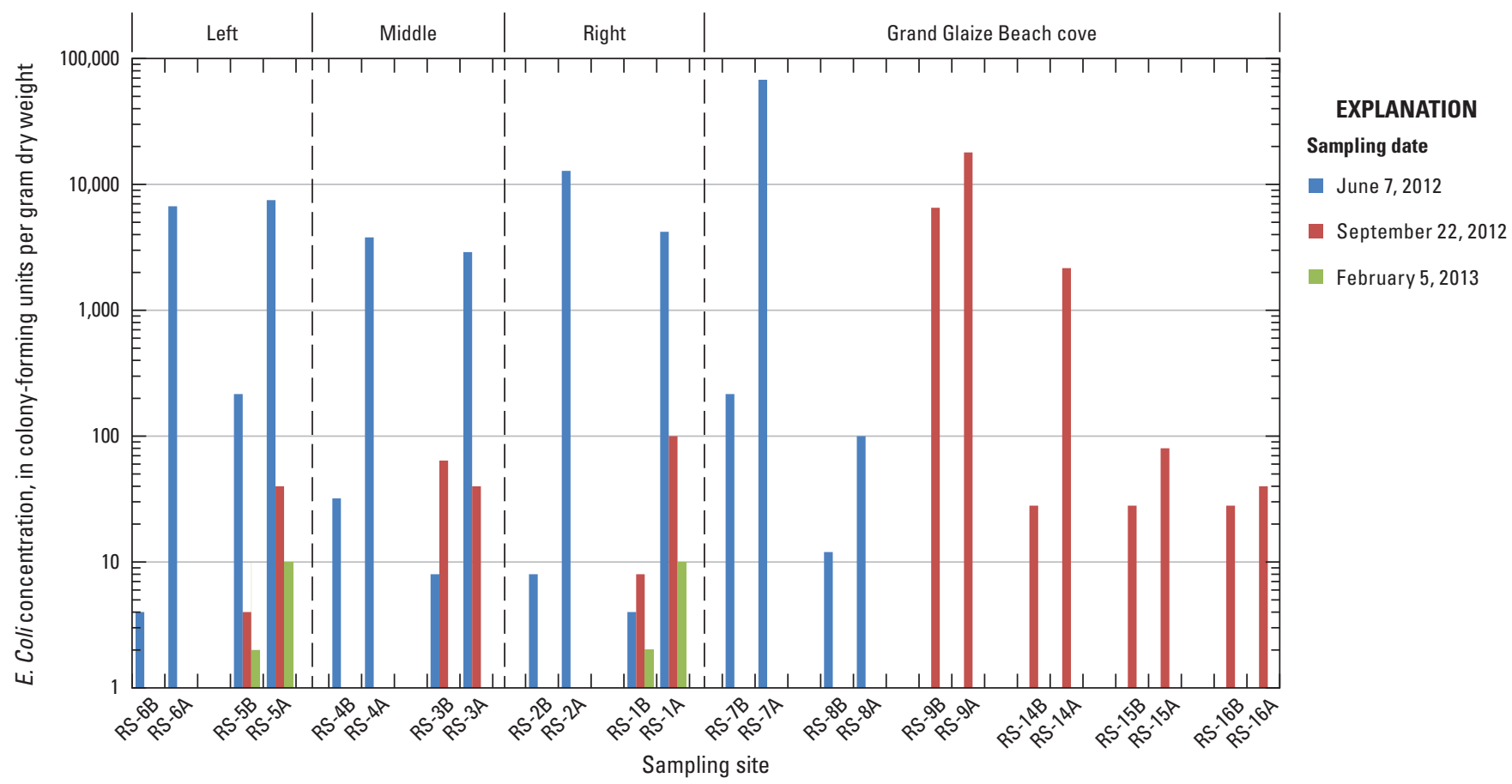

Figure 24. Escherichia coli (E. coli) concentrations in resuspended sediment samples at Grand Glaize Beach (GGB) between June 8, 2012, and February 5, 2013. Sample locations are arranged from the leftmost side to the rightmost side of GGB. Samples ending in "B" were collected before mixing and samples ending in " $A$ " were collected after mixing. 
Table 5. Escherichia coli (E. coli) concentrations in resuspended sediment samples collected at Grand Glaize Beach (GGB) and GGB cove, 2012-13.

[USGS, U.S. Geological Survey; MWSC, Missouri Water Science Center; E. coli, Escherichia coli; CFU/100 mL, colony-forming units per 100 milliliters; OWML, Ohio Water Microbiology Laboratory; MPN/100 mL, most probable number per 100 milliliters; RS, resuspended sediment; B, before mixing; <, less than; --, no data; A, after mixing]

\begin{tabular}{|c|c|c|c|c|}
\hline $\begin{array}{c}\text { Site } \\
\text { identifier } \\
\text { (figure 11) }\end{array}$ & Date & $\begin{array}{l}\text { USGS MWSC } \\
\text { E. coli concentration } \\
\text { (CFU/100 mL), } \\
\text { membrane-filtration method }\end{array}$ & $\begin{array}{l}\text { USGS OWML } \\
\text { E. coli concentration } \\
\text { (MPN/100 mL), } \\
\text { Colilert@ method }\end{array}$ & $\begin{array}{l}\text { Relative percent } \\
\text { difference } \\
\text { (RPD) }\end{array}$ \\
\hline RS-1B & $6 / 7 / 2012$ & $<4$ & -- & -- \\
\hline $\mathrm{RS}-1 \mathrm{~A}^{\mathrm{a}}$ & $6 / 7 / 2012$ & 4,200 & 440 & 162 \\
\hline RS-2B & $6 / 7 / 2012$ & 8 & -- & -- \\
\hline RS-2A & $6 / 7 / 2012$ & 13,000 & -- & -- \\
\hline RS-3B & $6 / 7 / 2012$ & 8 & -- & -- \\
\hline $\mathrm{RS}-3 \mathrm{~A}^{\mathrm{a}}$ & $6 / 7 / 2012$ & 2,900 & 220 & 172 \\
\hline RS-4B & $6 / 7 / 2012$ & 32 & -- & -- \\
\hline $\mathrm{RS}-4 \mathrm{~A}^{\mathrm{a}}$ & $6 / 7 / 2012$ & 3,800 & 1,800 & 71 \\
\hline RS-5B & $6 / 7 / 2012$ & 220 & -- & -- \\
\hline $\mathrm{RS}-5 \mathrm{~A}$ & $6 / 7 / 2012$ & 7,500 & -- & -- \\
\hline RS-6B & $6 / 7 / 2012$ & 4 & -- & -- \\
\hline $\mathrm{RS}-6 \mathrm{~A}^{\mathrm{a}}$ & $6 / 7 / 2012$ & 6,700 & 3,400 & 65 \\
\hline RS-7B & $6 / 7 / 2012$ & 220 & -- & -- \\
\hline RS-7A & $6 / 7 / 2012$ & 68,000 & -- & -- \\
\hline $\mathrm{RS}-8 \mathrm{~B}$ & $6 / 7 / 2012$ & 12 & -- & -- \\
\hline RS-8A & $6 / 7 / 2012$ & 100 & -- & -- \\
\hline RS-9B & $9 / 22 / 2012$ & 6,500 & -- & -- \\
\hline RS-9A & $9 / 22 / 2012$ & 18,000 & -- & -- \\
\hline RS-14B & $9 / 22 / 2012$ & 28 & -- & -- \\
\hline RS-14A & $9 / 22 / 2012$ & 2,200 & -- & -- \\
\hline RS-15B & $9 / 22 / 2012$ & 28 & -- & -- \\
\hline RS-15A & $9 / 22 / 2012$ & 80 & -- & -- \\
\hline RS-16B & $9 / 22 / 2012$ & 28 & -- & -- \\
\hline RS-16A & $9 / 22 / 2012$ & 40 & -- & -- \\
\hline RS-1B & $9 / 22 / 2012$ & 8 & -- & -- \\
\hline RS-1A & $9 / 22 / 2012$ & 100 & -- & -- \\
\hline RS-3B & $9 / 22 / 2012$ & 64 & -- & -- \\
\hline RS-3A & $9 / 22 / 2012$ & 40 & -- & -- \\
\hline RS-5B & $9 / 22 / 2012$ & 4 & -- & -- \\
\hline RS-5A & $9 / 22 / 2012$ & 40 & -- & -- \\
\hline RS-1B & $2 / 5 / 2013$ & 2 & 3 & 40 \\
\hline RS-1A & $2 / 5 / 2013$ & 10 & $<1$ & -- \\
\hline RS-5B & $2 / 5 / 2013$ & 2 & $<1$ & -- \\
\hline RS-5A & $2 / 5 / 2013$ & 10 & $<1$ & -- \\
\hline Average: & & & & 102 \\
\hline
\end{tabular}

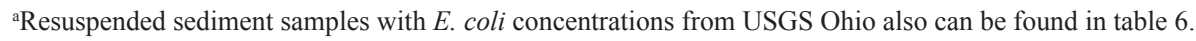


(250 CFU/100 mL on May 26, 2012); however, the MDNR weekly sample measured that week was below the standard.

Cove geometry and commercial development seemed to affect water movement and E. coli transport. Escherichia coli concentrations at sites B1-L and B1-R at PB1 (average of $31 \mathrm{CFU} / 100 \mathrm{~mL}$ ) were significantly larger than at the background site at Camp Rising Sun Beach (RS-B) ( $p$-value $=0.026 ; 13 \mathrm{CFU} / 100 \mathrm{~mL}$; fig. 25) likely due to the fact that RS-B is substantially less populated and developed in comparison to PB1 and RS-B is located farther downstream. Comparing PB1 to GGB, located in a cove with a substantially different geometry, E. coli concentrations at sites B1-L and B1-R at PB1 were significantly smaller than at sites GB-L and GB-R at GGB (p-value $=0.000$; average of $210 \mathrm{CFU} / 100 \mathrm{~mL}$ ), most likely due to the fact that $\mathrm{PB} 1$ is located on the main arm of the lake and has more volumetric flushing (smaller residence time) than GGB. GGB also is located in a long, narrow cove that limits mixing with water from the main arm of the lake, has adjacent tributaries, and has more intense nearby development than PB1. Although samples were not collected at PB1 for grain-size analyses, another potential explanation may be that the coarse and more gravelly sediments visually observed at PB1 have smaller $E$. coli concentrations than the fine sand at GGB. Despite having significantly smaller $E$. coli concentrations, the turbidity samples from PB1 (average of 12 NTU) were significantly larger than GGB samples (p-value $=0.000$; average of $5.3 \mathrm{NTU}$ ), indicating that the traditional positive correlation between E. coli and turbidity is not the dominant relation at both beaches.

Spatial analysis of PB1 indicates that $E$. coli concentrations are smaller at the beach than nearby shoreline areas, suggesting that during the mostly nonrunoff period sampled, activity at B1-L and B1-R at PB1 and the immediate areas around the beach likely is not a substantial source of $E$. coli in contrast to what was observed at GGB. The largest concentrations were measured at sites B1-OUT (average of $280 \mathrm{CFU} / 100 \mathrm{~mL}$ ) and B1-P (average of $180 \mathrm{CFU} / 100 \mathrm{~mL}$ ), a site near a wastewater treatment outfall $0.25 \mathrm{mi}$ downstream from PB1 and a location about 0.5 mi upstream from PB1, respectively (fig. 8). Although E. coli concentrations at site B1-OUT were substantially larger than at PB1, they were not significantly different during the nonrunoff period sampled. Escherichia coli concentrations at site B1-P were significantly larger than sites B1-L and B1-R at PB1 (p-values $=0.000)$ possibly because of the close proximity of site B1-P to the Grand Glaize arm inflow, shallower (less than 3-ft deep) water, and finer-grained silty sediments observed at site B1-P compared to the coarser and more sandy sediments observed at beach sites B1-L and B1-R. In fact, turbidity values in samples from site B1-P (average of 15 NTU) were significantly larger

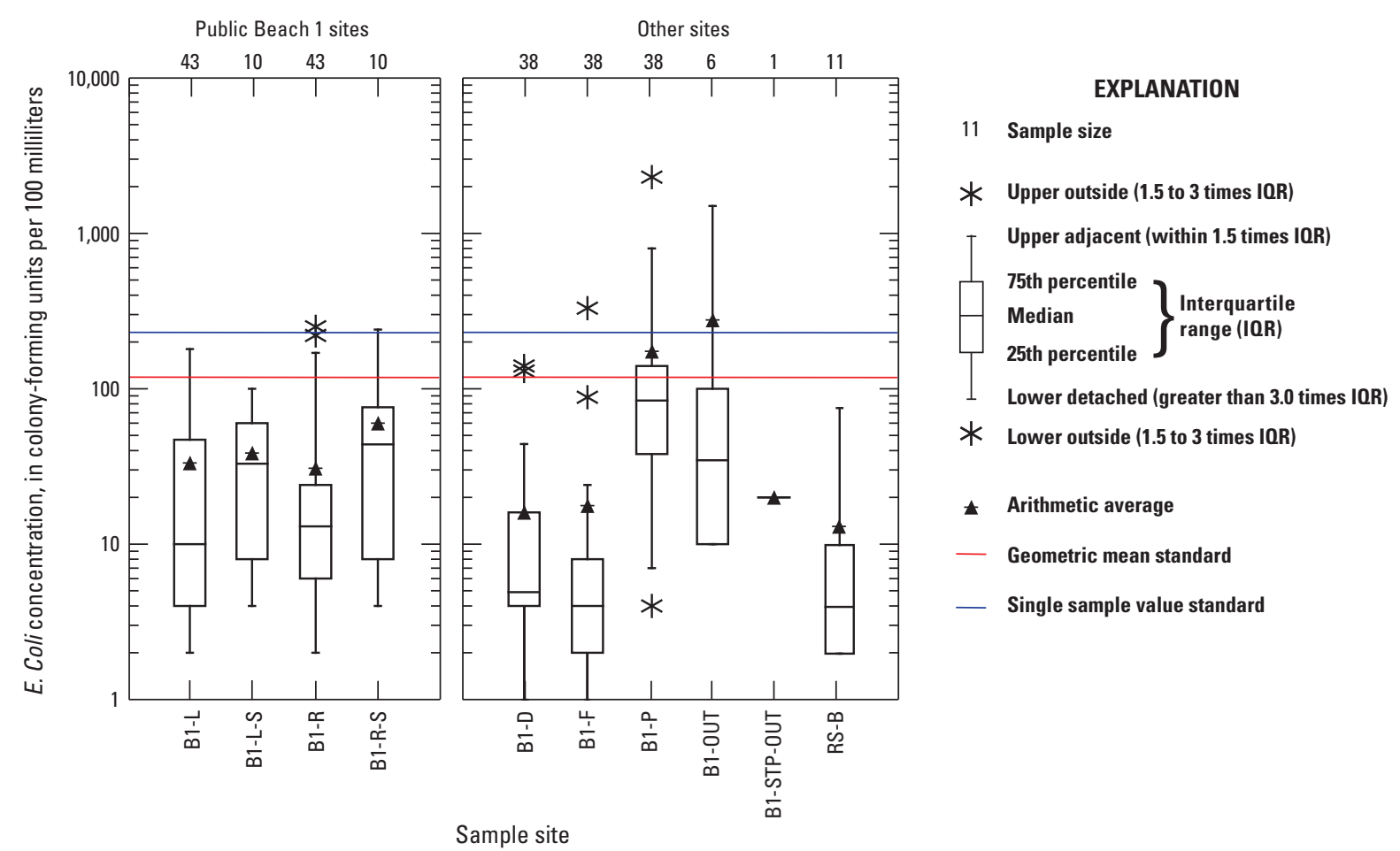

Figure 25. Concentrations of Escherichia coli (E. coli) in water samples collected during 2012 from Public Beach 1 (PB1) and vicinity, Lake of the Ozarks State Park, Missouri. 
than at sites B1-L and B1-R ( $\mathrm{p}$-value $=0.000 ; 12$ NTU). Concentrations of E. coli at sites B1-D and B1-F located adjacent to PB1 (fig. 8) were significantly smaller ( $p$-value $=0.000$ ) than at sites B1-L and B1-R possibly because of the absence of bathers or deeper water compared to the beach sample sites.

\section{Use of Microbial Source Tracking to Aid in Determining Escherichia coli Origins}

Of the 72 water samples, 19 sediment samples, and 10 fecal source samples collected, a total of 46 water, 17 sediment, and 7 source samples were selected by the MWSC and the OWML for analysis of E. coli as well as four MST markers: GenBac, a general Bacteroides marker; HF183, a human-associated marker; BoBac, a ruminant-associated marker and GFD, a waterfowl-associated marker. Escherichia coli concentrations in water samples measured by the MWSC using membrane filtration were well-correlated $(\rho=0.958$; p-value $=0.000)$ with $E$. coli concentrations measured by the OWML using the Colilert Quanti-Tray $/ 2000^{\circledR}$ method and had a low average RPD of 35 percent with a range of 2 to 111 percent (table 6). This low RPD value indicates that although two different enumeration methods were used, similar results were obtained for water samples. Escherichia coli concentrations in sediment samples also were well-correlated $(\rho=0.879 ; p$-value $=0.000)$, were not significantly different $(p$-value $=0.776)$ likely because of the inherent spatial variability of $E$. coli in beach sand and sediment, but had a high average RPD of 92 percent with a range of 0 to 188 percent (table 4). In contrast, E. coli concentrations in resuspended sediment samples reported by the MWSC were significantly larger than those reported by the OWML $(p$-value $=0.021)$ and also had a high average RPD of 102 percent and a range of 40 to 172 percent (table 5). This difference in E. coli concentrations in resuspended sediment is potentially a result in sample collection, because resuspended sediment samples were collected sequentially with MWSC samples collected before OWML samples, thus more sediment, and attached bacteria, may have settled before the OWML samples bottles were filled. In addition, the MWSC membrane-filtration samples were analyzed within 6 hours of collection compared to the OWML Colilert ${ }^{\mathbb{R}}$ samples, which were analyzed more than 24 hours after collection.

A total of four goose and two vulture fecal source samples were collected from GGB and analyzed for E. coli concentrations and the four MST markers. The average $E$. coli concentration in goose feces was $1.0 \times 10^{6} \mathrm{MPN} / \mathrm{g}_{\mathrm{DW}}$. Both the GenBac and GFD markers were detected in all four goose fecal samples with average concentrations of $2.4 \times 10^{10}$ and $7.7 \times 10^{10} \mathrm{MPN} / \mathrm{g}_{\mathrm{DW}}$, respectively. The HF183 marker was not detected in these four samples; however, the BoBac marker was detected in two samples: one at 2 percent of the average GFD marker concentration and the other at a concentration that was greater than the GFD marker. It is not uncommon for markers to be detected in fecal samples associated with other hosts. In some cases, this may occur because different species cohabitate in close proximity with one another and, in other cases, the qPCR assay lacks specificity and can cross-react with genetic material from other hosts. In addition, the humanassociated marker is more sensitive and selective compared to the waterfowl-associated marker, limiting quantitative interpretation of results (Green and others, 2012). Nevertheless, the general absence of ruminant (deer) fecal matter observed at GGB casts considerable uncertainty on BoBac marker detections as a reliable indicator of ruminant fecal loading in this study. Instances where large GenBac marker concentrations were measured in environmental samples with little detection of the other markers are most likely explained by the GenBac marker reacting with the genetic material of Bacteroides from hosts (such as dogs or wildlife) other than the three general groups examined in this study, or possibly the low sensitivity of the source markers examined to specific source groups in the study area. The two vulture fecal samples contained an average $E$. coli concentration of $9.7 \times 10^{5} \mathrm{MPN} / \mathrm{g}_{\mathrm{DW}}$ and contained both the GenBac and GFD markers, with average concentrations of $9.1 \times 10^{8}$ and $8.6 \times 10^{5} \mathrm{MPN} / \mathrm{g}_{\mathrm{DW}}$, respectively. The HF183 and BoBac markers were not detected in these samples. Poor storage of MST samples on May 26 might explain the generally small GenBac marker concentrations associated with that date.

\section{Grand Glaize Beach}

Of the 46 water and 17 sediment samples collected at GGB and GGB cove, 41 water samples and 16 sediment samples were submitted for MST. Of the 41 water samples, 30 were routine water samples, 4 were resuspended sediment samples, and 7 were samples collected in the west tributary. MST marker detections, other than GenBac, in sediment samples primarily consisted of GFD and BoBac detections (table 7); whereas, marker detections in water samples were mixed and no marker was dominant (table 6).

Markers present in water samples collected at GGB had human- and waterfowl-associated markers and reflect well the type of contamination expected. Of the 30 routine water samples, 11 contained detectable concentrations of the HF183 marker, 10 contained the GFD marker, and 5 contained the BoBac marker (fig. 26). These detections corroborate well with field observations that beaches typically were populated with bathers and geese or vultures.

MST results of sediment samples indicated a predominance of the waterfowl-associated marker. Of the 16 sediment samples analyzed at GGB, the GFD marker was detected in 14 samples, the BoBac marker was detected in 6 samples, and the HF183 marker was detected in only 1 sample. The large frequency of GFD marker detections in sediment samples is consistent with field observations of goose and vulture feces at GGB beach and indicates that $E$. coli contamination in sediments during 2012 most likely originated from goose and vulture feces. Historical beach grooming practices tended to 
Table 6. Concentrations of Escherichia coli (E. coli) and genetic markers and relative percent difference between concentrations of E. coli in U.S. Geological Survey (USGS) Missouri Water Science Center (MWSC) and USGS Ohio Water Microbiology Laboratory (OWML) samples in water, resuspended sediment, and runoff samples collected at Public Beach 1, Grand Glaize Beach (GGB), and GGB cove, 2012.

[USGS, U.S. Geological Survey; MWSC, Missouri Water Science Center; E. coli, Escherichia coli; CFU/100 mL, colony-forming units per 100 milliliters; OWML, Ohio Water Microbiology Laboratory; MPN/100 mL, most probable number per 100 milliliters; NTU; Nephelometric Turbidity Unit; GenBac, general Bacteroides genetic marker; HF183, human-associated genetic marker; BoBac, ruminant-associated genetic marker; GFD, waterfowl-associated genetic marker; W, water; E, estimated; BDL, below detection limit; --, no data; RS, resuspended sediment; R, runoff]

\begin{tabular}{|c|c|c|c|c|c|c|c|c|c|c|}
\hline \multirow{2}{*}{$\begin{array}{c}\text { Sample } \\
\text { type } \\
\text { (figures } \\
8 \text { or 11) }\end{array}$} & \multirow{2}{*}{$\begin{array}{c}\text { Site } \\
\text { identifier }\end{array}$} & \multirow{2}{*}{ Date } & \multirow{2}{*}{$\begin{array}{c}\text { USGS MWSC } \\
\text { E. coli } \\
\text { concentration } \\
\text { (CFU/100 mL), } \\
\text { membrane- } \\
\text { filtration method }\end{array}$} & \multirow{2}{*}{$\begin{array}{c}\text { USGS OWML } \\
\text { E. coli } \\
\text { concentration } \\
\text { (MPN/100 mL), } \\
\text { Colilert }{ }^{\circledR} \\
\text { method }\end{array}$} & \multirow{2}{*}{$\begin{array}{c}\text { Relative } \\
\text { percent } \\
\text { difference } \\
\text { (RPD) }\end{array}$} & \multirow{2}{*}{$\begin{array}{c}\text { Turbidity } \\
\text { (NTU) }\end{array}$} & \multicolumn{4}{|c|}{ Genetic marker, in copies per 100 milliliters } \\
\hline & & & & & & & GenBac & HF183 & BoBac & GFD \\
\hline \multicolumn{11}{|c|}{ Public Beach 1} \\
\hline W & B1-P & $6 / 21 / 2012$ & 210 & 190 & 10 & 12 & 51,000 & 4,400 & BDL & BDL \\
\hline W & B1-R & $5 / 26 / 2012$ & 250 & -- & -- & 11 & $740 \mathrm{E}$ & BDL & BDL & BDL \\
\hline W & $\mathrm{B} 1-\mathrm{R}$ & $6 / 21 / 2012$ & 40 & 36 & 9 & 8 & 9,000 & BDL & BDL & BDL \\
\hline W & BI-R & $5 / 17 / 2012$ & 16 & 18 & 12 & 10 & 4,200 & $190 \mathrm{E}$ & BDL & BDL \\
\hline $\mathrm{W}$ & GI-L & $6 / 30 / 2012$ & 40 & -- & -- & 12 & $1,300 \mathrm{E}$ & $\mathrm{BDL}$ & BDL & $\mathrm{BDL}$ \\
\hline $\mathrm{W}$ & GI-L & $7 / 4 / 2012$ & 14 & -- & -- & 7 & 7,300 & $\mathrm{BDL}$ & $78 \mathrm{E}$ & $\mathrm{BDL}$ \\
\hline $\mathrm{W}$ & GB-L & $5 / 17 / 2012$ & 87 & 100 & 14 & 7 & 7,600 & $\mathrm{BDL}$ & BDL & $\mathrm{BDL}$ \\
\hline $\mathrm{W}$ & GB-L & $5 / 26 / 2012$ & 9,200 & -- & -- & 15 & 3,700 & $96 \mathrm{E}$ & BDL & $32 \mathrm{E}$ \\
\hline W & GB-L & $5 / 31 / 2012$ & 68 & 39 & 53 & 9 & 5,300 & BDL & BDL & $48 \mathrm{E}$ \\
\hline W & GB-L & $6 / 21 / 2012$ & 850 & 550 & 43 & 5 & 24,000 & $240 \mathrm{E}$ & BDL & $96 \mathrm{E}$ \\
\hline W & GB-L & $6 / 23 / 2012$ & 500 & -- & -- & 7 & $1,000 \mathrm{E}$ & $96 \mathrm{E}$ & BDL & BDL \\
\hline W & GB-R & $5 / 26 / 2012$ & 5,200 & -- & -- & 16 & $2,900 \mathrm{E}$ & BDL & BDL & $40 \mathrm{E}$ \\
\hline W & GB-R & $5 / 31 / 2012$ & 20 & 12 & 48 & 6 & 12,000 & $170 \mathrm{E}$ & $220 \mathrm{E}$ & BDL \\
\hline W & GB-R & $6 / 23 / 2012$ & 140 & -- & -- & 7 & 7,700 & $72 \mathrm{E}$ & BDL & BDL \\
\hline W & GB-R & $6 / 30 / 2012$ & 80 & -- & -- & 14 & $380 \mathrm{E}$ & $120 \mathrm{E}$ & BDL & BDL \\
\hline W & GB-R & $7 / 4 / 2012$ & 76 & -- & -- & 15 & 2,100 & BDL & BDL & BDL \\
\hline W & GB-R & $8 / 31 / 2012$ & 180 & -- & -- & -- & $1,100 \mathrm{E}$ & BDL & BDL & BDL \\
\hline W & GB-R & $8 / 31 / 2012$ & 430 & -- & -- & -- & $870 \mathrm{E}$ & BDL & BDL & BDL \\
\hline W & GB-R & $9 / 2 / 2012$ & 55 & -- & -- & -- & $800 \mathrm{E}$ & $80 \mathrm{E}$ & BDL & BDL \\
\hline W & GI-R & $5 / 17 / 2012$ & 490 & 480 & 2 & 5 & 56,000 & BDL & $350 \mathrm{E}$ & $170 \mathrm{E}$ \\
\hline
\end{tabular}


Table 6. Concentrations of Escherichia coli (E. coli) and genetic markers and relative percent difference between concentrations of E. coli in U.S. Geological Survey (USGS) Missouri Water Science Center (MWSC) and USGS Ohio Water Microbiology Laboratory (OWML) samples in water, resuspended sediment, and runoff samples collected at Public Beach 1, Grand Glaize Beach (GGB), and GGB cove, 2012.-Continued

[USGS, U.S. Geological Survey; MWSC, Missouri Water Science Center; E. coli, Escherichia coli; CFU/100 mL, colony-forming units per 100 milliliters; OWML, Ohio Water Microbiology Laboratory; MPN/100 mL, most probable number per 100 milliliters; NTU; Nephelometric Turbidity Unit; GenBac, general Bacteroides genetic marker; HF183, human-associated genetic marker; BoBac, ruminant-associated genetic marker; GFD, waterfowl-associated genetic marker; W, water; E, estimated; BDL, below detection limit; --, no data; RS, resuspended sediment; R, runoff]

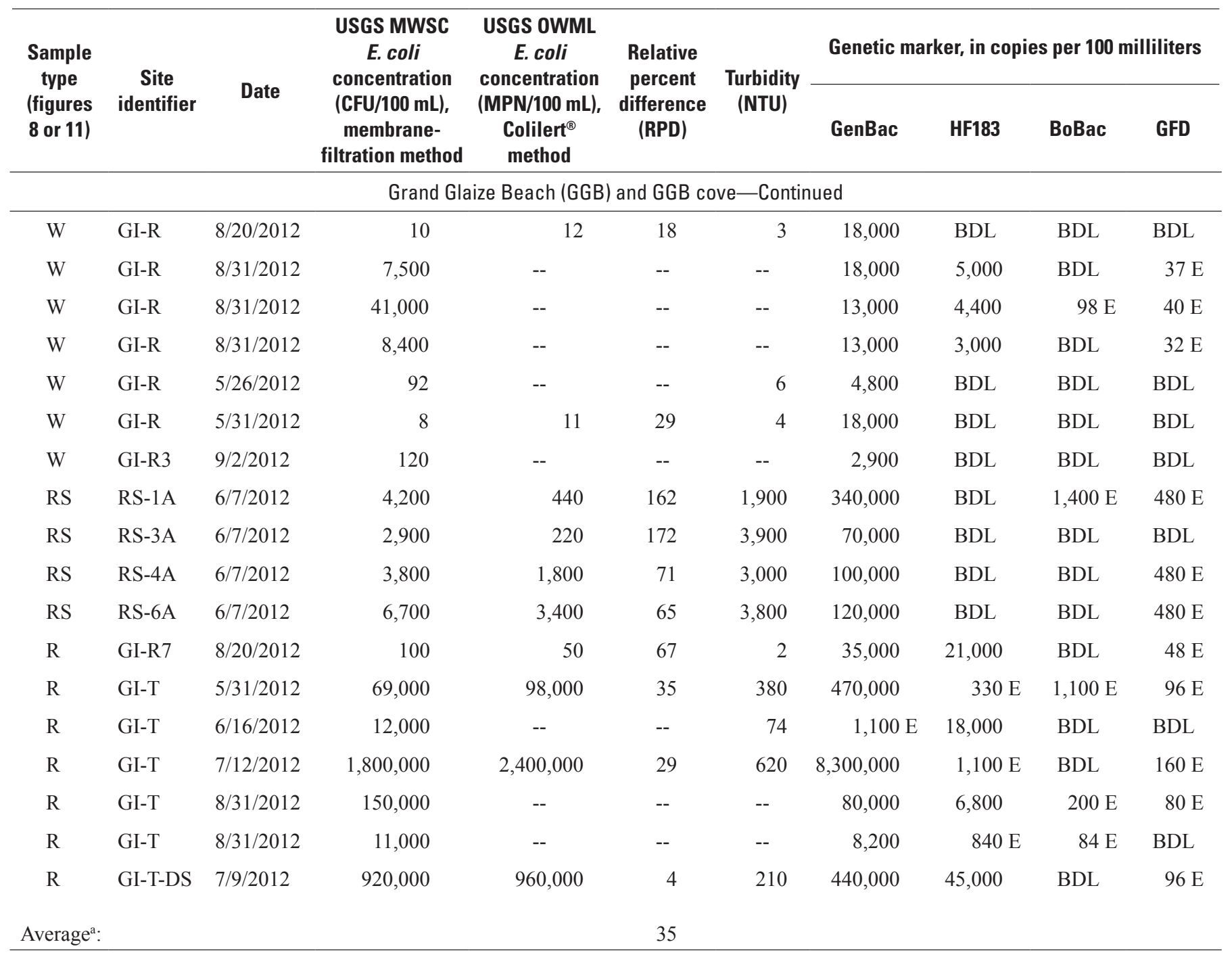

${ }^{a}$ The RPD average is calculated only on the water and runoff samples and not the resuspension samples. 
Table 7. Concentrations of Escherichia coli (E. coli) and genetic markers and relative percent difference between concentrations of E. coli in U.S. Geological Survey (USGS) Missouri Water Science Center (MWSC) and USGS Ohio Water Microbiology Laboratory (OWML) samples in sediment samples collected at Public Beach 1, Grand Glaize Beach (GGB), and GGB cove, 2012.

[USGS, U.S. Geological Survey; MWSC, Missouri Water Science Center; E. coli, Escherichia coli; CFU/g ${ }_{\mathrm{DW}}$, colony-forming units per gram dry weight; OWML, Ohio Water Microbiology Laboratory; MPN $/ \mathrm{g}_{\mathrm{DW}}$, most probable number per gram dry weight; GenBac, general Bacteroides genetic marker; HF183, human-associated genetic marker; BoBac, ruminant-associated genetic marker; GFD, waterfowl-associated genetic marker; SS, sediment sample; AD, ankle deep water; --, no data; BDL, below dection limit; E, estimated; FS, foreshore; WD, waist deep water]

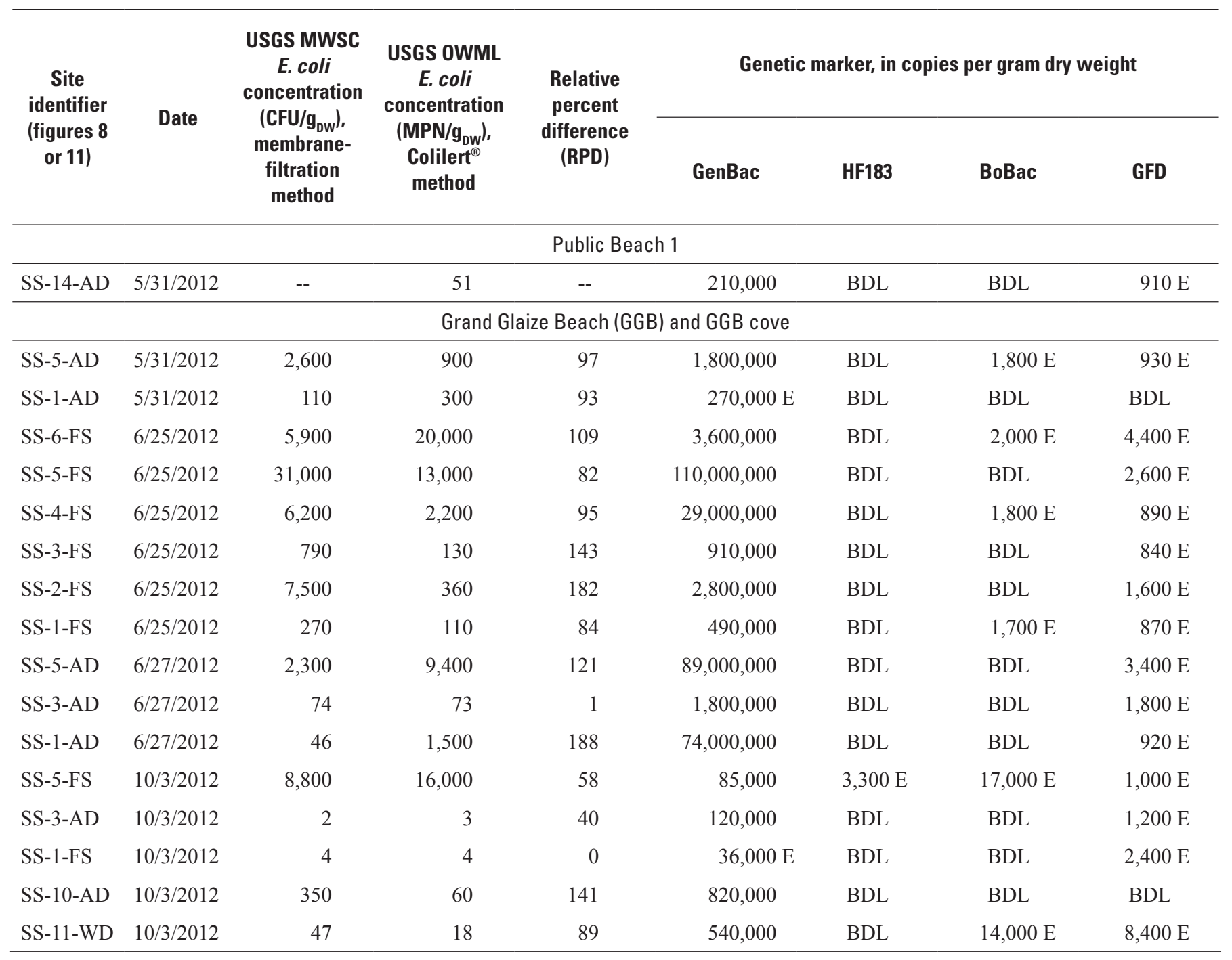



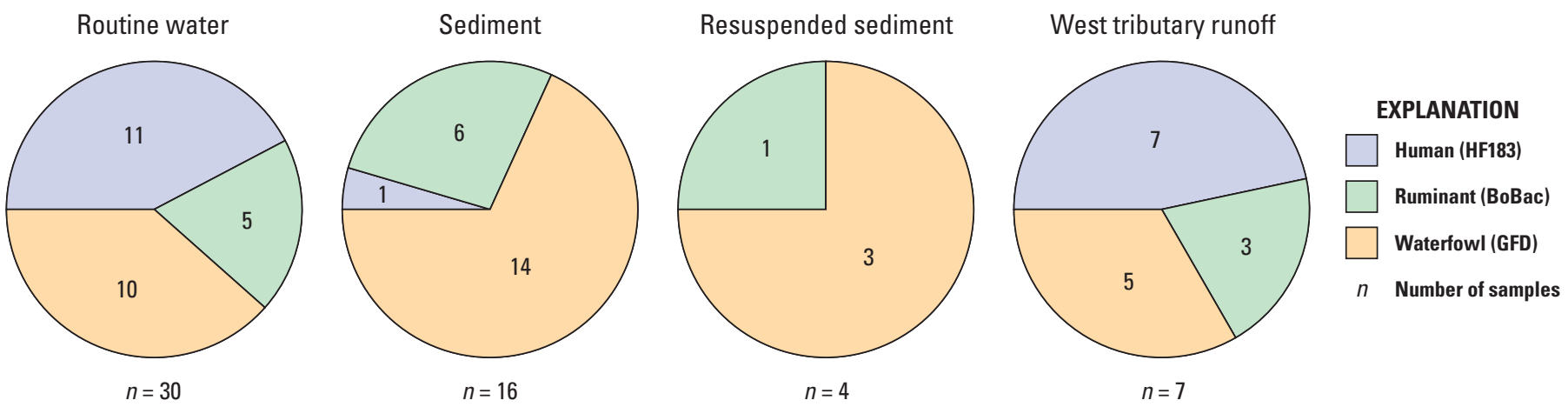

Figure 26. Total number of microbial source tracking (MST) markers detected in routine water, sediment, resuspended sediment, and west tributary runoff samples at Grand Glaize Beach (GGB) and GGB cove, 2012.

bury fecal matter, protecting fecal organisms from exposure to sunlight and drying and possibly prolonging their survival.

MST results from the four resuspended sediment samples matched the results from the sediment analysis and indicated a predominance of the GFD marker. Of the four resuspended sediment samples, the GFD marker was detected in three samples, the BoBac marker was detected in one sample, and the HF183 marker was not detected. Frequent occurrences of the waterfowl-associated marker in resuspended sediment and sediment samples supports the hypothesis that goose and vulture fecal matter is harbored in sediment and is present in the water column after resuspension of sediments by bathers.

Water samples from the west tributary had detections of the HF183 marker consistent with substantial E. coli concentrations downstream from soils recently disturbed during removal of the septic tank at the seasonal residence. Of the seven west tributary samples collected, all contained detectable concentrations of the HF183 marker, five contained the GFD marker, and three contained the BoBac marker. West tributary samples contained the highest concentrations of the HF183 marker and largest $E$. coli concentrations in water samples collected during this study. A sample from GI-T-DS contained the largest HF183 marker concentration detected and had E. coli concentrations indicative of raw sewage $(920,000 \mathrm{CFU} / 100 \mathrm{~mL})$. These large detections of HF183 markers corroborate field measurements in the west tributary during several minor rainfall events, where local runoff from the seasonal residence area contained substantial E. coli concentrations. The markers used in these MST assays do not encompass all fecal hosts present in the watershed, and it is likely that other origins of fecal contamination (hosts) not measured in this study are present in the west tributary and contribute to the $E$. coli loading during runoff events.

Low lake levels during the fall, winter, and spring constrict the inundated area near GGB so that inflow from the west tributary is directed away from GGB toward site GI-R3, and E. coli-contaminated sediment from the west tributary likely is not deposited along much of the beach because it is above water and dry during that time (fig. 10). During periods of lower lake stage, most of the sediment from the west tributary probably is deposited away from the beach as the inflow moves in a counterclockwise manner traveling along the south shore past site GI-R3 toward the swimming boom; however, some sediment from the west tributary eventually may be deposited at the beach during larger runoff events. The lack of tributary loading into GGB cove before the Hurricane Isaac event and the low lake stage associated with the event could be the cause for the absence of the HF183 marker in any sediment samples from GGB before Hurricane Isaac and the presence of the HF183 marker in one nearshore sediment sample after Hurricane Isaac.

Microbial source tracking adds to the spatial and temporal evidence supporting the hypothesis that bathers at GGB resuspend E. coli-contaminated sediment resulting in increased E. coli concentrations in the water column. Spatial and temporal analyses of routine water samples indicated that E. coli are concentrated at locations closer to GGB, suggesting a local source, and that the total number of bathers was correlated with E. coli concentration. Sediment and resuspended sediment analyses indicated that $E$. coli concentrations in sediment at GGB were large, representing a substantial E. coli source, and contribute to significant increases in E. coli concentration in the water column when resuspended. The predominance of the waterfowl-associated marker in nearshore sediments was consistent with field observations of goose and vulture fecal matter in sediment, especially in the left and middle areas of the beach, indicating that the source of $E$. coli contamination in the sediment was from goose and vulture feces. Analysis of water pooled after minor rainfall events that generated only local runoff in the west tributary indicated substantial $E$. coli contamination originating from disturbed soils and shallow groundwater from the recent removal of 
a septic tank at a seasonal residence near GGB. MST confirmed $E$. coli contamination in pooled samples was of human origin as all MST samples collected from the west tributary contained the human-associated marker (HF183) and at the largest concentrations of all samples collected during this study. However, during 2012 the west tributary may not have contributed substantially to E. coli loading of nearshore sediment at GGB because the waterfowl-associated marker was predominate in sediments at GGB, and the human-associated marker was detected in only one sample, which was collected after Hurricane Isaac. Integrating spatial, temporal, and MST studies, data collected during this study indicate that an important source of $E$. coli contamination at GGB during 2012 was E. coli released into the water column by bathers resuspending E. coli contaminated sediments, especially during high-use days early in the recreational season. The predominate origin of the $E$. coli in the sediments appears to be from geese and vultures that frequent the beach, especially during the winter and early spring when lake water levels are low and sediments exposed. Additional contributions of $E$. coli from other sources within the west and east tributary watersheds occur during runoff events, which cause inflow of runoff into GGB cove.

\section{Public Beach 1}

Of the five water samples collected at PB1 no waterfowl- or ruminant-associated markers were detected; however, the human marker (HF183) was detected in three of the five samples collected. The largest HF183 marker concentration was collected at site B1-OUT (the outfall of a nearby wastewater treatment plant) and had an associated $E$. coli concentration of 1,500 CFU/100 mL. The other two water samples with HF183 detections were collected at sites B1-P and B1-R. The concentration of the HF183 marker in the B1-P sample was comparable to site B1-OUT, and the associated E. coli concentration was $210 \mathrm{CFU} / 100 \mathrm{~mL}$; whereas, the HF183 marker and E. coli concentrations at site B1-R were an order of magnitude smaller. One sediment sample (site SS-14-AD) was collected at PB1 for analysis for MST markers, and only the waterfowl marker was detected (table 7). Although overall E. coli concentrations in water samples collected from PB1 during 2012 were generally well below standards, analysis of water samples for MST markers and E. coli suggests that E. coli contamination at PB1 may be caused by contamination from the nearby downstream wastewater treatment plant as a clockwise recirculation patterns indicated by the MDNR dye trace could transport wastewater upstream to the beach. Although contamination through this connection was not substantial during the nonrunoff period of this study, it may become an important contributor to $E$. coli loading at $\mathrm{PB} 1$ during major runoff events.

\section{Summary and Conclusions}

Based on correlations between Escherichia coli (E. coli) and gastroenteritis rates from epidemiological studies, E. coli is used as an indicator organism for the presence of pathogens at freshwater beaches. In the past several years, the Missouri Department of Natural Resources (MDNR) had to implement several beach closures at two public beaches, Grand Glaize Beach (GGB) and Public Beach 1 (PB1), at Lake of the Ozarks State Park (LOSP) in Osage Beach, Missouri due to exceedances of the established E. coli standard. In 2011, GGB was closed for more than one-third of the recreational season. In response to the controversy with beach closures at LOSP as well as new U.S. Environmental Protection Agency water-quality criteria, bills were passed in July 2013, causing Missouri State Parks to change from a beach closure policy to one that directed each state park to post advisories when monitoring results exceeded the established standard for E. coli bacteria.

As a result of beach closures, the U.S. Geological Survey (USGS), in cooperation with the MDNR, and in collaboration with Missouri University of Science and Technology, conducted an investigation into the occurrence and origin of E. coli at GGB and PB1 that spanned two summers between August 2011 and February 2013. The study included a summary of historical beach monitoring data collected by the MDNR and included the collection of more than 1,300 water, sediment, and fecal source samples from the two beaches and vicinity. Surface-water and sediment samples at and in the vicinity of GGB and PB1 were collected and analyzed for $E$. coli concentrations for a variety of environmental and hydrologic conditions. Spatial and temporal patterns in E. coli concentrations in water and sediments combined with measurements of environmental variables, beach-use patterns, and MDNR water-tracing results were used to identify possible sources of $E$. coli contamination at the two beaches and to corroborate microbial source tracking (MST) sampling efforts.

The following two field studies were completed: a reconnaissance study during late-summer and fall 2011, and an intense monitoring study during the 2012 recreational season. During 2011, water samples were collected at GGB, GGB cove, and nearby coves, and those results were used to design an intensive study at GGB and PB1 during the 2012 recreational season. Sampling during the 2012 season was organized into one of three sampling trips referred to as routine, intensive, and runoff trips. Intensive sampling events (multiple samples per day) were conducted on low-traffic weekdays, higher traffic weekends, and the three major holidays (Memorial Day, Independence Day, and Labor Day) during the recreational season. Runoff sampling events focused on capturing the effect of stormwater runoff. 
As part of an effort to determine the origin of bacterial contamination at LOSP swimming beaches, the MDNR Geological Survey Program injected fluorescent dye at various locations in wastewater systems near GGB and PB1. Results indicated that a hydrologic connection existed between nearby wastewater systems and the beach at both GGB and PB1.

Results from the 2011 reconnaissance study indicate that water samples from GGB cove contained significantly larger $E$. coli concentrations than two nearby mostly undeveloped coves and were largest at sites at the upper end of GGB cove. As the lake level declined later in the season, the lake shoreline receded and samples from pools in the lower reach of the west tributary that enters GGB cove adjacent to GGB contained large E. coli concentrations [20 to 4,800 colonyforming units per 100 milliliters $(\mathrm{CFU} / 100 \mathrm{~mL})]$, small temperatures $\left[14.1\right.$ degrees Celsius $\left.\left({ }^{\circ} \mathrm{C}\right)\right]$, and large specific conductance values (444 microsiemens per centimeter at 25 degrees Celsius $\left[\mu \mathrm{S} / \mathrm{cm}\right.$ at $\left.25^{\circ} \mathrm{C}\right]$ ) compared to samples from GGB indicating a possible shallow groundwater source of the E. coli. These results indicate a probable local source of E. coli contamination within the upper part of GGB cove.

Results from the 2012 intensive study indicate that $E$. coli concentrations in water samples from GGB cove (average $=380 \mathrm{CFU} / 100 \mathrm{~mL}$ ) were significantly larger than samples from nearby undeveloped cove A (average $=89 \mathrm{CFU} / 100 \mathrm{~mL}$ ) and were significantly larger in ankle-deep water than waist-deep water. Overall, concentrations of $E$. coli in water samples from GGB trended downward during the 2012 recreational season, significantly increased with an increase in the total number of bathers at the beach, and were largest in the middle of the day. After an initial spike of 9,200 CFU/100 mL the Saturday of Memorial Day weekend (May 26, 2012), the first high-use day of the season, subsequent spikes in E. coli concentrations decreased in amplitude when comparing high-use days. On these days turbidity and the total numbers of bathers were similar or larger than May 26, yet $E$. coli concentrations were nearly an order of magnitude smaller. The observed decline in E. coli concentrations on high-use days despite steady bather activity and turbidity on high use days during the 2012 recreational season and the strong correlation between turbidity and total number of bathers (Spearman's rho $=0.637$ ) indicated that bather activity, rather than the bathers themselves, may be an important component of the observed spikes in E. coli concentrations through resuspension and mobilization of E. coli-contaminated sediment.

Using the daily maximum $E$. coli values from the two MDNR sites at GGB, 9 of the 45 days sampled by the (USGS) exceeded the single sample value, and there were significantly more exceedances on weekends than weekdays. A comparison was made using USGS daily maximum $E$. coli concentrations from the two GGB sites (GB-L and GB-R) to determine the accuracy of weekly 2012 MDNR monitoring results to correctly forecast single sample standard exceedances on days that the USGS sampled. Most closures were correctly predicted by MDNR; however, more than one-third of daily samples collected on weekends were false negatives (MDNR weekly sample did not exceed the single sample standard but a USGS sample on one or more days that week did). These results along with other studies and the variation of $E$. coli concentrations measured at GGB on single days during this study indicate that fecal bacteria concentrations at public swimming beaches vary by orders of magnitude not only dayby-day but also within a given day making weekly forecasting potentially problematic and inaccurate.

Weather in the LOSP region included an extreme drought during 2012, and the only rainfall event that produced measurable inflow into GGB cove was the remnants of Hurricane Isaac that hit the region on August 31, 2012. Sampling of minor rainfall events that resulted in only localized runoff in the west tributary adjacent to GGB indicated large $E$. coli concentrations and, on several occasions, $E$. coli concentrations indicative of raw sewage (as large as 2,400,000 CFU/100 mL) related to contamination from soils disturbed during the removal of a septic tank at a nearby seasonal residence in early May 2012. The fact that the seasonal residence had not been used since 2010 indicates that $E$. coli in the former tank or soils and shallow groundwater within the drain field have remained viable for nearly 2 years.

On August 31, 2012, major rainfall (1.81 inches in 19 hours) brought by Hurricane Isaac occurred at GGB cove with most of the rainfall falling during a 2-hour period. Continuous water-quality monitors at GGB indicated that runoff inflow bypassed GGB initially, but probably recirculated back towards GGB later the following day. Data collected during this event indicated that runoff can be an important source of E. coli contamination at GGB as approximately 20,000 cubic feet of runoff and a total estimated load of $2.9 \times 10^{11}$ colonies of $E$. coli entered the upper end of GGB cove from the west tributary during this event. However, most of this loading during runoff probably was not from the seasonal residence septic tank area but from farther up in the watershed. Because the total precipitation for the 2012 recreational season was below normal (4.29 inches compared to the normal 12.22-inch total), runoff into GGB cove may be a more important source of E. coli contamination at GGB during a more typical year than during 2012.

Sediment samples (imported beach sand above and below the shoreline; native, finer-grained sediment; and a mixture of both) collected at GGB had substantially larger concentrations of $E$. coli than sediment samples collected by the USGS Ohio Water Science Center at E. coli-contaminated beaches on Lake Erie in three similar studies. Escherichia coli concentrations in foreshore samples (samples collected above the shoreline) from GGB were significantly larger than samples in ankledeep water. Concentrations also were significantly larger on the left and middle areas of the beach compared to the right side, which may be related to deposition of geese fecal matter or the spatial distribution of fine-grained sediments on the left and middle sides of the beach. Results of the resuspended 
sediment study indicated that $E$. coli concentrations in the water column were significantly larger after resuspending sediments indicating that, if disturbed, sediment at GGB can be an important source of $E$. coli in the water column.

Analysis of water samples collected at PB1 indicated that E. coli concentrations at $\mathrm{PB} 1$ were significantly larger than at a background beach (site RS-B) probably because RS-B is used infrequently and located farther upstream. Also, E. coli concentrations at PB1 were significantly smaller than at GGB. Spatial analysis of $\mathrm{PB} 1$ indicate that $E$. coli concentrations at PB1 are smaller than at nearby shoreline areas, suggesting that during the nonrunoff period sampled, activity at PB1 and the immediate areas around the beach likely is not a substantial source of $E$. coli in contrast to what was measured at GGB. Although E. coli concentrations at a nearshore site by the outfall of a wastewater treatment plant (site B1-OUT) about 0.25 mi northeast of PB1 were larger than at PB1, they were not significantly different during the nonrunoff period sampled. Escherichia coli concentrations at a nearshore site in a campground (site B1-P) $0.50 \mathrm{mi}$ southeast of PB1 were significantly larger than at $\mathrm{PB} 1$ and may be related to the close proximity of site B1-P to the Grand Glaize arm inflow compared to PB1, the shallower water at PB1, and the fine-grained silty sediments at site B1-P.

Microbial source tracking (MST) adds to the spatial and temporal evidence supporting the hypothesis that bathers resuspend E. coli-contaminated sediment at GGB, which results in increased E. coli concentrations in the water column. The predominance of the waterfowl-associated marker in nearshore sediment samples from GGB was consistent with the frequent field observation of goose and vulture fecal matter in sediment, especially in the left and middle areas of the beach. Sampling during and after minor rainfall events that generated only local runoff in the west tributary indicated substantial E. coli contamination originating from disturbed soils and shallow groundwater from the recent removal of a septic tank at a seasonal residence near GGB. Microbial source tracking confirmed $E$. coli contamination in pooled samples was of human origin as all MST samples collected from the west tributary contained the human-associated marker (HF183) and had the largest HF183 marker concentrations of all samples collected during this study. However, during 2012 the west tributary may not have contributed substantially to $E$. coli loading of nearshore sediment at GGB because the waterfowlassociated marker was predominate in nearshore sediments at GGB, and the human-associated marker was detected in only one sample, which was collected after Hurricane Isaac. The combination of spatial and temporal sampling and MST indicate that an important source of $E$. coli contamination at GGB during 2012 was E. coli released into the water column by bathers resuspending E. coli-contaminated sediments, especially during high-use days early in the recreational season. The predominate origin of $E$. coli in sediments appears to be from geese and vultures that frequent the beach, especially during the winter and early spring when lake water levels are low and sediments are exposed. Additional contributions of E. coli from other sources within the west and east tributary watersheds occur during runoff events, which cause inflow of runoff into GGB cove.

Results from analyses of water samples for MST markers at PB1 indicated only detections of the human-associated marker. Although overall E. coli concentrations in water samples collected from PB1 during 2012 were generally well below standards, water sample analysis suggests that $E$. coli contamination at PB1 may be caused by contamination from the nearby downstream wastewater treatment plant as recirculation patterns indicated by the MDNR during dye tracing of the wastewater systems near PB1 could transport wastewater upstream to the beach. Although this connection was not substantial during the nonrunoff period of this study, it may become an important contributor to $E$. coli loading at PB1 during major runoff events.

\section{References Cited}

Ameren Corporation, 2012, Shoreline Management PlanRev. 1: p. 54, accessed January 2013, at $h t t p: / / w w w$. ameren.com/sites/AUE/lakeoftheozarks/Documents/ ShorelineManagementPlan.pdf.

Ameren Corporation, 2013, Bagnell Dam-Harry S Truman reports: accessed January 2013, at http://apps.ameren.com/ HydroElectric/Reports/Osage/.

Anderson, K.L., Whitlock, J.E., and Harwood, V.J., 2005, Persistence and differential survival of fecal indicator bacteria in subtropical waters and sediments: Applied Environmental Microbiology, v. 71, no. 6, p. 3,041-3,048.

Bergier, T., and Wlodyka-Bergier, A., 2013, Effectiveness of the household hybrid wastewater treatment plant in removing mesophilic, psychrophilic and Escherichia coli bacteria, in Pawlowski, A., and others, eds., Environmental Engineering IV: Boca Raton, Florida, CRC Press, 578 p.

Boehm, A.B., Grant, S.B., Kim, J.H., Mowbray, S.L., McGee, C.D., Clark, C.D., Foley, D.M., and Wellman, D.E., 2002, Decadal and shorter period variability of surf zone water quality at Huntington Beach, California: Environmental Science and Technology, v. 36, no. 18, p. 3,885-3,892.

Burton, G.A., Gunnison, D., and Lanza, G.R., 1987, Survival of pathogenic bacteria in various freshwater sediments: Applied and Environmental Microbiology, v. 53, no. 4, p. 633-638. 
Carlucci, A.F., and Pramer, D., 1960, An evaluation of factors affecting the survival of Escherichia coli in sea water: Applied Microbiology, v. 8, no. 4, p. 254-256.

Craig, D.L., Fallowfield, H. J., and Cromar, N. J., 2004, Use of microcosms to determine persistence of Escherichia coli in recreational coastal water and sediment and validation with in situ measurements: Journal of Applied Microbiology, v. 96 , no. 5, p. 922-930.

Critchlow, D.E., and Fligner, M.A., 1991, On distribution-free multiple comparisons in the one-way analysis of variance: Communications in Statistics-Theory and Methods, v. 20, no. 1, p. 127-139.

Davies, C.M., Long, J.A., Donald, M., and Ashbolt, N.J., 1995, Survival of fecal microorganisms in marine and freshwater sediments: Applied and Environmental Microbiology, v. 61 , no. 5 , p. $1,888-1,896$.

Dick, L.K., and Field, K.G., 2004, Rapid estimation of numbers of fecal Bacteroidetes by use of a quantitative PCR assay for 16S rRNA genes: Applied and Environmental Microbiology, v. 70, no. 9, p. 5,695-5,697.

Doyle, J.D., Tunnicliff, B., Kramer, R., Kuehl, R., and Brickler, S.K., 1992, Instability of fecal coliform populations in water and bottom sediments at recreational beaches in Arizona: Water Research, v. 26, no. 7, p. 979-988.

Dwass, Meyer, 1960, Some k-sample rank-order tests, in Olkin, I., and others, eds., Contributions to probability and statistics: Stanford, Stanford University Press, p. 198-202.

Flint, K.P., 1987, The long-term survival of Escherichia coli in river water: Journal of Applied Bacteriology, v. 63, no. 3, p. $261-270$.

Francy, D.S., and Darner, R.A., 1998, Factors affecting Escherichia coli concentrations at Lake Erie public bathing beaches: U.S. Geological Survey Water-Resources Investigations Report 98-4241, 41 p.

Francy, D.S., Gifford, A.M., and Darner, R., 2002, Escherichia coli at Ohio bathing beaches - distribution, sources, wastewater indicators, and predictive modeling: U.S. Geological Survey Scientific Investigations Report 02-4285, 47 p.

Francy, D.S., Bertke, E.E., Finnegan, D.P., Kephart, C.M., Sheets, R.A., Rhoades, J., and Stumpe, L., 2006, Use of spatial sampling and microbial source-tracking tools for understanding fecal contamination at two Lake Erie beaches: U.S. Geological Survey Scientific Investigations Report 2006-5298, 29 p.

García-Armisen, T., and, Servais, P., 2009, Partitioning and fate of particle-associated E. coli in river water: Water Environment Research, v. 81, no. 1, p. 21-28.
Green, H.C., Dick, L.K., Gilpin, B., Samadpour, M., and Field, K.G., 2012, Genetic markers for rapid PCR-based identification of gull, Canada goose, duck, and chicken fecal contamination in water: Applied Environmental Microbiology, v. 78, no. 2, p. 503-510.

Guy, Harold, 1977, Laboratory theory and methods for sediment analysis: U.S. Geological Survey Techniques of Water-Resources Investigations, book 5, chap. C1, 64 p.

Hach Company, 2008, Portable turbidimeter-Model 2100PInstrument and procedure manual (9th ed.): Loveland, Colo., 78 p.

Harwood, V.J., Levine, A.D., Scott, T.M., Chivukula,V., Lukasik, J., Farrah, S.R., and Rose,J.B., 2005, Validity of the indicator organism paradigm for pathogen reduction in reclaimed water and public health protection: Applied and Environmental Microbiology, v. 71, no. 6, p. 3,163-3,170.

Helsel, D.R., and Hirsch, R.M., 1992, Statistical methods in water resources: U.S. Geological Survey Techniques of Water-Resources Investigations, book 4, chap. A3, 510 p.

Howell, J.M., Coyne, M.S., and Cornelius, P.L., 1995, Effect of sediment particle size and temperature on fecal bacteria mortality rates and the fecal coliform/fecal streptococci ratio: Journal of Environmental Quality, v. 25, no. 6, p. 1,216-1,220.

HNTB Corporation, 1999, Lake of the Ozarks water and wastewater conceptual plan: Kansas City, Mo., 52 p., accessed January 2013, at http://www.soslowa.org/ pastreport1999.pdf.

Kruskal, W.H., and Wallis, W.A., 1952, Use of ranks in onecriterion variance analysis: Journal of the American Statistical Association, v. 47, no. 260, p. 583-621.

Kinzelman, J.L., Pond, K.R., Longmaid, K.D., and Bagley, R.C., 2004, The effect of two mechanical beach grooming strategies on Escherichia coli density in beach sand at a southwestern Lake Michigan beach: Aquatic Ecosystem Health and Management, v. 7, no. 3, p. 425-432.

Lake Area Chamber of Commerce, 2012, Central Missouri's Lake of the Ozarks-Demographic Snapshot-2012: Lake Ozark, Lake Area Chamber of Commerce, 11 p.

Larson, R., and Edwards, B., 2009, Calculus (9 ed.): Stamford, Conn., Cengage Learning, p. 311.

Layton, A., McKay, L., Williams, D., Garrett, V., Gentry, R., and Sayler, G., 2006, Development of Bacteroides 16S rRNA gene TaqMan-based real-time PCR assays for estimation of total, human, and bovine fecal pollution in water: Applied and Environmental Microbiology, v. 72, no. 6, p. 4,214-4,224. 
Lee, C.M., Lin, T.Y., Lin, C.C., Kohbodi, G.A., Bhatt, A., Lee, R., and Jay, J.A., 2006, Persistence of fecal indicator bacteria in Santa Monica Bay beach sediments: Water Research, v. 40 , no. 14 , p. $2,593-2,602$.

Mann, Henry, 1945, Nonparametric tests against trend: Econometrica-Journal of the Econometric Society, v. 13, no. 3, p. 245-259.

Missouri Attorney General's Office, 2010, Protecting water quality at the Lake of the Ozarks - An environmental road map for the future: Jefferson City, Mo., 43 p., accessed January 2013, at http://www.soslowa.org/agwhitepaper.pdf.

Missouri Department of Natural Resources, 2011, Environmental Services Program: accessed January 2013, at http:// dnr.mo.gov/env/esp/esp-wqm.htm.

Missouri Department of Natural Resources, 2012a, Facts and Figures: accessed January 2013, at http://mostateparks.com/ page/55072/facts-and-figures.

Missouri Department of Natural Resources, 2012b, E. coli concentrations in Lake of the Ozarks: Jefferson City, Mo., Division of Environmental Quality, 5 p., accessed January 2013, at http://dnr.mo.gov/loz/documents/LOZ\%20 Water\%20Quality\%20Survey\%20Report\%202007-2011\%20 $v 2 \% 20(3) . p d f$.

Missouri House of Representatives, 2013, House Bill 51 (HB 51)-To amend chapter 640 , RSMo, by adding thereto one new section relating to water quality standards for Missouri beaches: accessed February 2013, at http://www.house. mo.gov/billtracking/bills131/biltxt/intro/HB00511.htm.

Missouri State Senate, 2013, Senate Bill 140 (SB 140)-Requires certain testing methods for E. coli at Missouri State Parks' swim beaches: accessed February 2013, at http://www.senate.mo.gov/13info/pdf-bill/intro/SB140.pdf.

Muela, A., Garcia-Bringas, J.M., Arana, I., and Barcina, I., 2000, The effect of simulated solar radiation on Escherichia coli-The relative roles of UV-B, UV-A, and photosynthetically active radiation: Microbial Ecology, v. 39, no. 1, p. $65-71$.

Myers, D.N., Stoeckel, D.M., Bushon, R.N., Francy, D.S., and Brady, A.M.G., 2007, Fecal indicator bacteria (ver. 2.0): U.S. Geological Survey Techniques of Water-Resources Investigations, book 9, chap. A7, section 7.1, accessed January 2013, at http://water.usgs.gov/owq/FieldManual/ Chapter7/7.1.html.

National Climatic Data Center, 2013a, Surface data-Hourly global: 2009-2012: accessed February 9, 2013, at http:// wwwl.ncdc.noaa.gov/pub/orders/4890036145088dat.html.
National Climatic Data Center, 2013b, Summary of Monthly Normals: 1981-2010: accessed October 24, 2013, at http:// www1.ncdc.noaa.gov/pub/data/cdo/samples/NORMAL MLY_sample_pdf.pdf.

National Oceanic and Atmospheric Association, 2013, Point precipitation frequency estimates: Atlas 14, v. 8, ver. 2, accessed September 2013, at http://hdsc.nws.noaa.gov/hdsc/ pfds/pfds_printpage.html? lat $=38.1287 \&$ lon $=-92.6018 \& d a t$ $a=$ depth\&units $=$ english\&series $=p d s$.

Natural Resources Defense Council, 1996, Testing the watersVolume VI: New York, 116 p.

O’Hearn, Rebecca, 2009, Nutrients, chlorophyll, and bacterial fecal indicators in coves and open water areas of Lake of the Ozarks, Missouri: Columbia, University of Missouri, Master's Thesis, $165 \mathrm{p}$.

Pierce, Larry, 2012a, Results of groundwater tracing at Lake of the Ozarks' State Park Grand Glaize Beach, Camden County, Missouri: Rolla, Division of Geology and Land Survey Geological Survey Program, Missouri Department of Natural Resources, $14 \mathrm{p}$.

Pierce, Larry, 2012b, Results of groundwater tracing at Lake of the Ozarks' State Park Public Beach 1, Camden and Miller counties, Missouri: Rolla, Missouri Department of Natural Resources, Division of Geology and Land Survey Geological Survey Program, 16 p.

Pote, J., Haller, L., Kottelat, R., Sastre, V., Arpagaus, P., and Wildi, W., 2009, Persistence and growth of faecal culturable bacterial indicators in water column and sediments of Vidy Bay, Lake Geneva, Switzerland: Journal of Environmental Sciences, v. 21, no. 1, p. 62-69.

Rantz, S.E., and others, 1982, Measurements and computation of streamflow-Volume 1, Measurement of stage and discharge, and volume 2, Computation of discharge: U.S. Geological Survey Water-Supply Paper 2175, 631 p., accessed January 2014, at http://pubs.usgs.gov/wsp/wsp2175/.

Seurinck, S., Defoirdt, T., Verstraete, W., and Siciliano, S.D., 2005, Detection and quantification of the human-specific HF183 Bacteroides 16S rRNA genetic marker with realtime PCR for assessment of human faecal pollution in freshwater: Environmental Microbiology, v. 7, no. 2, p. 249-259.

Shapiro, S.S., and Wilk, M.B., 1965, An analysis of variance test for normality (complete samples): Biometrika, v. 52, no. 3, p. 591-611.

Spearman, Charles, 1904, Proof and measurement of association between two things: American Journal of Psychology, v. 15 , no. 1 , p. $72-101$.

Steel, Robert, 1960, A rank sum test for comparing all pairs of treatments: Technometrics, v. 2, no. 2, p. 197-207. 
U.S. Department of Agriculture, 2012, USDA designates an additional 39 counties in 8 states as primary natural disaster areas due to worsening drought: accessed January 2013, at http://www.usda.gov/wps/portal/usda/usdamediafb? conte ntid $=2012 / 07 / 0243 . x m l \&$ printable $=$ true \& contentidonly $=t$ rue.

U.S. Environmental Protection Agency, 1976, Quality criteria for water: Washington, D.C., U.S. Environmental Protection Agency, Office of Water, $501 \mathrm{p}$.

U.S. Environmental Protection Agency, 1986, EPA's ambient water quality criteria for bacteria-1986: Washington, D.C., U.S. Environmental Protection Agency, Office of Water, EPA440/5-84-002, $18 \mathrm{p}$.

U.S. Environmental Protection Agency, 1999, Action plan for beaches and recreational waters: Washington, D.C., U.S. Environmental Protection Agency, Office of Water, EPA/600/R-98/079, 19 p.

U.S. Environmental Protection Agency, 2007, Guidelines establishing test procedures for the analysis of pollutantsAnalytical methods for the biological pollutants in wastewater and sewage sludge-Final rule: Federal Register 40 CFR Part 136 and 503, v. 72, no. 157, p. 14,220-14,233, accessed December 2013, at http://www.idexx.com/pubwebresources/ pdf/en_us/water/5BA.pdf.

U.S. Environmental Protection Agency, 2010, Method B: Bacteroidales in water by TaqMan quantitative polymerase chain reaction (qPCR) assay: Washington, D.C., U.S. Environmental Protection Agency, Office of Water, EPA822-R-10-003, $26 \mathrm{p}$.

U.S. Environmental Protection Agency, 2012, Recreational water quality criteria: Washington, D.C., U.S. Environmental Protection Agency, Office of Water, EPA-820-F-12-058, $63 \mathrm{p}$.

Vandike, J.E., Whitefield, J.W., Meier, D.H., and Endicott, C., 1985, An engineering geologic approach to evaluating groundwater and surface-water contamination potential at Lake of the Ozarks, Missouri: Jefferson City, Mo., Geology and Land Survey Division, Missouri Department of Natural Resources, OFR-85-26-EG, 13 p.

Wilcoxon, Frank, 1945, Individual comparison by ranking methods: Biometrics Bulletin, v. 1, no. 6, p. 80-83.

Wilson, Jordan, 2013, Distribution and occurrence of Escherichia coli in water and sediments at Grand Glaize Beach in Lake of the Ozarks State Park: Rolla, Missouri, University of Science and Technology, Master's Thesis, $144 \mathrm{p}$. 

Prepared by the Rolla and West Trenton Publishing Service Centers

For more information, contact:

Missouri Water Science Center

U.S. Geological Survey

1400 Independence Road, MS-100

Rolla, M0 65401

http://mo.water.usgs.gov/ 


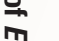

ल.

).

$\stackrel{8}{8}$

.

言

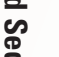

言

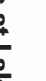

市

옿

胥

$\stackrel{\infty}{*}$

章

气

$\vec{\omega}$

¿s.

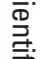

ISSN 2328-0328 (online) 